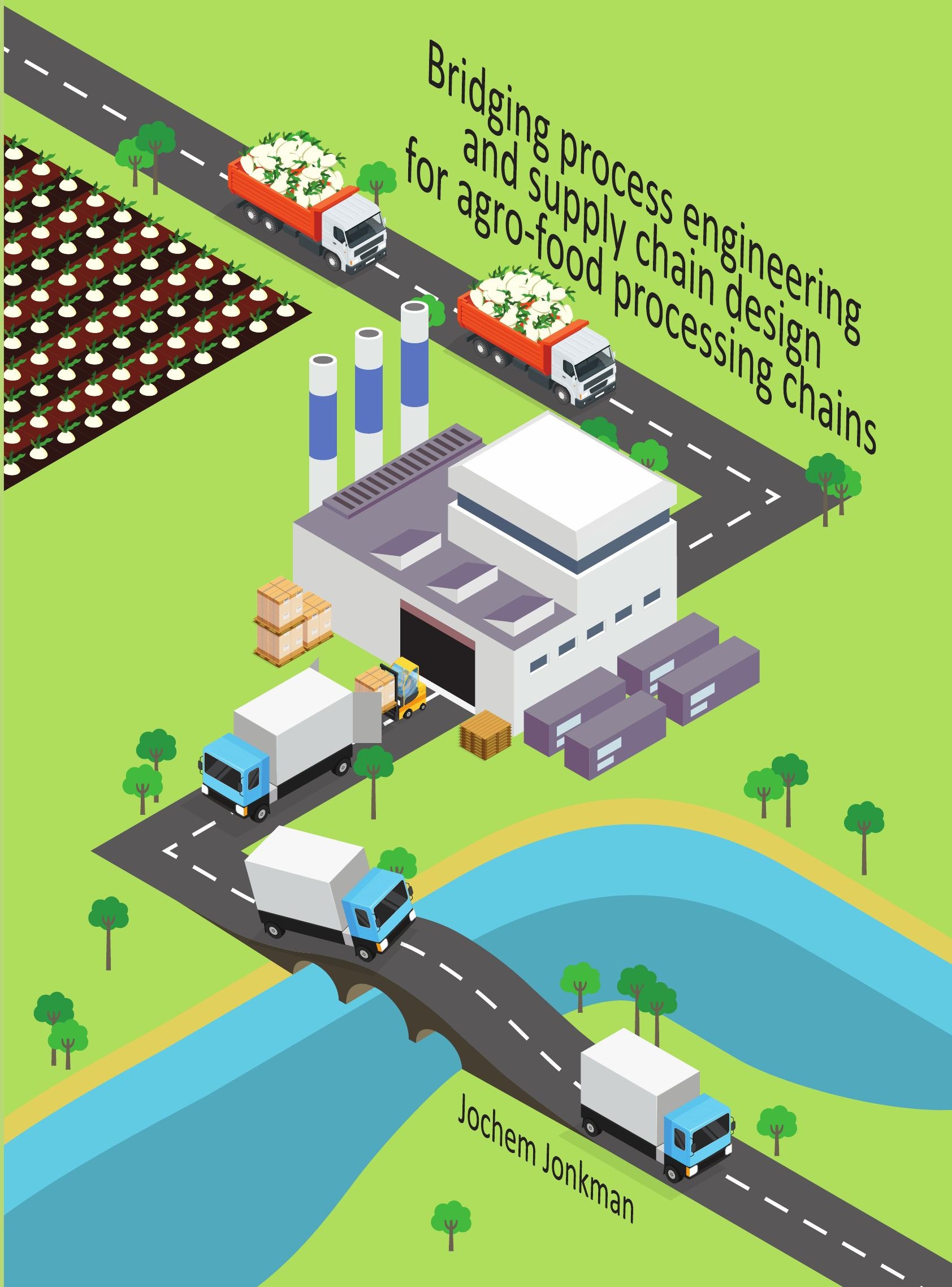




\section{Bridging process engineering and supply chain design for agro-food processing chains}




\section{Thesis committee}

\section{Promotors}

Prof. Dr J.M. Bloemhof

Professor of Operations Research and Logistics

Wageningen University \& Research

Prof. Dr A. van der Padt

Professor of Sustainable Production of Food

Wageningen University \& Research

\section{Other members}

Prof. Dr M.P.M. Meuwissen, Wageningen University \& Research

Prof. Dr W.E.H. Dullaert, VU Amsterdam

Prof. Dr E. Zondervan, University of Bremen, Germany

Dr M. Dekker, Wageningen University \& Research

This research was conducted under the auspices of the Wageningen School of Social Sciences (WASS) 


\section{Bridging process engineering and supply chain design for agro-food processing chains}

Jochem Jonkman

Thesis

submitted in fulfilment of the requirements for the degree of doctor

at Wageningen University

by the authority of the Rector Magnificus

Prof. Dr A.P.J. Mol,

in the presence of the

Thesis Committee appointed by the Academic Board

to be defended in public

on Friday 5 October 2018

at 4 p.m. in the Aula. 
Jochem Jonkman

Bridging process engineering and supply chain design for agro-food processing chains 132 pages.

PhD thesis, Wageningen University, Wageningen, NL (2018)

With references, with summary in English

ISBN 978-94-6343-338-9

https://doi.org/10.18174/458233 


\section{Contents}

Page

Contents $\quad$ v

Chapter 1 Introduction 1

1.1 Historic development of the European food industry . . . . . . . . . . . . 2

1.2 Problem description . . . . . . . . . . . . . . . . . . . . . . . . . . 4

1.3 Aim and outline . . . . . . . . . . . . . . . . . 6

Chapter 2 Product level: Selection of fractionation pathways and intermediates for mixed consumer products $\quad 9$

2.1 Introduction . . . . . . . . . . . . . . . . . . . . . . . . . 11

2.2 Decision support approach . . . . . . . . . . . . . . . . 11

2.3 Case study . . . . . . . . . . . . . . . . . . . . . . . . . . . . . . . . 17

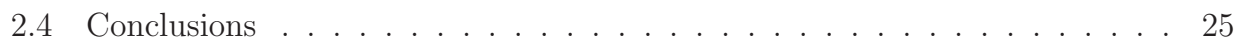

Chapter 3 Process and enterprise level: Selecting food process designs $\begin{array}{ll}\text { from a supply chain perspective } & 27\end{array}$

3.1 Introduction . . . . . . . . . . . . . . . . . . . . . . . . . . . . 29

3.2 Selecting food process designs . . . . . . . . . . . . . . . . 31

3.3 Illustrative case: sugar beet processing in The Netherlands . . . . . . . . . 34

3.4 Discussion . . . . . . . . . . . . . . . . . . . . . . . . 45

3.5 Conclusions and future work . . . . . . . . . . . . . . . 46

Chapter 4 Supply chain level: Integrating harvesting decisions in the de$\begin{array}{ll}\text { sign of agro-food supply chains } & 49\end{array}$

4.1 Introduction . . . . . . . . . . . . . . . . . . . 51

4.2 Literature survey . . . . . . . . . . . . . . . . . . . . . . . . . . . 53

4.3 Problem description and model formulation . . . . . . . . . . . . 55

4.4 Case study description . . . . . . . . . . . . . . . . . . . . . . 66

4.5 Case results and discussion . . . . . . . . . . . . . . . . . . . . . . . . 69

4.6 General discussion and conclusions . . . . . . . . . . . . . . . . . 74 
Chapter 5 Network level: Designing a biobased supply chain using a multi$\begin{array}{ll}\text { actor optimisation model } & 77\end{array}$

5.1 Introduction . . . . . . . . . . . . . . . . . . . . . . . . . 79

5.2 Case description . . . . . . . . . . . . . . . . . . . . . . 80

5.3 Model formulation . . . . . . . . . . . . . . . . . . . . . 83

5.4 Results and discussion . . . . . . . . . . . . . . . . . . . . . 96

5.5 Conclusions . . . . . . . . . . . . . . . . . . . . . . . . . . . . . 99

5.A Shapley-value with an illustrative example . . . . . . . . . . . 101

$\begin{array}{lll}\text { Chapter } 6 & \text { Multi-level synthesis } & 103\end{array}$

6.1 Multi-level interdependency . . . . . . . . . . . . . . . . . . . . . 104

6.2 Applicability in agro-food supply chains . . . . . . . . . . . . . . . 107

6.3 Directions for future research . . . . . . . . . . . . . . . . . . . . 108

$\begin{array}{ll}\text { References } & 111\end{array}$

$\begin{array}{ll}\text { Summary } & 123\end{array}$

$\begin{array}{lr}\text { Publications } & 125\end{array}$

$\begin{array}{lr}\text { Acknowledgements } & 127\end{array}$ 


\section{Chapter 1}

\section{Introduction}

Parts of this chapter are published in:

Jonkman, J., Bloemhof, J. M., van der Vorst, J. G. A. J., van der Padt, A. (2015). A Sustainability Driven Methodology for Process Synthesis in Agro-Food Industry. Computer Aided Chemical Engineering, 37, 1289-1294 
The current estimates on future population growth and agricultural productivity indicate that feeding the world population in 2050 will be a challenge (Searchinger et al., 2013). Considering that $31 \%$ of all produced food is wasted, much of the resources, capital, and labour invested in the production of food are lost (Gustavsson et al., 2011; Timmermans et al., 2014). Hence, changes are required in the production of food, in order to reduce the impact of food production on the environment and natural resources (Govindan, 2018).

In Europe, the food industry plays an important role in the production of food and is of great economic importance. It represents almost $13 \%$ of the total turnover of the manufacturing industry (ECSIP Consortium, 2016). On the other hand, the food supply chains in which food industry operates also have a significant environmental impact. Together they contribute to $31 \%$ of the total global warming potential (Perrot et al., 2016). Reducing the environmental impact of the food industry and food supply chains is not possible without making changes to their set-up and to the composition and characteristics of the produced food products (Raak et al., 2017)

\subsection{Historic development of the European food in- dustry}

The configuration of most Food Supply Chains (FSCs) has grown historically with a strong focus on economy of scale (Augustin et al., 2016). At the start of the twentieth century, the agro-food industry generally extracted one product from an agro-material, for example starch from potatoes and sugar from sugar beet (van der Padt, 2014). These product intermediates were combined and further processed by the food assembly industry into final consumer products (Figure 1.1).

Over time, the agro-food industry included new technologies into their production processes in a step-wise sequential manner, and process pathways were reshaped to meet new requirements (e.g. consumer demands, legislation, and competition). This is represented schematically in Figure 1.2. Environmental concerns and decreasing margins forced the industry to valorise and reduce waste streams, extracting, for instance, whey proteins from whey and using sugar beet pulp for yeast production (van der Padt, 2014). Hence, the public concern with the environment and safety issues, environmental regulations and global competition drive agro-food industrial companies to increase their efficiency and develop sustainable products and processes (Charpentier, 2009). These products and processes with improved sustainability allowed the food assembly industry to source more sustainable ingredients. Hence, the two-stage set-up of most food processing chains remained intact. This set-up is nowadays considered one of the main causes responsible for 


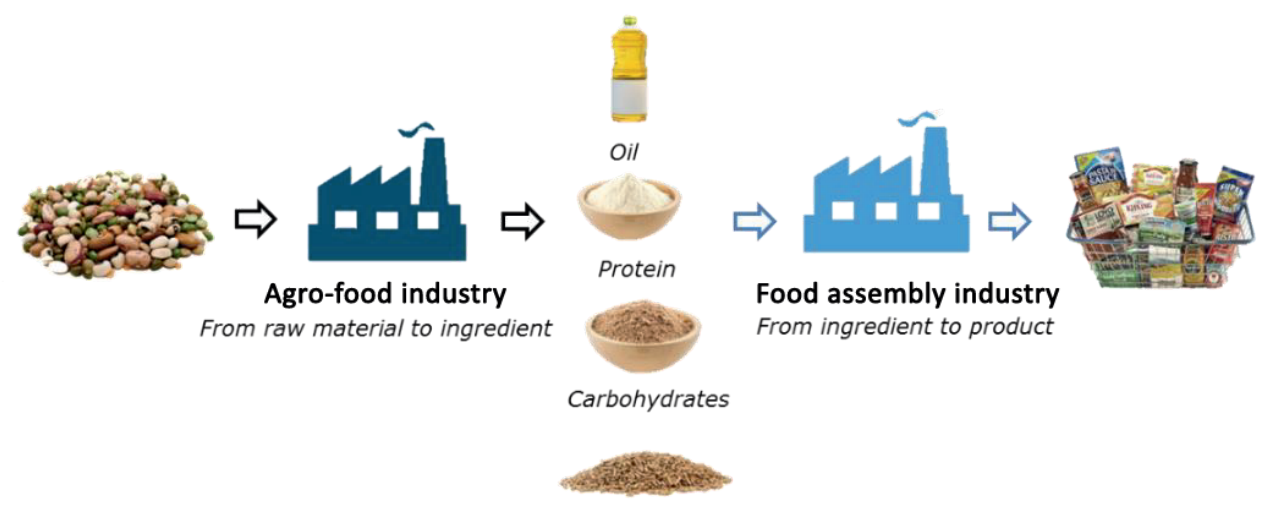

Rest: non-food application

Figure 1.1: Typical two-stage organisation of the food industry (Geerts, 2018)

the inefficiencies in the food production system (van der Goot et al., 2016).

To guarantee a controlled quality of final consumer products, the food assembly industry mainly uses dry and purified intermediates, purchased from the agro-food industry. The production of these intermediates is disconnected from the production of the final consumer products, and requires water and energy-intensive processing steps (van der Goot et al., 2016). Additionally, the yield of processing generally reduces when higher purity has to be obtained (Tamayo Tenorio et al., 2018). Hence, reconsidering the disconnection between intermediate production in agro-food industry and the production of final consumer products in the food assembly industry supports a more resource efficient production of food.

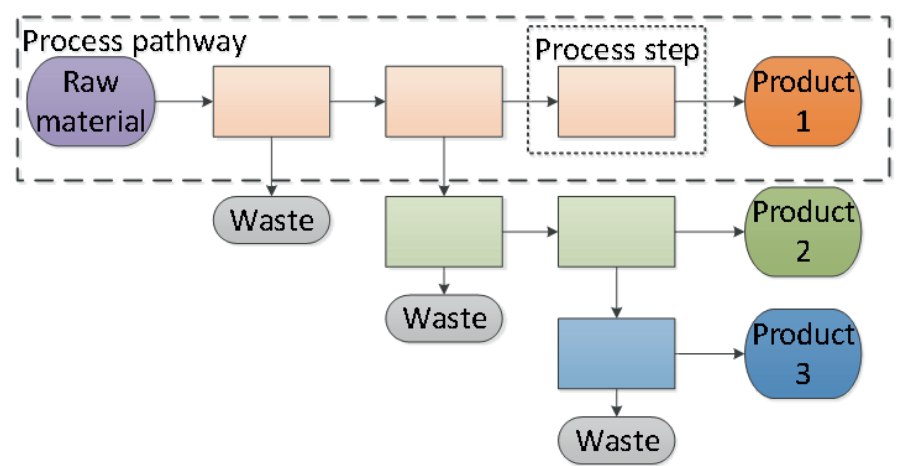

Figure 1.2: The sequential development of process pathways in the food industry over time 


\subsection{Problem description}

Reconsidering the current set-up of food industry confronts decision makers in agro-food industry with several strategic questions:

- Which intermediates to make from the available agro-materials in order to produce the desired consumer products?

- Which production processes to produce the desired intermediates?

- Where to execute production processes in the FSC, and at what time?

- How to ensure the participation of all the required actors in the desired FSC network?

In answering these questions, many possibilities exist and decisions can be interconnected on levels of different scale. Intermediates are produced from agro-materials using a number of technologies or process steps, jointly called a process pathway. This process pathway determines to a great extent the properties of the obtained intermediates. Therefore, there is a direct link between selecting an intermediate at the product level and selecting a process pathway at the process level. Several process pathways can be operated by an enterprise to produce their desired product portfolio. The SC in which the enterprise is operating can affect which process pathway and product portfolio are optimal, connecting the SC level to the enterprise level and its underlying process and product levels. Additionally, aligning the goals of all the actors participating in a SC is necessary for its optimal performance. Because actors can participate in several SCs at the same time, taking into account the SC network can prevent sub-optimal operation of a SC. These interconnected levels make an approach to answering these questions not straightforward.

However, decisions can be made using decision support models as they are developed in the fields of Process Systems Engineering (PSE) and Supply Chain Management (SCM). Related respectively to Chemical Engineering and Operational Research, these fields have been extending their scope in recent years, spanning a scale from the product level up to the SC network. This is schematically represented in Figure 1.3.

PSE aims at improving decision making for the creation and operation of chemical supply chains from the molecular scale up to the whole enterprise (Grossmann \& Westerberg, 2000). Research in PSE has provided methods to find alternative designs for process pathways, and to search for the better designs among many options (Westerberg, 2004).

Decision support models from PSE are widely used in chemical industries, but are not directly applicable or extendable to the food industry, due to the difference between types of production processes and between typical chemical products and food products 
Supply Chain Management

Process Systems Engineering

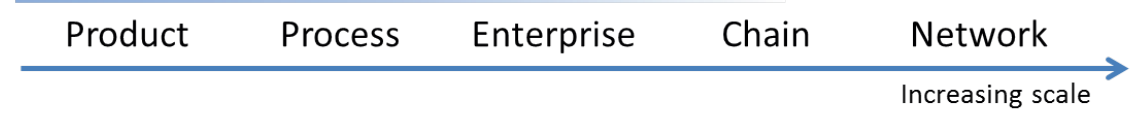

Figure 1.3: Schematic representation of the scope of the research fields of Process Systems Engineering and Supply Chain Management

(Hadiyanto et al., 2008; Meeuse, 2007). Food products are generally made from several intermediates, containing multiple chemical components. The quality of a final food product depends not only on the chemical composition of all the ingredients, but also on the functionality of these ingredients, and how they are distributed in the food through processing. The creaminess of ice cream, for instance, depends on the composition of the intermediates used, like fat, but also on the size of air-bubbles and ice-crystals inside the ice cream resulting from processing (Meeuse, 2007). Such processing effects make food processing different from other (chemical) processing (Datta, 2016). Moreover, the agro-materials used as raw materials consist of several chemical components. These components provide the functionality desired by the food assembly industry, such as foaming or emulsifying capacity. The agro-materials are therefore processed into multiple fractions, making the processing of agro-materials by agro-food industry divergent in nature. Additionally, the agro-materials vary more in quality than the raw materials used by the chemical industry, and they are often perishable leading to waste along the Supply Chain (SC). Moreover, they are subject to seasonality and are only produced in certain areas (Halasz et al., 2005). Hence, location-related characteristics of the SC are very relevant to the food industry.

Due to its origin in chemical engineering, the field of PSE has a strong focus on products, production technologies, and process pathways. Over time, the scope extended to include more and more aspects of an enterprise and the related SC, and started to link to the fields of Operational Research and SCM (Grossmann, 2005; Barbosa-Póvoa, 2014).

The field of SCM focuses on value creation in the SC through optimising the flows of products, money, and information (Chopra \& Meindl, 2015). Compared to PSE it has a stronger emphasis on logistics and distribution while product and production characteristics are typically not considered explicitly. However, products and production characteristics have recently become more important due to the developments in Sustainable Supply Chain Management (SSCM) and Closed Loop Supply Chains (CLSCs). The extension of SCM towards SSCM has shifted the focus from creating economic value to include environmental and social objectives (Soysal et al., 2012). Commonly, Life Cycle 
Analysis (LCA) techniques are used to evaluate the environmental performance of a SC, and products are considered as the functional unit to compare different SC configurations. Additionally, the valorisation of side-streams investigated in studies on CLSC increases the importance of taking into account the production processes and information at the product level (Banasik et al., 2017).

SCM methods have been applied to FSCs, although there is a need to adapt these methods to the specific characteristics of the FSCs (Akkerman et al., 2010a; Soysal et al., 2012). Several regional and time constraints exist due to the seasonality and perishability of food products, which are not relevant in many other SCs. Hence, the entire food processing chain with its specific characteristics is of importance in answering the strategic questions of agro-food industry. Methods and tools from the field of PSE have to be combined with food engineering knowledge to consider the questions at product and processing levels. Additionally, work from the field of SCM, and in specific Food Supply Chain Management (FSCM) is required for widening the scope to include the whole processing chain and the related network in which the chain operates.

\subsection{Aim and outline}

The aim of this study is to bridge the fields of PSE and SCM in the context of agro-food processing chains. Our approach shows how methods from the fields of PSE and SCM can be used to support answering the strategic questions relevant for agro-food industry on which (intermediate) products to produce where, using which process pathways, and at what time. The combination of these complimentary fields in the context of food processing chains leads to better FSC networks.

At the product level, a company has to decide which intermediates to produce from an agro-material. The chemical composition of the agro-material and the functionality of intermediates desired by the food assembly industry are leading. In Chapter 2 we investigate how to select a product portfolio taking into account the valorisation of the full portfolio of intermediates, and the final application of the intermediates.

At the process level and enterprise level, several process pathways are available for the conversion of an agro-material. Due to the seasonal and regional availability of agromaterials, operating these process pathways is often different from chemical industry. Therefore, Chapter 3 studies how to select process pathways with their product portfolio given the regional differences in supply and demand of FSCs.

At the supply chain level, agro-food industry has to deal with uncertainties resulting from the typical characteristics of food. Supply is of uncertain quality and quantity and 
also the time of availability varies. In Chapter 4, an approach is studied to identify $\mathrm{SC}$ configurations that perform well under these uncertainties and take into account the specific characteristics of agro-food processing chains.

At the network level, an agro-food industrial company is collaborating with other actors. The industry depends on primary producers, the farmers, to produce and supply agromaterials. The objectives of these farmers have to be aligned with those of the agro-food industry for the industry to be able to purchase the desired quantity of agro-materials. Chapter 5 explores benefit sharing between the agro-food industry and farmers as a means to align the individual objectives of farmers and processors in SC design.

Building on the insights from the previous chapters, Chapter 6 discusses the applicability to the food industry and directions for future research to further benefit from the symbiosis between PSE and SCM in the context of food processing chains. 



\section{Chapter 2}

\section{Product level}

\section{Selection of fractionation pathways and intermediates}

\section{for mixed consumer products}

- Non-conventional intermediates can improve the resource efficiency in food industry

- Ternary diagrams are introduced to pre-select product and process selection alternatives

- The selection of intermediates and fractionation processes is optimised

- The case of a legume processor shows a reduction in energy use, water use, and costs

This chapter is based on:

Jonkman, J., Castiglioni, A., Akkerman, R., van der Padt, A. Non-conventional intermediate products improve the resource use in agro-food industry. (in preparation)

Castiglioni, A., Jonkman, J., Akkerman, R., van der Padt, A. (2018). Selection of fractionation pathways and intermediates for mixed consumer products. Computer Aided Chemical Engineering, 43, 651-656 


\section{Abstract}

Many consumers products, such as cosmetics and foods, consist of a mixture of intermediates. Most of these intermediates are currently produced through the fractionation of agro-materials, a production process in which multiple intermediates are obtained from a single raw material. These intermediates are subsequently combined into products to satisfy customer demand and quality requirements. The fractionation processes are often focused on obtaining intermediates with high chemical purity. The chemical purity of intermediates is, however, not always necessary, and mild fractionation of raw materials can be sufficient. Selecting the optimal set of intermediates is not straightforward. We propose an optimisation-based decision support approach to select resource-efficient fractionation pathways and intermediates. An illustrative case for the processing of legumes shows that mildly refined intermediates can be selected to cover the demand for the majority of products, saving costs, energy use, and water use. While minimising cost, energy use and water use were reduced by $22 \%$ and $37 \%$, respectively. The case results indicate that using fractionation pathways leading to intermediates with lower purity provides opportunities for more resource-efficient production of mixed consumer products. 


\subsection{Introduction}

Consumer products such as cosmetics and foods are often a blend of intermediates. The production of these intermediates can be resource intensive due to a focus on purity, with the aim to guarantee a standard quality and broad applicability (van der Goot et al., 2016). Generally, there is a reduction in yield and an increase in the resources required to refine a raw material into intermediates with a higher degree of purity (Tamayo Tenorio et al., 2018). However, the purity of intermediates is often not required for application in mixed products. The functionality of products does not only depend on a single pure component, but is expressed in the combination of different components with their native functionality (Geerts et al., 2017a). Therefore, applying mild fractionation and using less-refined intermediates could improve resource efficiency (Berghout et al., 2015).

The selection of the set of intermediates is not a straightforward decision for the intermediates producer. Intermediates need to be selected in such a way that a variety of products could be made while minimising costs and resource consumption. Additionally, the divergent nature of fractionation processes inherently leads to the production of multiple intermediates that all have to be valorised (Jonkman et al., 2015).

This chapter provides an optimisation-based approach for decision support for the selection of raw materials, fractionation pathways, as well as the associated intermediates. Producers of intermediates can use this approach to improve their integrated product and process design. The intermediate selection problem and the decision support approach are further described in Section 2.2. Section 2.3 shows the potential benefits of the approach for optimising the intermediate selection problem using the case of a legume processor. The consequences of focusing on functionality rather than chemical composition are further discussed in Section 2.4, concluding that more research is required to relate intermediate composition, processing, and functionality.

\section{$2.2 \quad$ Decision support approach}

A producer of intermediates has to decide how to meet customer demands based on product specifications resulting from the final application in which the intermediate is used. The intermediate producer must select the materials and the fractionation processes required to produce intermediates that can be used to make products according to the customer requirements. Intermediates can be used directly in the fulfillment of customer requirements, but can also be blended. Hence, a limited set of versatile intermediates can be produced to be blended according to customer requirements, or a wider variety of 


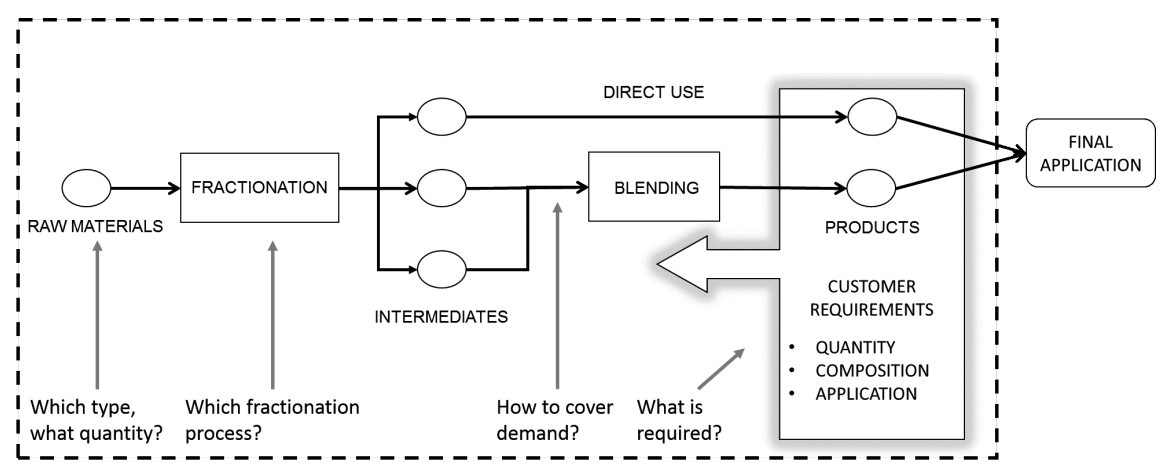

Figure 2.1: Schematic representation the decisions related to intermediate production

more customer-specific intermediates can be produced. These decisions are illustrated in Figure 2.1.

The goal of the producer is to minimise production cost and resource use, such as energy and water consumption. The number of alternative possibilities, however, complicates the selection problem. An approach is needed that allows for the representation of the alternatives and their evaluation, and that supports identifying the best alternatives (Li \& Kraslawski, 2004; Grossmann \& Guillen-Gosalbez, 2010). The approach should support finding the optimal combination of raw materials, processing, and intermediates while taking into account that handling a larger number of intermediates increases the complexity of processing operations at the intermediates producer.

We propose the four stage decision support approach presented in Figure 2.2. The first stage of the approach is focused on determining the needs of the different customers and should lead to insight into the final application of the intermediate, to the required functionality, and to a description of the properties the intermediate should have. In the second stage, the intermediate producer has to create an inventory of the possible raw materials and fractionation pathways to use, and identify the properties of these materials and pathways. This information is combined in the third stage, leading to a set of potential intermediates with associated properties, co-production relationships, and fractionation costs. In the fourth stage, an optimisation model is used to select the combination of raw materials, fractionation pathways, and intermediates that satisfies the demand of the customers while minimising the total raw material and production (i.e. fractionation and blending) costs. The representation and evaluation of alternatives related to stages 1-3, and the identification of the best alternatives in stage 4 are discussed in the following sections. 


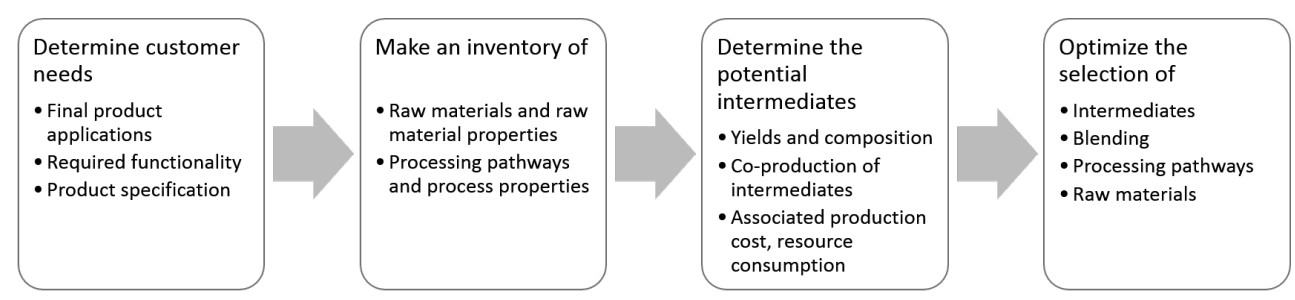

Figure 2.2: Four stage decision support approach for the selection of intermediates for mixed consumer products

\subsubsection{Representation and evaluation of alternatives}

An important problem in the design of production processes is to develop a representation that enables the inclusion of the relevant product and processing alternatives and that supports the evaluation of alternatives to ignore irrelevant options (Li \& Kraslawski, 2004). For example, in the context of fossil fuels a van Krevelen diagram is frequently used to obtain insights from the graphical representation of raw materials and products based on the atomic ratios of carbon to hydrogen and oxygen (Dusselier et al., 2014). However, consumer products cannot be reduced to such dimensions, and a more elaborate representation is required to obtain meaningful insights.

In the context of intermediates for mixed products, we propose the use of ternary diagrams in which raw materials, intermediates, and target products are plotted based on their composition. The axes should be defined according to the specific case investigated. Figure 2.3a shows an example related to agro-food industry, plotting agro-materials and target products based on the ratios between their macro-nutrient content (carbohydrate, fat, protein). The representation makes it possible to identify likely alternatives for the blending of intermediates to obtain the composition of a target product (Figure 2.3b), and to relate intermediates to raw materials through their production processes (illustrated in Figure 2.3c).

Creating ternary diagrams such as the examples in Figure 2.3 will provide decision makers with an overview of their selection alternatives. Using the graphical representation already shows that producing chemically pure intermediates is not a strict necessity for mixed consumer products. After the representation filters out irrelevant alternatives, an additional method is needed to select the optimal combination of raw materials and intermediates with their fractionation processes in order to satisfy the demand of the target products required by the customers. 


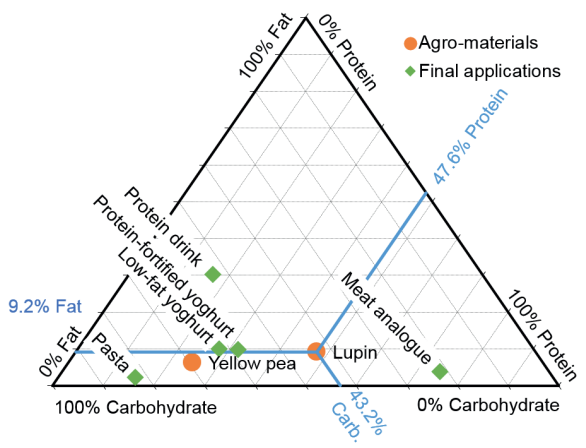

(a) Agro-materials and composition for some final applications

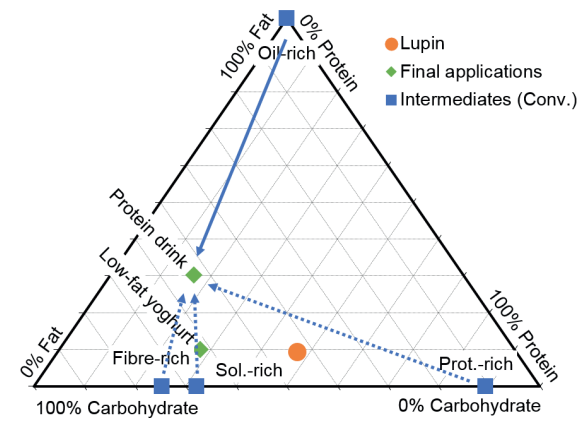

(b) Possibilities for blending conventional intermediates to achieve the composition of a target application

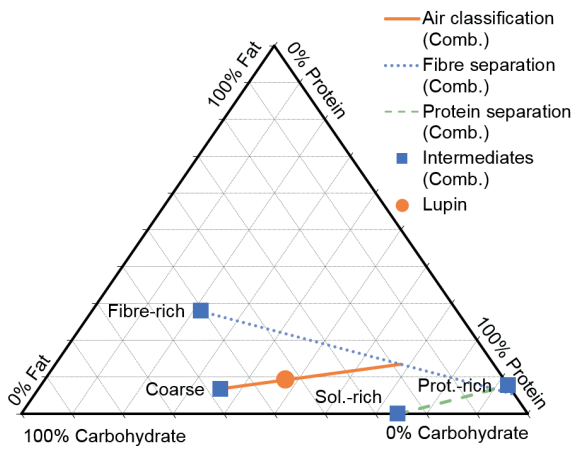

(c) Intermediates produced from lupin using a non-conventional combination of dry and aqueous fractionation processes

Figure 2.3: Ternary diagram examples for agro-materials and target products 


\subsubsection{Identification of the best alternative}

In this stage, the selection of raw materials, intermediates and fractionation pathways, and intermediate blending is optimised using a Mixed-Integer Linear Programming (MILP) model based on the work of Akkerman et al. (2010b). Their model is extended to allow for (i) the selection of different fractionation pathways; (ii) the consideration of co-production of intermediates in intermediate portfolios, including related material balance relationships; and (iii) the consideration of the resource consumption of water and energy.

Given the considered raw materials $m \in M$ and fractionation pathways $f \in F$, the objective is to minimise the costs for raw materials and processing:

$$
\operatorname{Min} \sum_{m \in M} \sum_{f \in F} c_{m f} X_{m f}
$$

where $c_{m f}$ is the cost of sourcing and processing raw material $m$ using fractionation pathway $f$ and $X_{m f}$ is the quantity of material $m$ fractionated with pathway $f$. Each produced intermediate $i \in I$ has to be used in a product $p \in P$, and the total demand $d_{p}$ of a product has to be met:

$$
\begin{array}{llll}
\sum_{i \in I} Z_{i p} & =1 & \forall p \in P \\
\sum_{m \in M} \sum_{f \in F} r_{m f i} X_{m f} & =\sum_{p \in P} d_{p} Z_{i p} & \forall i \in I
\end{array}
$$

where $Z_{i p}$ is the fraction of intermediate $i$ in product $p$ and $r_{m f i}$ is the conversion parameter for material $m$ through pathway $f$ into intermediate $i$. In the case several intermediates $i$ are used in product $p$, the blending of intermediates is required:

$$
\begin{gathered}
Y_{i p}= \begin{cases}1, & \text { if intermediate } i \text { is used in product } p . \\
0, & \text { otherwise. }\end{cases} \\
U_{p}= \begin{cases}1, & \text { if blending is required to produce product } p . \\
0, & \text { otherwise. }\end{cases} \\
\sum_{i \in I} Y_{i p} \leq n \quad \forall p \in P \\
Z_{i p} \leq Y_{i p} \quad \forall i \in I, p \in P \\
\sum_{i \in I} Y_{i p}-1 \leq n U_{p} \quad \forall p \in P \\
\sum_{p \in P} d_{p} U_{p} \leq b
\end{gathered}
$$


where Equation (2.6) is an operational restriction to limit the total number of intermediates used in a product $p$ to the maximum of $n$. The combination of Equation (2.7) and Equation (2.8) relate fractions of intermediates used in a product to the binary variable indicating that blending is required. Equation (2.9) ensures that the total quantity of products which require blending should not exceed the available blending capacity $b$.

Customer requirements may specify that intermediates of a specific origin are not allowed in a product, for instance, to avoid allergens:

$$
Z_{i p} \leq a_{i p} \quad \forall i \in I, p \in P
$$

where $a_{i p}$ indicates to what level an intermediate $i$ may be used in product $p$. Additionally, for each component $k \in K$ the compositional requirement of product $p$ is enforced according to:

$$
q_{k p}^{\min } \leq \sum_{i \in I} q_{i k} Z_{i p} \quad \leq q_{k p}^{\max } \quad \forall k \in K, p \in P
$$

where $q_{i k}$ is the composition parameter of intermediate $i$ for component $k$, and $q_{k p}^{\min }$ and $q_{k p}^{\max }$ are the lower and upper limits for component $k$ in product $p$. This uniform formulation of the compositional requirements allows for product specifications by the customer which consider a range of values to be acceptable. In the cases where there is no lower or upper limit defined in the product specification, the values of the limits can be set to zero or one, respectively.

An intermediate producer can limit the total number of intermediates selected to manage the operational simplicity of the production operations:

$$
\begin{aligned}
& W_{i}= \begin{cases}1, & \text { if intermediate } i \text { is used. } \\
0, & \text { otherwise. }\end{cases} \\
& \sum_{p \in P} Z_{i p} \leq n W_{i} \quad \forall i \in I \\
& \sum_{i \in I} W_{i} \leq j
\end{aligned}
$$

where $j$ is the maximum number of intermediates the producer is willing to handle. The consideration of the co-production of intermediates, and the selection of fractionation pathways are integrated in Equation (2.1) and Equation (2.3). Resource consumption is described by:

$$
\begin{aligned}
& \sum_{m \in M} \sum_{f \in F} e_{m f} X_{m f} \\
& \sum_{m \in M} \sum_{f \in F} w_{m f} X_{m f}
\end{aligned}
$$


where $e_{m f}$ and $w_{m f}$ are the respective energy and water consumption of processing material $m$ using fractionation pathway $f$. Equation (2.15) and Equation (2.16) can be used as objective functions in addition to Equation (2.1).

\subsection{Case study}

We illustrate the decision support approach with an example from the food industry and investigate the potential benefits of selecting non-conventional intermediates. The example considers an intermediate producer conventionally focused on producing proteinrich intermediates for its customers, using yellow pea (Pisum sativum) and lupin seeds (Lupinus angustifolius) as raw materials. Yellow peas are pulses rich in starch and protein, whereas lupin is an oilseed legume with a protein content similar to soy but with a lower oil content.

\subsubsection{Description and data}

The customers demand protein-rich intermediates for applications in products that can be grouped into categories, such as solid and liquid foods, nutraceuticals and supplements, and non-food applications. Although the conventional high-purity intermediates meet the customers' demand, the first stage of the decision support framework leads to the insight that the different product categories do not strictly need high-purity protein intermediates (Figure 2.3).

For example, in the category of solid foods considered in the case are pasta or pasta-like products. Pasta enriched with vegetable protein targets the need for protein supplement in vegan or similar diets (Duranti, 2000) while also containing other components. In liquid foods, protein-rich drinks require the addition of protein without negatively affecting the viscosity of the drink by adding too much fibre. Supplements like protein powders for athletes, on the other hand, do require a higher degree of protein purity. Non-food applications, such as livestock feed, dot not have strict targets on the presence of other components besides protein.

Often, the exact composition of the product required by the customer is not specified completely, and acceptable upper and lower levels can be determined. Examples of such quality requirements for some products are summarised in Table 2.1. The specific restrictions to the intermediate products for each of the final applications considered are shown in Table 2.2. Customers' demand for the products are estimated based on the average demand for the final applications in the Netherlands (van Rossum et al., 2016), additionally assuming that all surplus intermediates can be directed to non-food applications. 
Table 2.1: Examples of final applications for the produced products, and their requirements

\begin{tabular}{lll}
\hline Final application category & $\begin{array}{l}\text { Examples of final } \\
\text { applications }\end{array}$ & Examples of requirements \\
\hline Solid state foods & $\begin{array}{l}\text { Pasta enriched with } \\
\text { veg-protein } \\
\text { Doughs for bakery } \\
\text { application }\end{array}$ & $\begin{array}{l}\text { High protein content and } \\
\text { water holding capacity } \\
\text { Relatively high water } \\
\text { holding capacity }\end{array}$ \\
& & Balanced content of protein \\
& & $\begin{array}{l}\text { and fibre, high water } \\
\text { holding capacity, }\end{array}$ \\
& & medium-high protein \\
& Polubility \\
Liquid state foods & Low fibre content, high \\
& & protein solubility and low \\
& viscosity \\
Gels & Good gelation properties \\
Nutraceuticals & Dietary supplement & High purity and low \\
Non-food application & Animal feed & moisture \\
\hline
\end{tabular}

Table 2.2: Quality bounds for the product according to the final applications

\begin{tabular}{llr}
\hline Product description & Quality requirements & Demand ratio \\
\hline Pasta, protein enriched & Protein content $\geq 55 \%$, fibre content & 35 \\
& $\leq 68 \%$, other carbohydrates $\leq 10 \%$, fat & \\
& content $\leq 23 \%$ & \\
Dough & Protein content $\geq 65 \%$, protein content & 100 \\
& $\leq 90 \%$ & \\
Meat analogue & Protein content $\geq 64 \%$, fibre content $\geq 18 \%$ & 2 \\
Low-fat yoghurt & Protein content $\geq 67 \%$, fat content $\leq 2 \%$ & 41 \\
Drink & Fibre content $\leq 5 \%$, fat content $\leq 10 \%$ & 5 \\
Nutraceutical & Protein content $\geq 78 \%$ & 2 \\
Non-food application & Flexible, no restrictions & \\
\hline
\end{tabular}


Table 2.3: Water use and energy use for processing based on Berghout et al. (2015), Schutyser et al. (2015), and Geerts et al. (2017a), costs estimated based on Berk (1992) and Apaiah \& Hendrix (2005)

\begin{tabular}{llccc}
\hline Agro-material & Pathway & Water $(\mathrm{kg} / \mathrm{kg})$ & Energy $(\mathrm{MJ} / \mathrm{kg})$ & Cost $(€ /$ ton $)$ \\
\hline \multirow{4}{*}{ Lupin } & Conventional & 23.27 & 60.33 & 91.82 \\
& Aqueous & 15 & 50.31 & 70.45 \\
& Dry & 0 & 0.52 & 48.58 \\
& Combined & 4.95 & 17.13 & 55.87 \\
\multirow{2}{*}{ Pea } & Conventional & 12.5 & 60.55 & 85.02 \\
& Aqueous & 4.40 & 53.03 & 58.30 \\
& Dry & 0 & 0.52 & 48.58 \\
& Combined & 1.45 & 17.88 & 51.82 \\
\hline
\end{tabular}

For the second and third stages of the framework, the intermediate producer knows that conventional and mild fractionation processes can be used to produce a variety of intermediates with different degrees of purity from yellow peas (Pelgrom et al., 2014b) and lupin (Berghout et al., 2015). In these fractionation processes, several process steps are executed to split the raw material into the desired fractions (see Figure 2.3c). A series of process steps combined forms a fractionation pathway, of which four are considered: conventional, aqueous, dry, and a combination of dry and aqueous (Figure 2.4).

Each fractionation pathway consumes water and energy for processing (Table 2.3) and produces a specific portfolio of intermediates, i.e. producing one intermediate using the fractionation pathway implies co-producing the other intermediates. The yield of each intermediate and its composition are given in Table 2.4.

\subsubsection{Optimising the selection of intermediates and fractionation path- ways}

The model presented in section 2.2.2 was used to optimise the selection of intermediates and their fractionation pathways. The production of all required intermediates using the conventional processing of lupin was used as a base case for comparisons. An optimal selection of intermediates was determined while minimising cost, energy use, and water use using Equations (2.1), (2.15) and (2.16)as objective functions, respectively. Additionally, the model was used to explore the relation between the minimal energy use that could be obtained and the maximum number of intermediates that could be selected. 


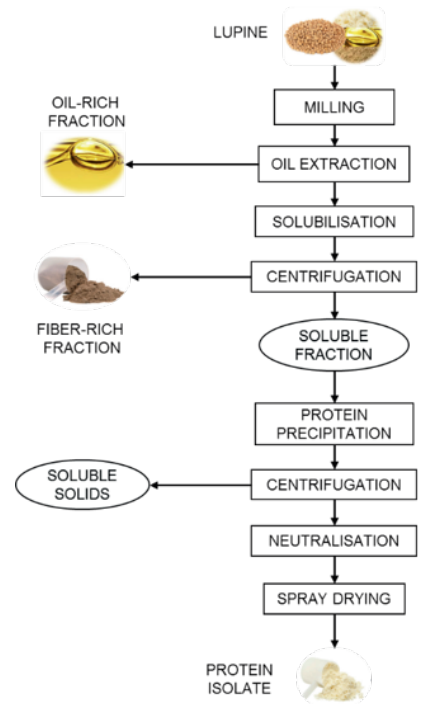

WET CONVENTIONAL

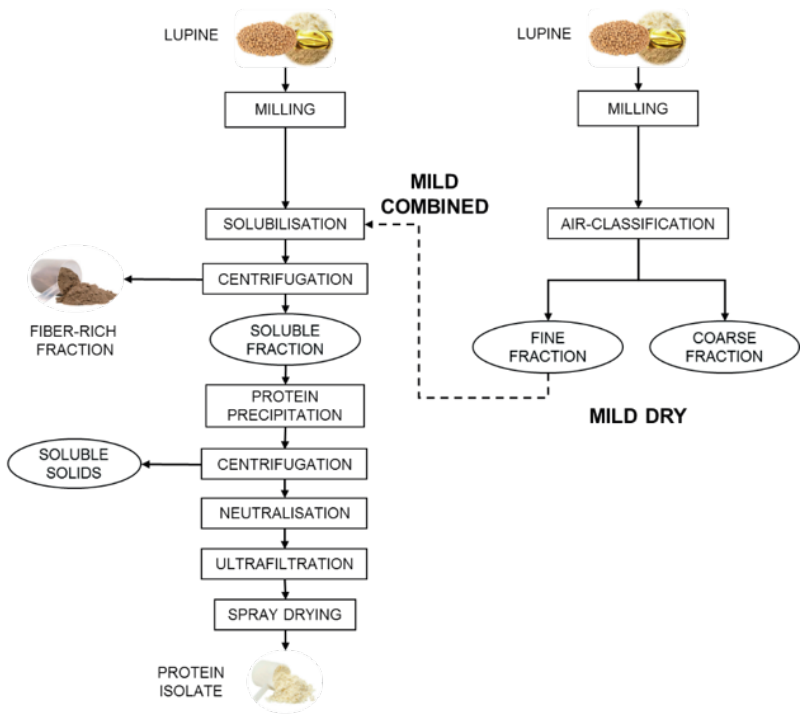

MILD AQUEOUS

(a) Conventional, mild aqueous, dry, and combined fractionation pathways for lupin (Berghout et al., 2014; Pelgrom et al., 2014a)
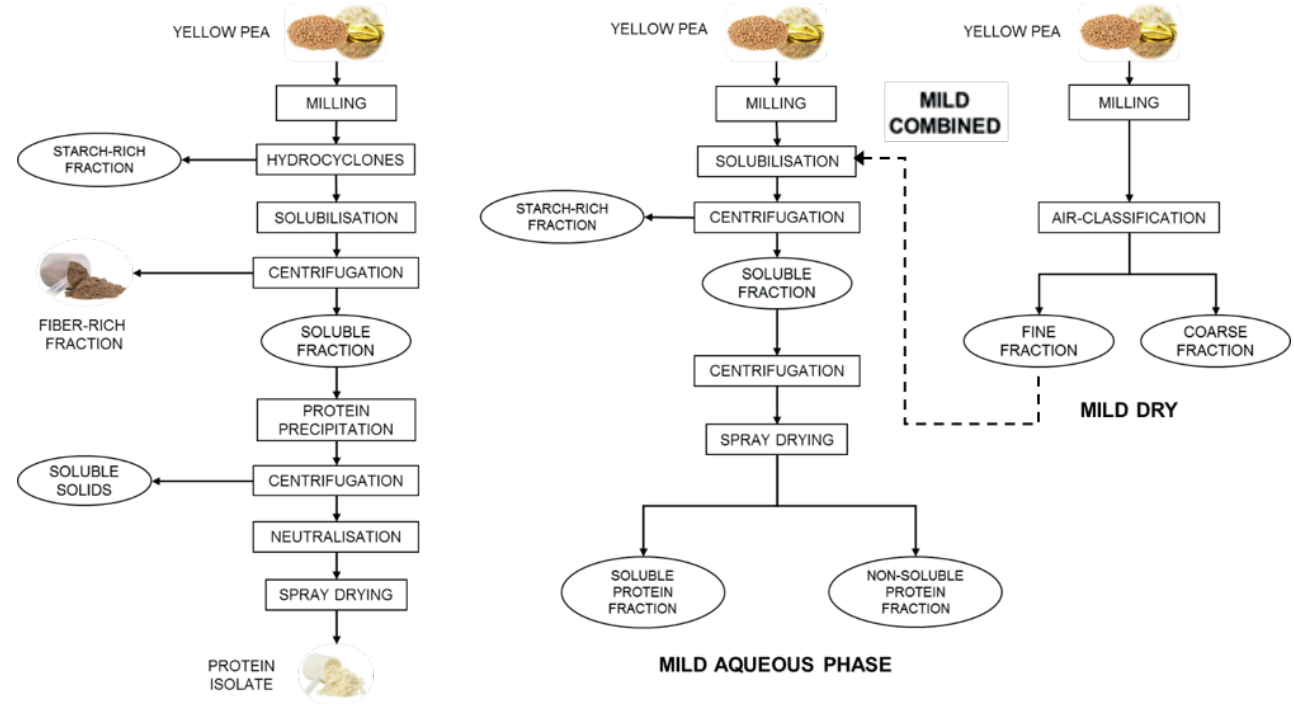

MILD AQUEOUS PHASE

\section{ISOELECTRIC PRECIPITATION}

(b) Conventional, mild aqueous, dry, and combined fractionation pathways for pea (Pelgrom et al., 2013; Schutyser et al., 2015; Geerts et al., 2017b)

Figure 2.4: Fractionation pathways for lupin and pea 
Table 2.4: Intermediate portfolios produced for lupin and pea per fractionation pathway. Yield and composition based on wet weight (ash and water content not shown, values from Berghout et al., 2015; Geerts et al., 2017a; Pelgrom et al., 2014b)

(a) Lupin

\begin{tabular}{|c|c|c|c|c|c|c|}
\hline Pathway & Fraction & $\begin{array}{c}\text { Yield } \\
(\mathrm{kg} / \mathrm{kg})\end{array}$ & $\begin{array}{l}\text { Fibre } \\
(\mathrm{w} / \mathrm{w})\end{array}$ & $\begin{array}{l}\text { Protein } \\
(\mathrm{w} / \mathrm{w})\end{array}$ & $\begin{array}{c}\text { Carbohydrate } \\
(\mathrm{w} / \mathrm{w})\end{array}$ & $\begin{array}{c}\text { Fat } \\
(\mathrm{w} / \mathrm{w})\end{array}$ \\
\hline Starting material & Lupin & & 0.30 & 0.41 & 0.07 & 0.08 \\
\hline \multirow[t]{4}{*}{ Conventional } & Oil-rich & 0.07 & 0 & 0 & 0 & 1 \\
\hline & Fiber-rich & 0.37 & 0.68 & 0.23 & 0 & 0 \\
\hline & Soluble & 0.27 & 0 & 0.28 & 0.59 & 0 \\
\hline & Protein-rich & 0.27 & 0 & 0.83 & 0.10 & 0 \\
\hline \multirow[t]{3}{*}{ Aqueous } & Fiber-rich & 0.46 & 0.65 & 0.12 & 0 & 0.16 \\
\hline & Soluble & 0.20 & 0 & 0.37 & 0.50 & 0 \\
\hline & Protein-rich & 0.29 & 0 & 0.80 & 0 & 0.07 \\
\hline \multirow[t]{2}{*}{ Dry } & Coarse & 0.67 & 0.37 & 0.32 & 0.14 & 0.06 \\
\hline & Fine & 0.33 & 0 & 0.49 & 0.35 & 0.07 \\
\hline Combined & Coarse & 0.67 & 0.37 & 0.32 & 0.14 & 0.06 \\
\hline aqueous & Fibre-rich & 0.11 & 0.47 & 0.20 & 0 & 0.26 \\
\hline \multirow[t]{2}{*}{ and dry } & Soluble & 0.07 & 0 & 0.64 & 0.22 & 0 \\
\hline & Protein-rich & 0.14 & 0 & 0.80 & 0 & 0.07 \\
\hline \multicolumn{7}{|c|}{ (b) Pea } \\
\hline Pathway & Fraction & $\begin{array}{c}\text { Yield } \\
(\mathrm{kg} / \mathrm{kg})\end{array}$ & $\begin{array}{l}\text { Fibre } \\
(\mathrm{w} / \mathrm{w})\end{array}$ & $\begin{array}{c}\text { Protein } \\
(\mathrm{w} / \mathrm{w})\end{array}$ & $\begin{array}{c}\text { Carbohydrate } \\
\qquad(\mathrm{w} / \mathrm{w})\end{array}$ & $\begin{array}{c}\text { Fat } \\
(\mathrm{w} / \mathrm{w})\end{array}$ \\
\hline Starting material & Pea & & 0.13 & 0.21 & 0.47 & 0.05 \\
\hline \multirow[t]{4}{*}{ Conventional } & Fibre-rich & 0.074 & 0.95 & 0 & 0 & 0 \\
\hline & Starch-rich & 0.42 & 0.31 & 0 & 0.64 & 0 \\
\hline & Sugar-rich & 0.18 & 0 & 0 & 0.87 & 0.08 \\
\hline & Protein-rich & 0.25 & 0 & 0.82 & 0.02 & 0.08 \\
\hline \multirow[t]{3}{*}{ Aqueous } & Carbohydr. & 0.66 & 0.23 & 0.04 & 0.66 & 0.01 \\
\hline & Sol. protein & 0.24 & 0.3 & 0.53 & 0.03 & 0.09 \\
\hline & Non-sol.prot. & 0.10 & 0.29 & 0.51 & 0.02 & 0.1 \\
\hline \multirow[t]{2}{*}{ Dry } & Coarse & 0.68 & 0.19 & 0.07 & 0.6 & 0.01 \\
\hline & Fine & 0.33 & 0.38 & 0.39 & 0.02 & 0.03 \\
\hline \multirow{4}{*}{$\begin{array}{l}\text { Combined } \\
\text { aqueous } \\
\text { and dry }\end{array}$} & Coarse & 0.68 & 0.19 & 0.07 & 0.6 & 0.01 \\
\hline & Fibre-rich & 0.04 & 0.47 & 0.08 & 0 & 0.38 \\
\hline & Soluble & 0.02 & 0 & 0.23 & 0.22 & 0 \\
\hline & Protein-rich & 0.26 & 0 & 0.58 & 0.21 & 0.06 \\
\hline
\end{tabular}




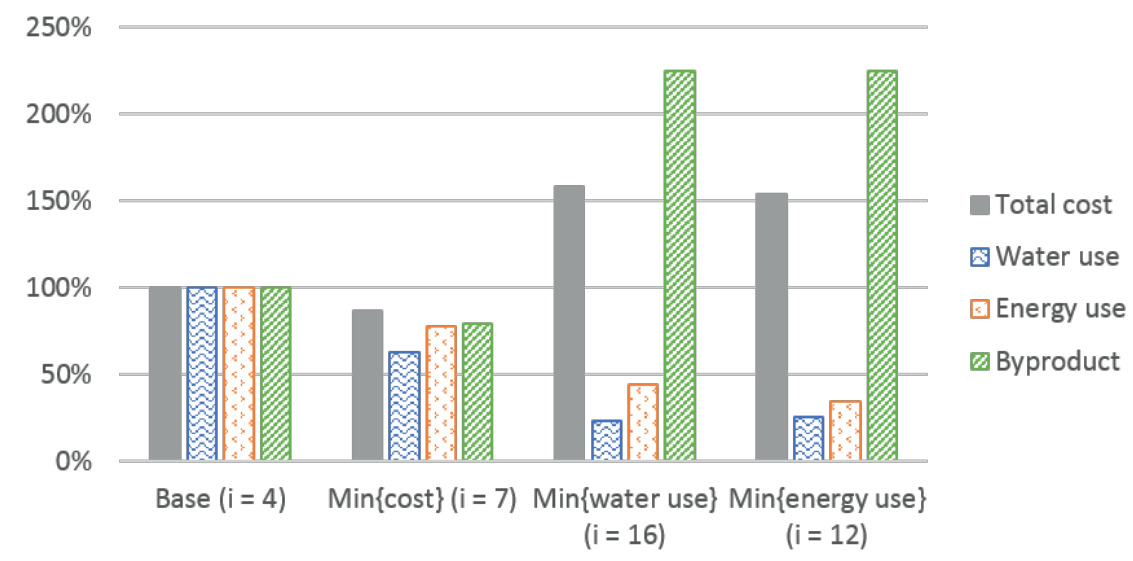

Figure 2.5: Performance indicators of optimised intermediate and pathway selection according to the different objectives and the resulting number of intermediates in the selection

\section{Optimisation results}

From the base case we observe that it is indeed possible to meet the customers' demand for all products using the intermediates obtained from the conventional processing of lupin. In the modelled case, a quantity of 4400 ton lupin is required, with an associated cost of $\mathrm{k} € 1812$ for sourcing and processing. Water use for the base case was $102 \mathrm{kton}$, and energy use totalled at 265 TJ. The total quantity of intermediates that in this case is assigned to non-food by-products was 2462 ton. Further results are reported relative to these figures.

Figure 2.5 shows the performance indicators related to the optimal intermediate and pathway selection according to the different objectives to minimise cost, water use, and energy use. In all these cases, non-conventional intermediates from the mild fractionation pathways were incorporated into the selection (see Figure 2.6). Lowest cost was achieved using a total of seven intermediates to blend all the desired products. The introduction of non-conventional intermediates improved cost, water use, energy use, and by-product production with respectively $13 \%, 37 \%, 22 \%$, and $21 \%$. Consumption of raw materials was reduced by $9 \%$.

The blend of intermediates used to produce the required products is shown in Figure 2.7 for the base case and the minimal cost scenario. A clear shift is observed in the fractions blended to produce the end products. Additionally, it is seen that the fractions that in this case were assigned to the non-food product category (feed) are mainly fibre-rich and other carbohydrate-rich fractions. This shows that the current product portfolio 


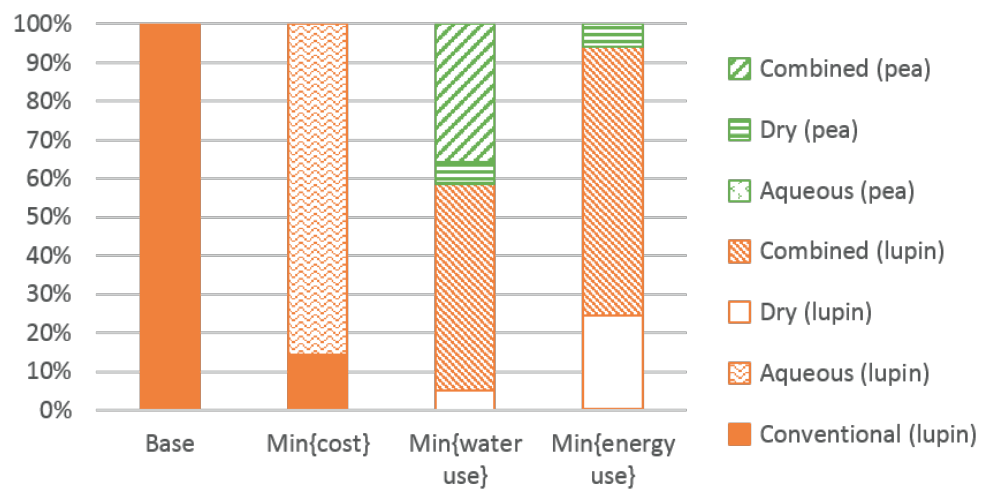

Figure 2.6: Overview of the percentage of raw material processed using the selected fractionation pathways according to the different objectives

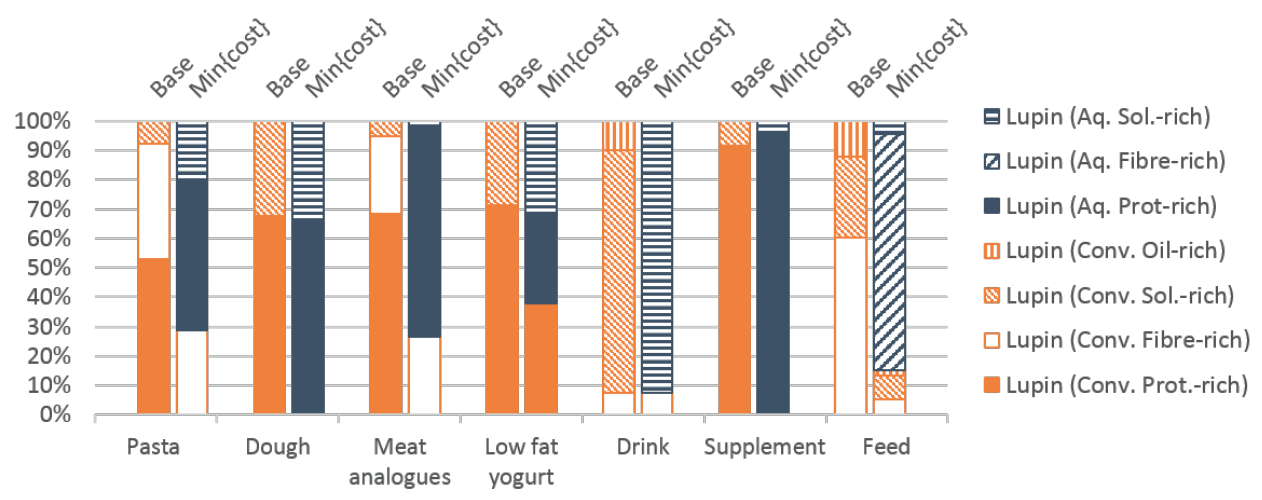

Figure 2.7: Optimised blend of intermediates in products to fulfil customer demand

of the intermediate producer is short on applications for these intermediates. Finding applications will increase the intermediate producer's percentage of raw materials ending up as high-value products.

Window of possibilities for product portfolio development

The optimisation results show a further reduction of energy use and water use is possible to values as low as $34 \%$ and $23 \%$ of the base case. However, this comes at added cost and an increased quantity of intermediates that in this case is assigned to non-food by-products. This is related to the large percentage of the dry and combined fractionation pathways selected in these scenarios (Figure 2.6). These pathways lead to the co-production of a 


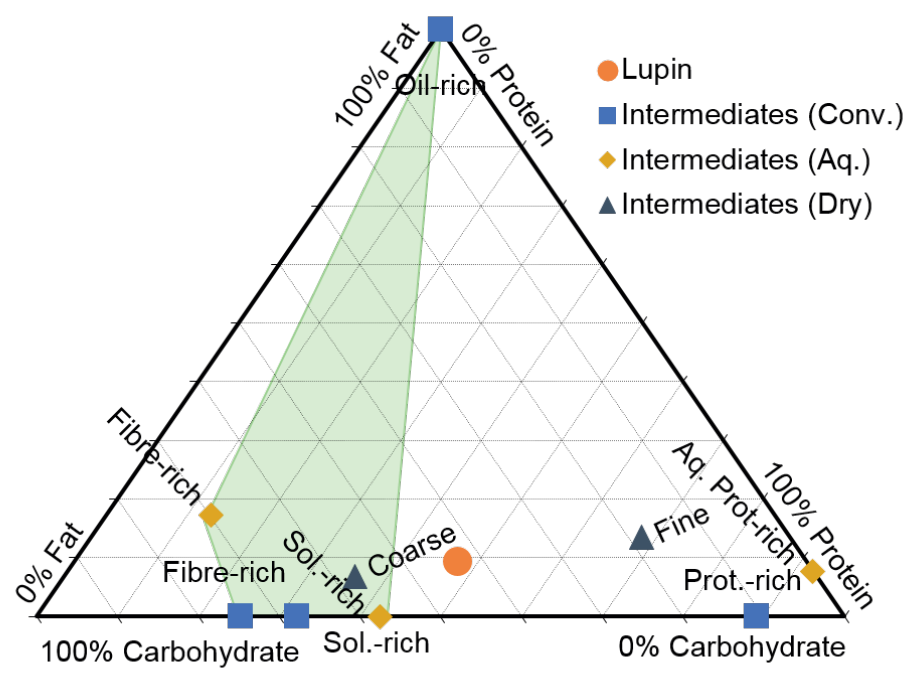

Figure 2.8: Identification of the desired product composition requirements (shaded area) that can be obtained with the intermediates which are produced in excess in the case study

coarse intermediate which is considered to be of feed quality in the case. If this fraction could be of food quality, a broader product portfolio is needed to assign this intermediate to a food product.

Redefining the product specifications together with customers, or developing new products can improve the use of the fractions that are produced in excess, which supports the intermediate producer in finding cost-neutral or cost-beneficial ways for reducing energy and water consumption. For this purpose, the ternary diagrams are again a useful tool to map the area of interest in which new products are to be formulated, depending on the blending possibilities of the intermediates which are produced in excess in the current case (Figure 2.8).

Resource use reduction vs. number of intermediates

Compared to the base case, the optimised selections of intermediates and pathways require an increased number of intermediates. The lower versatility in the applicability of the non-conventional intermediates could lead to an increased operational complexity at the intermediate producer (e.g. due to the handling of all the intermediate flows, inventories, and blending operations). Hence, the relation was investigated between the total number 


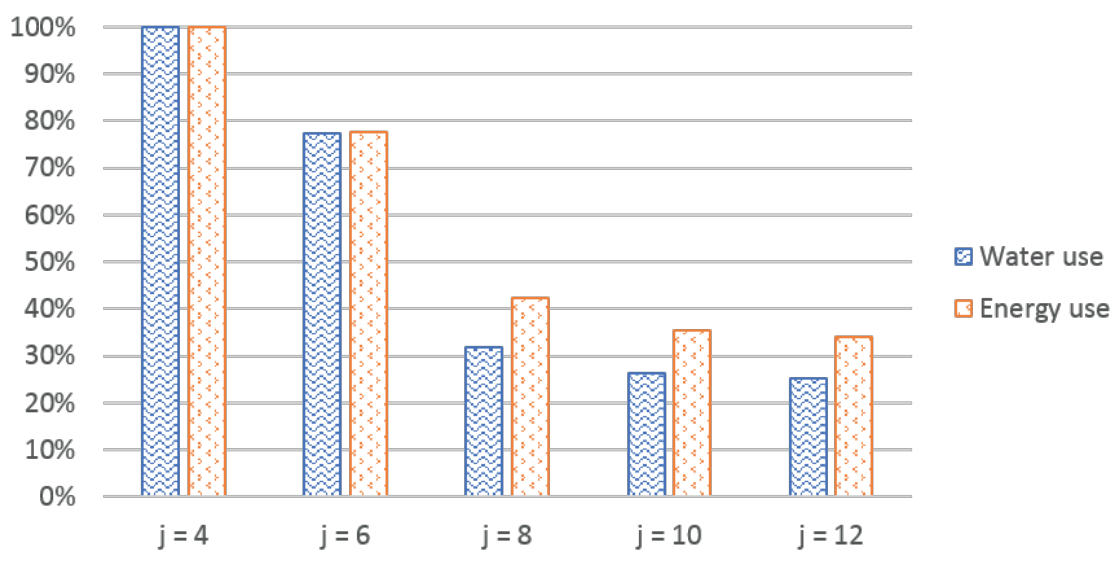

Figure 2.9: Resource use of the optimal intermediate and pathway selection minimising total energy use for different numbers of allowed intermediates

of intermediates the producer is willing to handle and the savings in resource use of water and energy. The right hand side of Equation (2.14) was used to limit the number of intermediates selected while minimising Equation (2.15).

While less than six intermediates are allowed, the conventional fractionation of lupin is selected due to its versatile intermediates. The non-conventional dry pathway is included besides the conventional pathway if the total number of intermediates should be less than eight. For less than ten intermediates, the dry pathway is replaced by the combined dry and aqueous pathway. This reduces the need for most conventional processing and leads to large savings in water use and energy use. If a maximum of ten or eleven intermediates can be selected, the dry pathway is introduced again besides the others. The minimal energy use in the case study is obtained using twelve intermediates, at which point also dry processed pea is included (Figure 2.5 and Figure 2.6). These results show a potential tradeoff between resource use and operational complexity at the intermediate producer.

\subsection{Conclusions}

This chapter presents an optimisation-based decision support approach for the selection of raw materials, intermediates, and fractionation pathways. The approach supports identifying gaps in a product portfolio and opportunities for integrated product and process design for mixed consumer products. Case study results show how non-conventional intermediates could lead to a more resource-efficient production of these products. Using non-pure intermediates enabled a reduction in costs, energy use, and water use. This 
would, however, lead to the use of more application-specific intermediates, which increases the operational complexity of an intermediate producer. Moreover, collaboration is required between an intermediate producer and their customers to identify and produce the optimal portfolio of intermediate products.

In the case of mixed consumer products such as food and cosmetics, the final properties of a product are not determined by their chemical composition alone (Bongers, 2009; Dubbelboer et al., 2015). The techno-functional characteristics (e.g. water-holding capacity, emulsifying properties) of intermediates are not determined by single components, and production processes affect the final properties of a blend of intermediates (e.g. Geerts et al., 2017a). The understanding of these interactions between intermediates and processing is limited (Datta, 2016). There is a very limited amount of data available in scientific literature relating functionality to product composition, and there can be large inconsistencies between studies. Having insight in the relation between composition and technical functionality of intermediates could enable the further reduction of resource use in the production of mixed consumer products through the identification of novel intermediates and fractionation pathways. Hence, studying the interaction between processing, intermediate composition, and product properties is a promising and much needed research avenue. 


\section{Chapter 3}

\section{Process and enterprise level}

\section{Selecting food process designs from a supply chain perspective}

- Food supply chain characteristics affect the performance of food process designs

- Process evaluation and selection methods need to account for these characteristics

- Adapting existing methods provides interesting insights when comparing designs

- Selection of the best process design is case dependent

- The entire product portfolio is key to select the best process designs

This chapter is published as:

Jonkman, J., Bloemhof, J. M., van der Vorst, J. G. A. J., van der Padt, A. (2017). Selecting food process designs from a supply chain perspective. Journal of Food Engineering, 195, 52-60. 


\section{Abstract}

The food industry can convert agro-materials into products using many alternative process designs. To remain competitive, companies have to select the design leading to the best supply chain performance. These designs differ in the technologies used and the product portfolio produced. Additionally, characteristics, such as seasonal production and quality decay of food products, lead to specific requirements regarding processing, transportation and storage. The importance of these characteristics of the food industry on process design selection is investigated using sugar beet processing as an illustrative case. The characteristics are included in a multi-period, multi-product location-allocation model. The model shows that a supply chain perspective leads to changes in process design selection. The design with the best portfolio value and processing costs does not lead to the best supply chain performance. This shows the importance of a chain perspective to avoid sub-optimisation in food process design selection. 


\subsection{Introduction}

Developments in resource availability, consumer trends and legislation require the food industry to regularly evaluate their mode of operation to remain competitive (van der Padt, 2014; van der Goot et al., 2016). This includes aligning strategic and tactical decisions on supply chain (SC) organisation, the product portfolio produced, and the process design (Chopra \& Meindl, 2015). Companies therefore have to select the process design from a range of alternatives on a regular basis to arrive at the best SC performance.

A process design is the combination of process steps or technologies used to convert an agro-material into products. Commonly, selection of a design is done by assessing alternative designs (through experiments or modelling) based on their technical performance characteristics such as yield, costs, or emissions to the environment (e.g. Leone et al., 2015; Manfredi \& Vignali, 2015). Such a comparison leads to the selection of a design without taking into account the related SC.

The performance of a design is influenced by the specific characteristics of the food industry. The food industry is distinguished from other industries by characteristics such as seasonality, specific legislation, and changing product quality (van der Vorst \& Beulens, 2002; Bourlakis \& Weightman, 2004; Tsolakis et al., 2014). This is especially the case in the agro-food industry, the part of the food industry concerned with conversion of agro-materials into a set of semi-finished and finished products (Figure 3.1). It relies on agro-materials, making seasonal and regional production and processing more important than for the food manufacturing industry, which does not rely on harvested crops or animals but on the use of commodity food products or ingredients (van der Padt, 2014). The characteristics of the food industry lead to specific requirements for transportation, storage, and processing. The food supply chain (FSC) for a process design is therefore relevant for selecting the best design, and selection of a design should be based on the performance of the entire FSC (Hosseini \& Shah, 2011; Jonkman et al., 2015).

Existing process evaluation and selection models generally do not take the characteristics of the food industry into account (Datta, 2016). These models therefore require adaptations to support process design evaluation and selection in the food industry. An approach illustrated in Figure 3.2 is required to include the influence of the FSC in selecting the preferred process design. After a process design is synthesised, simulation of the technical performance can be used to evaluate the process design and compare it with alternative designs. To include the FSC in this comparison, the performance of the process designs is included in the synthesis of an SC configuration. The performance of the SC configuration provides the basis for selecting the preferred process design from an SC perspective.

The importance of the characteristics of FSCs for process design selection is investigated 


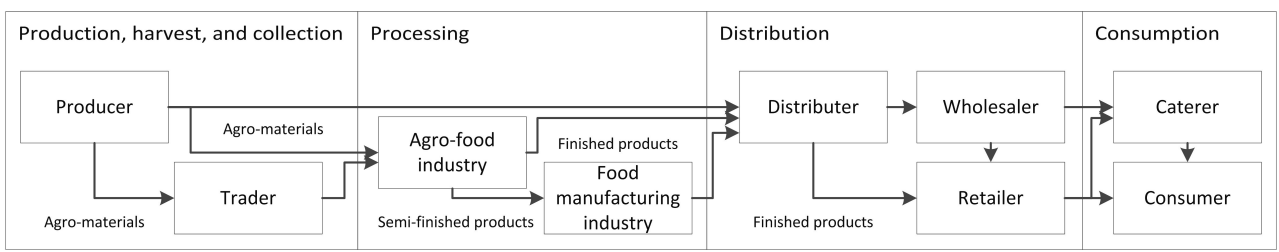

Figure 3.1: Schematic representation of the stages and actors in a food supply chain, and the principal flow of products between these actors

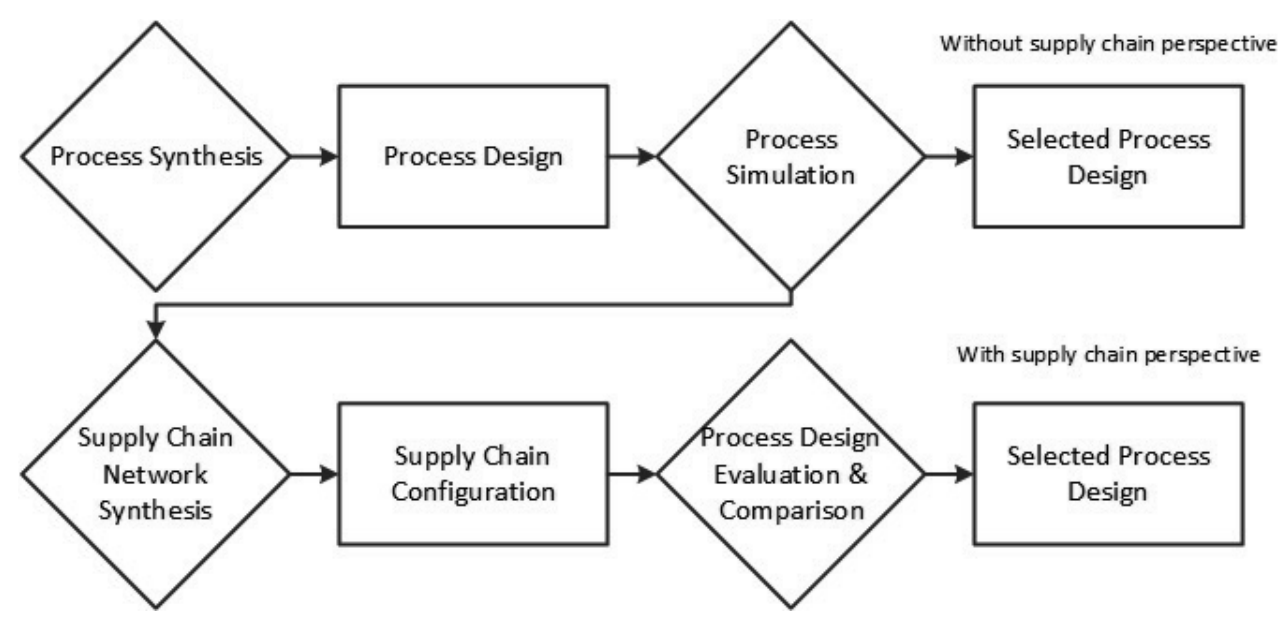

Figure 3.2: Food process design evaluation with and without a supply chain perspective 
in this chapter. Selection of a design based on the technical performance is compared with selection from an SC perspective for an illustrative case on sugar beet processing in The Netherlands. Existing models from the fields of Process Systems Engineering (PSE) and Operational Research (OR) are discussed, and a model is adapted to incorporate the specific characteristics of FSCs relevant to the case. In section 3.2, the specific characteristics of FSCs and related work in the fields of PSE and OR are discussed. Section 3.3 shows that adapting existing methods to account for the characteristics of FSCs provides new insights into the selection of process designs, using the illustrative case study. The effect of specific FSC characteristics on the selection of process designs is discussed in section 3.4. In section 3.5, conclusions are drawn for the general case of selecting food process designs from an SC perspective.

\subsection{Selecting food process designs}

Selecting food process designs from an SC perspective requires evaluating and comparing process designs while taking the specific characteristics of FSCs into account. The most important FSC characteristics for selecting process designs are discussed in section 3.2.1. The PSE and OR literature was reviewed, and an overview of tools for comparing process designs is presented in section 3.2.2, focusing in applications for food process designs.

\subsubsection{FSC characteristics}

The characteristics that distinguish FSCs are discussed in van der Vorst \& Beulens (2002), Bourlakis \& Weightman (2004) and Tsolakis et al. (2014). Of these, seasonality in production, the multi-product nature, and specific requirements regarding transportation, storage and processing to maintain product quality are the most important FSC characteristics affecting the process design performance.

Most agro-material production is seasonal, making the agro-material available only at a specific time in a certain region. A processor has to store the agro-material or source it from different regions around the world to operate the processing equipment throughout the year; operate a flexible process to switch to other agro-materials when a season has ended; or decide to only operate the equipment during the season in which the agromaterial is available. These decisions influence the performance of a design and should therefore be considered when selecting a process design.

Processing an agro-material inherently leads to a range of products. In the early twentieth century, the agro-food industry often extracted only one product from one agro-material (e.g. starch from potato) and regarded the remainder as waste (van der Padt, 2014). 
Nowadays, however, more value is created by valorising the remainder into useful products, for example by obtaining proteins from whey, which was initially discarded as waste from the production of cheese. Different process designs result in product portfolios with different quantities and values of products, and different transportation requirements. The multi-product nature is therefore important when evaluating and comparing food process designs.

The quality of agro-materials and their derived products changes over time. Exposing a product such as milk to increased temperatures for some time severely reduces its keeping quality (shelf life), whereas sterilising at high temperature extends the shelf life. The sensitivity of agro-materials to changes in quality puts constraints on, for instance, temperature during storage and transportation, processing conditions, and the time an agro-material or product can be kept in inventory. This, combined with seasonality and the multi-product nature, affects the operability of a process design.

\subsubsection{Process design evaluation and selection}

A variety of process evaluation approaches exist to support the selection of a preferred design. These approaches evaluate and compare alternative designs through empirical studies (e.g. Leone et al., 2015), simulation and optimisation modelling (e.g. Solana et al., 2016; Maia et al., 1997, , respectively) and Life Cycle Assessment (LCA) based approaches (e.g. Manfredi \& Vignali, 2015).

Selection of a design and the resulting product portfolio influences strategic decisions at the SC level, due to the relationship between supply and demand location, process design, and facility location (Melo et al., 2009). This interconnection between process design and SC design is recognised both in the field of PSE (e.g. Grossmann, 2005) and in the field of OR and SC network design (e.g. Kristianto et al., 2012).

In the field of PSE, much work exists on evaluating and selecting process designs. Mathematical programming techniques have been applied as useful tools to provide quantitative decision support (Grossmann \& Guillen-Gosalbez, 2010). optimisation models are used to determine which processing steps to use to produce a desired product (e.g. Zondervan et al., 2011), or which products in a product portfolio to produce in what amounts, given the process design and commodity prices (e.g. Henke et al., 2006). Developments in computational technology and optimisation theory have enabled a shift from optimisation of single process steps, production lines, or plants to multi-site optimisation and have shifted the scope beyond the manufacturing stage only (Grossmann \& Guillen-Gosalbez, 2010).

Typically location-allocation models are used in which the type of process design is one 
of the decisions to be optimised. Although existing models dealing with chemical SCs take into account e.g. inventory management, responsiveness and uncertainty (e.g. You \& Grossmann, 2008), the specific characteristics of FSCs are not relevant, and therefore not included. The design framework for enterprise-wide processing networks presented by Quaglia et al. (2012), for instance, reduces regional differentiation to a flat logistic cost, and does not mention FSC characteristics such as seasonality and quality constraints, even though the framework is applied to the soybean oil processing industry.

Many specific characteristics of FSCs, e.g. regional and seasonal availability, multiproduct processes and product quality decay, are relevant in the literature focusing on biobased SCs (De Meyer et al., 2015). Heuristics, simulation, and optimisation approaches are applied to determine the preferred process design and its related SC configuration for biobased SCs (e.g. Moncada et al., 2016; Sukumara et al., 2014; Santibañez-Aguilar et al., 2014, respectively). However, there are large legislative differences between food and nonfood SCs, and unlike FSCs, SCs converting biomass into chemicals and energy can often switch between several raw materials, which reduces the seasonal limitation often found in FSCs. Such differences limit the direct applicability of models focusing on biobased SCs to the case of an FSC.

The management of FSCs has received considerable attention in the OR and SC network design literature (Akkerman et al., 2010a). Location-allocation models applied to the agro-food industry or the food industry in general are covered by the reviews of Lucas \& Chhajed (2004) and Akkerman et al. (2010a), however, papers focusing on selecting a preferred process design are rare. Many papers studying an application in the food industry actually do not include characteristics that are specific to the food industry (Akkerman et al., 2010a), and focus mostly on logistical aspects, giving little attention to process design selection (Hosseini \& Shah, 2011). For example, an extensive decisionmaking framework for agro-food supply chain management was presented by Tsolakis et al. (2014), yet evaluating and selecting a process design in the configuration of the FSC was not discussed.

Process design selection is featured in the papers of, for instance, Wouda et al. (2002) and Vila et al. (2006), but seasonal availability of raw materials and seasonal production were not included, as these are not relevant in the case of dairy and lumber, respectively. The work of de Keizer et al. (2015a) on the design of distribution networks for perishable products includes many specific characteristics of FSCs. It supports finding the optimal SC configuration and allocation of supply, demand and processes to the facilities in this configuration. However, the case study on flowers did not feature alternative process designs for evaluation and selection.

Although SC characteristics are increasingly taken into account in the literature dealing 
with process design selection, the specific characteristics of FSCs have yet to be fully included. The next section shows how adapting existing methodology to account for the specific characteristics of FSCs provides interesting insights for the evaluation and selection of food process designs.

\subsection{Illustrative case: sugar beet processing in The Netherlands}

Recently, several authors identified opportunities for chain improvement in the sugar production industries (Higgins et al., 2007; Kolfschoten et al., 2014). In this industry, the traditional process design and its related SC has evolved in a context emphasising (e.g. due to legislation) the use of economies of scale in processing. Recent legislative changes in the European Union (EU) led to major changes in the EU sugar sector, causing the sector to reorganise. About 140,000 sugar beet growers in the EU stopped producing beet, and more than $40 \%$ of processing factories ceased production. Although total sugar production in the EU remained unchanged, five EU countries stopped producing sugar completely. Further policy changes are expected in the near future (Suiker Unie, 2011; EU, 2013). This gives rise to the need for re-evaluation of the current SC set-up. Alternative process designs can be compared with the traditional process design to select the preferred design for maximum SC performance. The effect of multi-product processes, regional and seasonal supply and quality constraints on the selection of process designs is shown using scenarios.

\subsubsection{Traditional sugar beet processing}

Traditionally, process designs in the sugar industry were developed to produce white sugar from sugar beet. The beets are washed, sliced, and sugar is extracted. This extract is processed into an intermediate product called thick juice, which is used to produce the crystallised sugar. By-products such as tare soil, beet pulp and molasses are considered for valorisation afterwards, and used, for instance, as soil improver, cattle feed and fermentation substrate (Asadi, 2006). Transportation of the products and by-products to customers and back to farms, and transporting sugar beet to the centralised processing facilities results in high transportation costs for the industry (Ioannou, 2005).

The sugar industry in Europe operates during a period called the beet campaign. This period typically lasts three to four months, from September to December. During the beet campaign, sugar beet is harvested, collected and processed. Weather conditions limit extension of the campaign, as frost will severely damage the beet. In addition, 
quality degradation of the beet upon harvesting limits the possibility of storing the beet for processing at a later time (Asadi, 2006). The seasonal supply of beet and its perishable nature thus limit the time available for processing. Processing facilities therefore require a yearly processing capacity about three times as large as the amount of beet being processed, because of the limited time available for processing. This installed processing capacity comes at a cost, even though the equipment cannot be operated to process beet most of the year.

\subsubsection{Sugar beet biorefining}

In this illustrative case study, the traditional process is compared with the biorefinery process design proposed by Kolfschoten et al. (2014), taking into account the multi-product nature, regional and seasonal supply and quality constraints relevant to the sugar beet processing chain. This design was developed with the possibility of balancing products in the product portfolio for maximum profit generation. The sugar beet and its leaves are converted into raw sugar, bioethanol and biogas, without an a priori preference for sugar. Other products are tare soil from beet washing and digestate from the fermenters. These products are recycled to the farms.

Kolfschoten et al. (2014) suggest that the biorefinery process design could lead to a reduction in transportation costs, because it can operate on a smaller scale than the traditional process. Their article does not include a quantitative analysis of the proposed biorefinery design comparing it with the traditional design.

A second alternative proposed is to decentrally process sugar beet into thick juice. This thick juice can be processed centrally into white sugar using the traditional process design. Unlike beet, the thick juice is not perishable and can therefore be stored and processed outside of the beet campaign (Asadi, 2006). This alternative reduces transportation of sugar beet and return flows such as tare, and it reduces the required processing capacity to process thick juice into sugar, as the equipment can be operated for a longer part of the year. The design does not reduce the required beet processing capacity compared with the traditional design.

This juice-traditional process design is not considered attractive by Kolfschoten et al. (2014) because of the necessity to transport the thick juice. They do not mention the opportunities it offers with regard to seasonality, however, which might make the design attractive from an SC perspective. The juice-traditional design is therefore included in the case study. Similar to these designs, other process designs and SC concepts for sugar beet processing are available in the literature (e.g. Higgins et al., 2007; Kostin et al., 2012), and can be included in future research on a detailed case study. 


\subsubsection{Scenario and model description}

The effect of multi-product processes, regional and seasonal supply and quality constraints on the selected process design for sugar beet processing is investigated using five scenarios (Table 3.1). As the base case, the existing sugar beet processing industry in The Netherlands is considered (illustrated in Figure 3.3). Scenario 2 evaluates the potential benefit of introducing the biorefinery design or the juice-traditional design into the existing chain. Scenario 3 is a green field counterpart of Scenario 1, in which the SC configuration is optimised focusing only on the flow of sugar beet and white sugar. Scenario 4 shows the influence of the multi-product nature of the SC on the results obtained in Scenario 3, by optimising the SC configuration while taking into account the flows of the entire product portfolio (including by-products and return flows). In Scenario 5, the multi-product nature of the processes, the changing quality in the beet and seasonality are taken into account by determining the optimal SC in a green field design, given the three process designs considered.

\section{Case data and assumptions}

To compare the process design performance from an SC perspective, the technical process design performances as mentioned by Kolfschoten et al. (2014) were combined with a multi-product capacitated facility location-allocation model. Product portfolios produced by the process designs are shown in Table 3.2. It was assumed that the raw sugar produced by the biorefinery was of equal quality and value as the sugar produced by the traditional design. Additional cost data on processing of sugar beet was obtained from Asadi (2006). Facilities were assumed to have a thirty-year lifetime, with a flat depreciation rate per year. Factors for economies of scale were based on Render (1989). Data on the location and supply of sugar beet were taken from the Dutch Bureau of Statistics for 2014 (Figure 3.3). Demand for sugar in a municipality was assumed to correlate with the population size, and demand for products that can be used as agricultural input was assumed to correlate with the area of beet cultivated or the amount of cattle kept in an agricultural region (note that in reality the sugar beet processing industry mainly works business to business).

In the calculations, it was assumed that the fixed cost of juice facilities was $40 \%$ of the fixed cost of traditional facilities (based on Render, 1989), and that traditional facilities and biorefineries of equal capacities have equal fixed and variable costs. It was assumed that the value of the products was constant in the seasons. All data were obtained from publicly available sources.

The data were structured to include the specific characteristics of the case in the model presented in Section 3.3.3. For example, processing costs varies between seasons; heat 
Table 3.1: Scenarios analysed in the case study. $\mathrm{BF}=$ brown field, $\mathrm{GF}=$ green field, $\mathrm{S}=$ single product, $\mathrm{P}=$ product portfolio, $\mathrm{T}=$ traditional process design, $\mathrm{B}=$ biorefinery process design, $\mathrm{J}=$ thick juice process design

\begin{tabular}{lccc}
\hline Scenario & Scope & Process Design & Seasonality \\
\hline 1. Base case & $\mathrm{BF}, \mathrm{P}$ & $\mathrm{T}$ & \\
2. Brown field selection & $\mathrm{BF}, \mathrm{P}$ & $\mathrm{T}, \mathrm{B}, \mathrm{J}$ & $\mathrm{x}$ \\
3. Single product & $\mathrm{GF}, \mathrm{S}$ & $\mathrm{T}$ & \\
4. Multi-product & $\mathrm{GF}, \mathrm{P}$ & $\mathrm{T}$ & \\
5. Green field selection & $\mathrm{GF}, \mathrm{P}$ & $\mathrm{T}, \mathrm{B}, \mathrm{J}$ & $\mathrm{x}$ \\
\hline
\end{tabular}

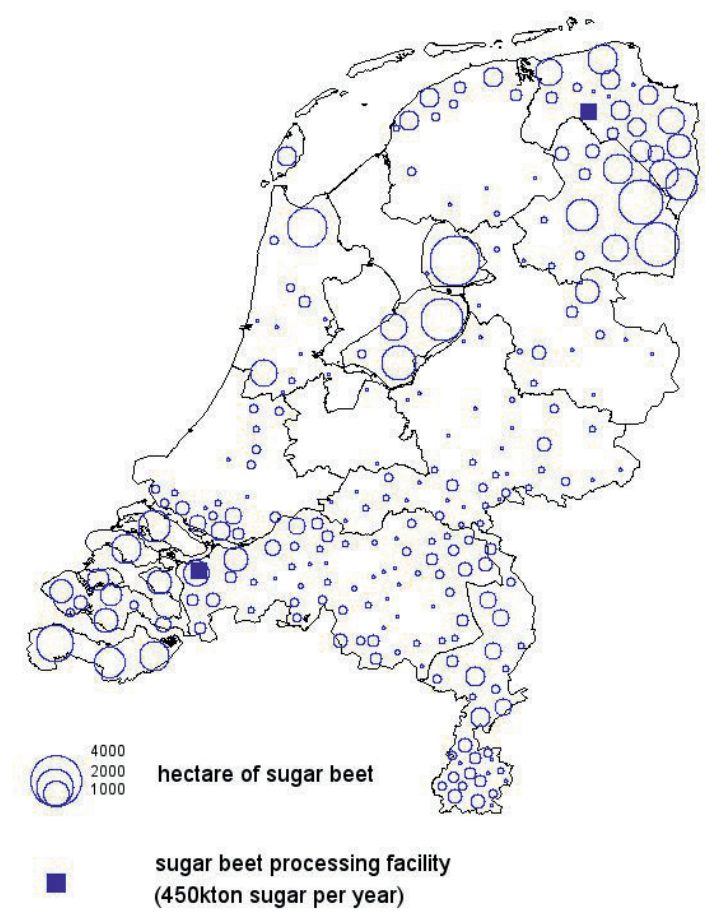

Figure 3.3: Sugar beet supply and existing sugar beet processing facilities in The Netherlands, based on CBS (2016) and Suiker Unie (2010) 
Table 3.2: Process design-related product portfolio based on Kolfschoten et al. (2014) and Asadi (2006)

\begin{tabular}{llccc}
\hline Process design & $\begin{array}{l}\text { Product } \\
\text { portfolio }\end{array}$ & $\begin{array}{c}\text { Conversion factor } \\
\text { (ton/ton beet) }\end{array}$ & $\begin{array}{c}\text { Value } \\
(€ / \text { ton })\end{array}$ & $\begin{array}{c}\text { Portfolio value } \\
(€ / \text { ton agro-material })\end{array}$ \\
\hline $\mathrm{T}$ & Tare & 0.125 & 10 & 84.1 \\
& Sugar & 0.14625 & 500 & \\
& Molasses & 0.03375 & 150 & \\
& Press pulp & 0.1 & 45 & \\
& Lime sludge & 0.0275 & 6 & \\
$\mathrm{~B}^{*}$ & Tare & 0.125 & 10 & \\
& Raw sugar & $0.0125-0.125$ & 500 & \\
& Bioethanol & $0.0625-0.01875$ & 400 & \\
& Biogas & 0.1575 & 90 & \\
$\mathrm{~J}$ and $\mathrm{T}^{* *}$ & Tare & 0.125 & 10 & \\
& Sugar & 0.144 & 500 & \\
& Molasses & 0.036 & 150 & \\
& Press pulp & 0.1 & 45 & \\
& Lime sludge & 0.0275 & 6 & \\
\hline
\end{tabular}

*The biorefinery design uses beet leaves as agro-material as well as beet

**Product portfolio for decentralised thick juice production with centralised further processing 
and water integration in the traditional process design makes processing of juice in the beet campaign cheaper than processing juice out of season. The process design selected for operation was included as the facility type, whereas a piecewise-linear approximation was used for economies of scale in the fixed costs of opening a facility and the operating costs of that facility.

\section{Model formulation}

A multi-product location-allocation model was used to select process designs from an SC perspective, taking into account the specific FSC characteristics of the case. The following index sets are used:

$$
\begin{array}{ll}
a \in A & \text { set of agro-materials } \\
c \in C & \text { set of facility capacities } \\
f \in F & \text { set of transformations } \\
I \subset P & \text { set of intermediate products } \\
l \in L & \text { set of possible facility locations } \\
m \in M & \text { set of demand markets } \\
p \in P & \text { set of products and by-products } \\
r \in R & \text { set of supply regions } \\
t \in T & \text { set of facility types } \\
s \in S & \text { set of seasons }
\end{array}
$$

Decision variables used in the model are:

$X_{\text {rltcas }} \quad$ quantity of agro-material $a$ transported from region $r$ to a processing facility at location $l$ of type $t$ with capacity $c$ in season $s$

$W_{l l^{\prime} t t^{\prime} c p s}$ quantity of product $p$ transported from a facility at location $l$ of type $t$ to facility $l^{\prime}$ of type $t^{\prime}$ with capacity $c$ in season $s$

$Z_{l m t p s} \quad$ quantity of product $p$ transported from a facility at location $l$ of type $t$ to

market $m$ in season $s$

$Y_{l t c} \quad$ processing facility at location $l$ of type $t$ with capacity $c$ open or not (binary) 
Parameters:

sup $_{\text {ras }} \quad$ supply in region $r$ of agro-material $a$ in season $s$

cap $\quad$ total capacity $c$ in season $s$

dem $_{m p s}$ demand at market $m$ for product $p$ in season $s$

$d r_{r l} \quad$ distance between supply region $r$ and facility location $l$

$d l_{l l^{\prime}} \quad$ distance between facility location $l$ and location $l^{\prime}$

$d m_{l m} \quad$ distance between facility location $l$ and market $m$

$f c_{l t c} \quad$ fixed costs for opening a facility at location $l$ of type $t$ with capacity $c$

$o c_{t c s a} \quad$ operating costs of facility type $t$ with capacity $c$ per ton of agro-material

$t c_{p} \quad$ transport costs of product $p$ per ton per $\mathrm{km}$

$v_{\text {val }} \quad$ value of product $p$ in season $s$

$c f_{\text {tpf }} \quad$ conversion factor for product $p$ in transformation $f$ in facility of type $t$

$c r_{\text {taf }} \quad$ converted fraction of agro-material $a$ in transformation $f$ in facility type $t$

The model is formulated as follows:

$$
\begin{aligned}
& \max \quad \sum_{L} \sum_{M} \sum_{T} \sum_{P} \sum_{S} v a l_{p s} \times Z_{l m t p s}-\sum_{L} \sum_{T} \sum_{C} f c_{l t c} \times Y_{l t c}- \\
& \sum_{R} \sum_{L} \sum_{T} \sum_{C} \sum_{A} \sum_{S} o c_{\text {tcsa }} \times X_{\text {rltcas }}- \\
& \sum_{R} \sum_{L} \sum_{T} \sum_{C} \sum_{A} \sum_{S} d r_{r l} \times t c_{a} \times X_{\text {rltcas }}- \\
& \sum_{L} \sum_{L^{\prime}} \sum_{T} \sum_{T^{\prime}} \sum_{C} \sum_{I} \sum_{S} d l_{l l^{\prime}} \times t c_{i} \times W_{l l^{\prime} t t^{\prime} c i s}- \\
& \sum_{L} \sum_{L^{\prime}} \sum_{T} \sum_{T^{\prime}} \sum_{C} \sum_{I} \sum_{S} d l_{l l^{\prime}} \times o c_{t^{\prime} c s i} \times W_{l l^{\prime} t t^{\prime} c i s}- \\
& \sum_{L} \sum_{M} \sum_{T} \sum_{P} \sum_{S} d m_{l m} \times t c_{p} \times Z_{l m t p s} \\
& \text { s.t. } \quad \sum_{L} \sum_{T} \sum_{C} X_{\text {rltcas }} \quad \leq \text { sup }_{\text {ras }} \quad \forall r \in R, a \in A, s \in S \\
& \sum_{R} \sum_{A} X_{\text {rltcas }}+ \\
& \sum_{L^{\prime}} \sum_{T^{\prime}} \sum_{I} W_{l^{\prime} l t^{\prime} t c i s-1} \leq \operatorname{cap}_{c s} \times Y_{l t c} \quad \forall l \in L, t \in T, c \in C, s \in S \\
& \sum_{T} \sum_{C} Y_{l t c} \quad \leq 1 \quad \forall l \in L \\
& \sum_{L} \sum_{T} Z_{l m t p s} \quad \leq \operatorname{dem}_{m p s} \quad \forall m \in M, p \in P, s \in S
\end{aligned}
$$




$$
\begin{aligned}
\sum_{M} Z_{l m t p s}+\sum_{L^{\prime}} \sum_{T^{\prime}} W_{l l^{\prime} t t^{\prime} c p s}= & \sum_{L^{\prime}} \sum_{T^{\prime}} \sum_{F} \sum_{I} c f_{t p f} \times c r_{t i f} \times W_{l^{\prime} l t^{\prime} t c i s-1}+ \\
& \sum_{R} \sum_{A} \sum_{F} c f_{t p f} \times c r_{t a f} \times X_{r l t a}+ \\
& \sum_{L^{\prime}} \sum_{T^{\prime}} W_{l^{\prime} l t^{\prime} t c p s-1} \quad \forall l \in L, t \in T, p \in P \\
X_{\text {rltcas }} \geq 0 & \forall r \in R, l \in L, t \in T, c \in C, a \in A, s \in S \\
W_{l l^{\prime} t t^{\prime} c i s} \geq 0 & \forall l, l^{\prime} \in L, t, t^{\prime} \in T, c \in C, i \in I, s \in S \\
Z_{l m t p s} \geq 0 & \forall l \in L, m \in M, t \in T, p \in P, s \in S \\
Y_{l t c} \in\{0,1\} & \forall l \in L, t \in T, c \in C
\end{aligned}
$$

The model determines the number, capacity and locations of facilities to open, the process design selected (facility type), and how to allocate supply and demand to these facilities to maximise the profitability of the SC (Equation 3.1). Equation 3.2 specifies that the amount of agro-material a transported from region $r$ is limited to the supply of region $r$. Equation 3.3 specifies that product flow to a facility at location $l$ of type $t$ is only allowed when it is open, and does not exceed the capacity $c$ and Equation 3.4 ensures that only one facility can be opened at location $l$. Equation 3.5 puts an upper boundary on the demand for product $p$ at market $m$ for season $s$. Conversion of agro-materials and intermediates to products is specified by Equation 3.6.

The model was programmed in Python (version 2.7.6, Python Software Foundation), using the open source Pyomo library version 4.0.9682 (see Hart et al., 2011, 2012). optimisations were run with a $2.8 \mathrm{GHz}$ Intel Core i7 computer with 4 GB RAM using CPLEX (version 12.6, IBM ILOG). The full optimisation problem consists of about 142,000 variables (of which approximately 250 are binary variables) and about 2500 constraints.

\subsubsection{Case results and discussion}

The order of magnitude for the modelled results of Scenario 1 (base case) was validated with information available in Asadi (2006), Suiker Unie (2010), Rosenboom et al. (2013) and Kolfschoten et al. (2014). The optimisation results are shown in Table 3.3. Results for Scenario 1 (base case) show the modelled performance for the current sugar beet processing chain in The Netherlands. In the illustrative case, the amount of beet available at farms for processing is larger than the amount that the existing facilities can process. The results for Scenario 2 (brown field selection) show that it is profitable to install additional processing capacity compared with the base case. Given the case assumptions, 


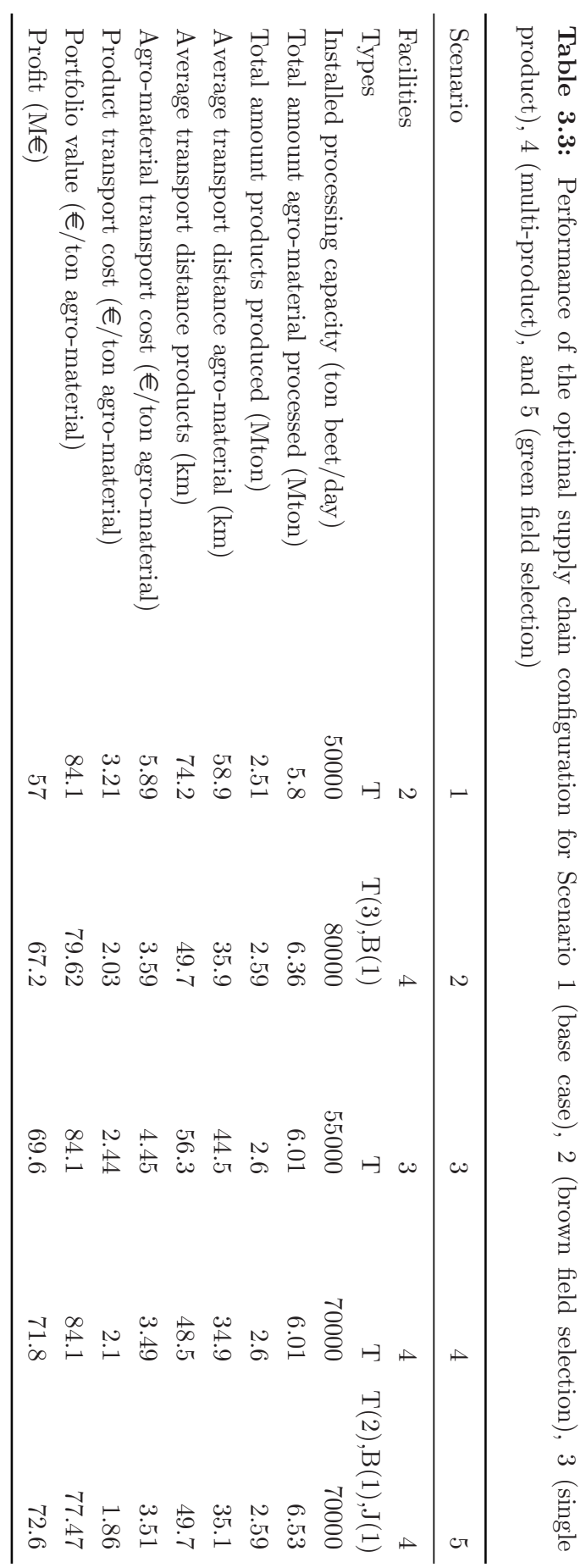


from table 3.2 it follows that the traditional process design is the preferred design to operate, with the highest product portfolio value per ton of agro-material. However, the biorefinery design is selected in Scenario 2, indicating this is the most attractive design for capacity extension in the case where the existing facilities and specific SC characteristics are taken into account.

The SC performance obtained in Scenario 3 corresponds to a green field equivalent of Scenario 1, in which only the flow of beet and sugar are taken into account. The results of Scenario 4 show that taking the flows of the entire product portfolio into account leads to a different number of facilities to be opened, at different locations than for the $\mathrm{SC}$ configuration obtained in Scenario 3 (Table 3.3). The difference in SC performance of both scenarios shows that the focus on a single end product leads to a sub-optimal performance in the industry.

In the optimal SC configuration of Scenario 5, several process designs are selected. Designs that are not the most profitable designs contribute to an overall SC performance that is better than what could be obtained with the most profitable process design only. The modelled profit increased over $4 \%$ compared to Scenario 3 in which the SC characteristics are not taken into account.

The juice-traditional design does not occur in the optimal SC for Scenario 2, whereas it does occur in Scenario 5. The processing capacity of the existing traditional facilities taken into account in Scenario 2 makes opening a juice processing facility unattractive. In Scenario 5, the existing facilities are not taken into account, giving more freedom to select the process designs that contribute most to SC performance. The differences between Scenario 2 and Scenario 5 show how an existing infrastructure (as assumed in Scenarios 1 and 2) limits the opportunities for innovation by excluding process designs that would be competitive in a green field design (Scenario 5).

The assumptions on the distribution and aggregation of demand influence the solutions obtained with the model. The model validation performed with the results of Scenario 1 indicate that the assumed level of demand aggregation provided an accurate enough approximation to reality. The biorefinery design is most attractive for capacity extension under the initial assumptions. Selection of the other process designs in the optimised green field design of Scenario 5 shows that from an SC perspective the other designs are still competitive. The differences between Scenario 2 and 5 show that the regional availability of supply and demand and an already existing infrastructure influence the selection of process designs. 


\subsubsection{Sensitivity analysis biorefinery design}

The optimisation results are sensitive to the value of the parameters used, such as the product portfolio value, the transport costs, and the facility and operational costs. In this section, the sensitivity of the result of Scenario 5 is explored, focusing on the biorefinery design, as this was the most attractive design for capacity extension. The effect of changing the transportation costs and the operating costs on the competitiveness of the process design is shown. Transportation costs were varied with $\pm 50 \%$ related to the original value due to their uncertainty. Because operating costs of the biorefinery design under the initial assumption are an upper estimate, the operating costs are varied in the range $+10 \%$ down to $-50 \%$ relative to the original value. A minimal product portfolio value is determined for the design to be selected from an SC perspective, reducing the price of raw sugar down to $75 \%$ of the original value.

Figure 3.4a, Figure 3.4b, and Figure 3.4c show the effect of transport cost, operating cost of the biorefinery, and product portfolio value of the biorefinery on the optimal solution of Scenario 5. The optimal solution is not very sensitive to reductions in transport cost, but an increase of more than $7 \%$ will cause a change in the optimal SC configuration and the selection of process designs. Lower operating cost of the biorefinery lead to SC configurations in which more capacity of the biorefinery process desing is installed. However, this design is not selected when its product portfolio value is reduced.

Initially, the raw sugar produced with this design was assumed to be of equal value to the sugar produced with the traditional process design. However, this raw sugar is less pure (Kolfschoten et al., 2014), and therefore will fetch a lower price on the market. The design is not competitive when the raw sugar produced is of equal value to internationally traded raw sugar at a reference price of $82.9 \%$ of white sugar (Rosenboom et al., 2013, which equals $€ 414.5$ in this case). Process development is therefore required to make the biorefinery design competitive, e.g. through a reduction in facility or operational costs.

An opportunity could be to use the biogas produced by the biorefinery to generate the electricity and heat required by the facility for processing. This will reduce the value of the product portfolio, but will also reduce the operational cost for utilities. Calculations based on Kolfschoten et al. (2014) and Asadi (2006) show there is more energy available in the biogas produced by a biorefinery than is required for processing, reducing the operational cost in the case to about $65 \%$. This power to plant opportunity is introduced in Scenario 5. The required biogas to cover energy requirements is subtracted from the product portfolio of the biorefinery design, and the operational costs are decreased accordingly to compensate for the decreased amount of utilities that have to be purchased externally. In this power to plant version of Scenario 5, the biorefinery process design is selected even at 

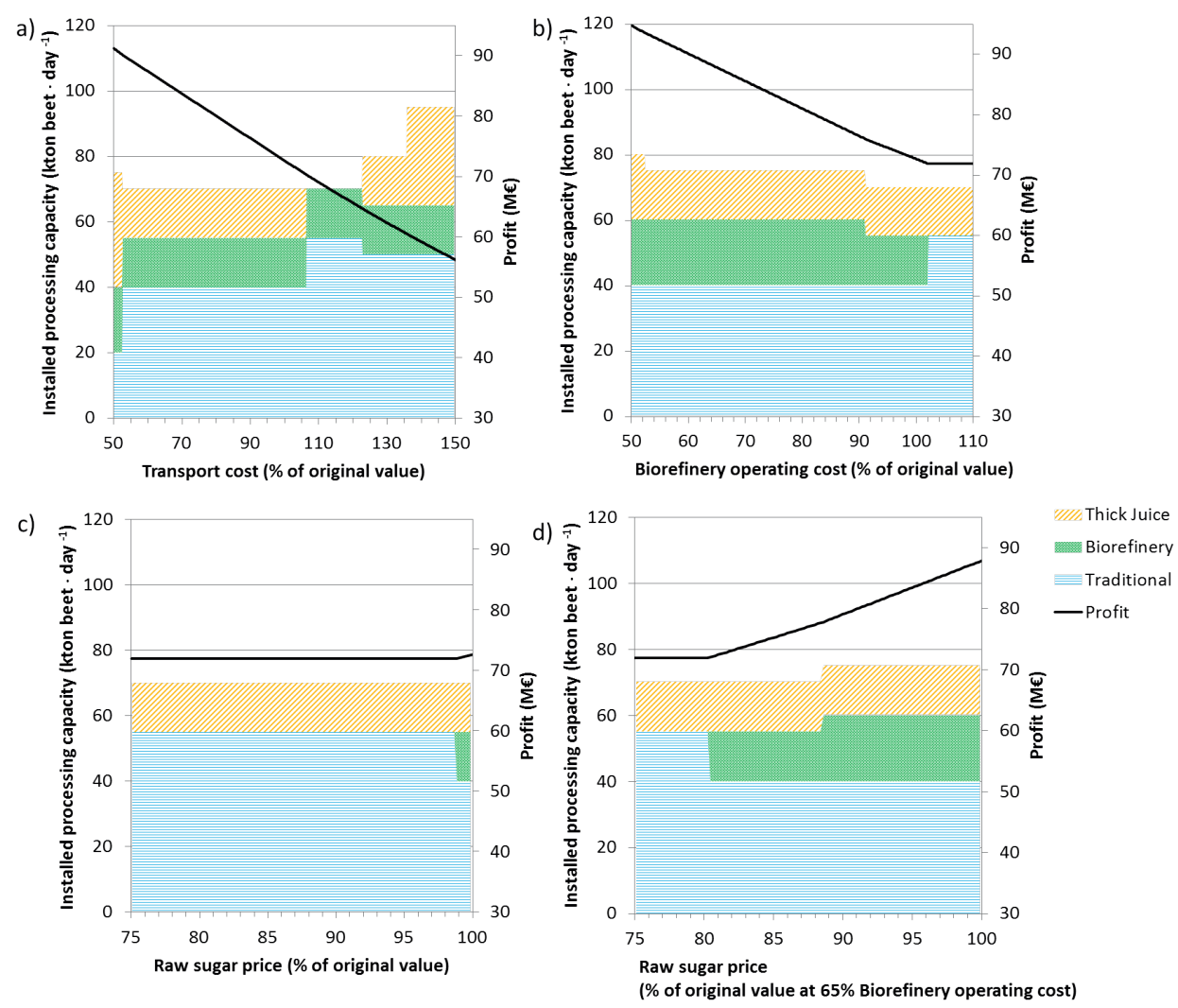

Figure 3.4: Sensitivity of the optimisation result of Scenario 6 (green field) to changes in (a) transport cost, (b) operating cost of the biorefinery and $(c, d)$ the values of the biorefinery product portfolio

a raw sugar price below the current reference price (Figure 3.4d), indicating that power to plant could be an interesting improvement opportunity for the biorefinery design.

\subsection{Discussion}

In the case study, the process designs were considered as a linearised black-box approximation. Evidently, more detailed process models can be directly integrated into an approach to select designs from an SC perspective. This will introduce nonlinearities in the process models. In this case, a nested process optimisation model or a multi-layered approach must be used. Such an approach will be computationally more complex, leading to a 
trade-off between the detail of insights gained and modelling and computational effort. In our linearised black-box approximation, a multi-product location-allocation model was adapted to select the process designs from an SC perspective. Other models available in the fields of PSE and OR can be used similarly after adaptation to include the required characteristics of FSCs.

The degree to which specific characteristics of FSCs influence process design evaluation depends on the case being investigated. In the illustrative case, perishability of end products was not an issue, whereas this is very relevant in, e.g. dairy chains. The limited availability and quality degradation that are important in the sugar beet chain are not as important in dry cereal processing (e.g. wheat, rice) or in the food manufacturing industry. For these industries, it is more important to balance the benefits of economies of scale with the disadvantages of having to source raw materials (agro-materials, food ingredients) from longer distances, which is associated with high transportation costs and complicated production planning. In turn, the products produced by the food manufacturing industry have an entirely different orientation towards the market compared with agro-food chains, i.e. the former are more focused on a plethora of innovative and consumer products, whereas the latter mainly produce a limited set of commodity products.

The illustrative case study shows that taking the entire product portfolio of a food process design into account improves SC performance. Traditional process designs often focus on obtaining as much of one or more main products as possible, and only consider valorisation of by-products afterwards. This could lead to under-utilisation of the agro-materials processed, or inefficient chains. More value can be achieved with process designs that balance all products in the product portfolio to achieve maximum valorisation of the agro-material. This is especially the case in the agro-food industry and biobased industry, where regionally distributed and seasonally available raw materials are converted into a diverse product portfolio to serve several different markets (e.g. other industries, farmers for feed and nutrients, retailers). Here, the use and value of products other than the main product greatly influence the overall profitability of a design.

In addition to the regional and seasonal SC aspects included in the illustrative case, many food and biobased chains deal with functionality and perishability of products, and uncertain process yields. These aspects will further influence process design selection, inventory management, and product distribution throughout the SC.

\subsection{Conclusions and future work}

This chapter shows the importance of an SC perspective for comparing and selecting process designs. Seasonality in production and regional availability of agro-materials, 
the multi-product nature of food processes, and the changing quality of agro-materials affect the performance of process designs in the context of their SC. The SC level and product level therefore affect the strategic decision making in the food industry to select those process designs that lead to the best SC performance. Integration of these levels is required to avoid sub-optimisation of the FSC.

The illustrative case study shows that the specific characteristics of the sugar beet processing chain influence the selection of process designs for the sugar industry. Therefore, comparing different process designs as such does not indicate which design, or combination of designs, leads to the best SC performance. Evaluating process designs from a SC perspective adds value by taking the specific characteristics of the chain into account. This makes process design evaluation and comparison case specific. A design that is not competitive in the infrastructure of one company could be attractive in the SC of another company in a different region or with another infrastructure in place.

The importance of characteristics for the evaluation and selection of the food process design under study is case dependent, because there are large differences between and within the agro-food industry and the food manufacturing industry. An integral view of the product portfolio is important in the design of food processes.

The effect of specific organisation structures, such as cooperatives, were not included in this study. A cooperative structure can oblige a processor to process, even at times when there is no demand for products, or the market price for certain products is low. Such a situation is not generally found in manufacturing industries and adds a different dimension to the evaluation and selection of process designs, because flexibility becomes more important.

Robustness of solutions is therefore important for real-life applications, and techniques such as robust optimisation or extensive sensitivity analysis can be applied to find robust solutions for real-world case studies. A study on robust optimisation of process designs in the context of FSCs is an interesting route for future research; the illustrative case presented in this chapter could be extended and investigated in further detail. 



\section{Chapter 4}

\section{Supply chain level}

\section{Integrating harvesting decisions in the design of agro-food supply chains}

- We present a generic supply chain design model for agro-food industrial supply chains

- The model is applied to the case of a sugar beet processing chain in the Netherlands

- Opportunities exist in the case to improve the economic and environmental performance

- Harvesting decisions affect supply chain design when yields vary largely in time

This chapter is based on:

Jonkman, J., Barbosa-Póvoa, A.P., Bloemhof, J.M. (submitted). Integrating harvesting decisions in supply chain design in agro-food industry. 


\section{Abstract}

The inefficiencies observed in current agro-food supply chains, and recent trends in agrofood industry, such as consolidation, increase the need for further studies on supply chain management in this field. Models are required for the complex task of determining the optimal supply chain configuration in order to improve their economic and environmental performance while taking into account the specific characteristics of agro-food supply chains. This chapter provides a general description of the supply chain design problem in agro-food industrial chains, considering the role of seasonality and harvesting decisions, perishability, and processing. A general model formulation is presented, which accommodates for these characteristics and for forward and backward flows along the chain. The general model is applied to a case study of the sugar beet processing chain in The Netherlands. The pareto-efficient frontier between maximising the total gross margin and minimising the global warming potential in $\mathrm{CO}_{2}$-eq is explored. Uncertainties in demand and harvest yield are taken into account using a stochastic version of the model. Results show that a supply chain design model tailored to the specific characteristics of an agro-food supply chain with its uncertainties leads to identifying better performing supply chain configurations. In the case study, supply chain configurations can be found in which the performance on both the economic and the environmental objective is better than the modelled current performance. Additionally, we observe that supply chain configurations with decentralised processing or pre-processing are an interesting topic for future research in the context of agro-food industry. 


\subsection{Introduction}

The current set-up of Food Supply Chains (FSCs) is an important cause for inefficiencies in food production (van der Goot et al., 2016). These inefficiencies should be reduced to guarantee food security for a growing world population, and improve the future responsible production of food products (in accordance with the United Nations sustainable development goals, UN General Assembly, 2015). The strategic redesign of FSCs can contribute to meet these challenges.

Inefficiencies in food production result in the creation of waste along the FSC, and a loss of the associated resources, capital, and labour invested. In Europe, the food industry represents almost $13 \%$ of the total manufacturing industry turnover (ECSIP Consortium, 2016). The related FSCs account for $31 \%$ of the global warming potential (Perrot et al., 2016). Moreover, 31\% of the food produced is wasted (Gustavsson et al., 2011; Timmermans et al., 2014). Addressing the inefficiencies improves the ability of FSCs to meet the demands of the population in a cost effective way while reducing their environmental impact, which is important both from an economic and an environmental perspective (Soysal et al., 2012; Tsolakis et al., 2014; Perrot et al., 2016).

The economic and environmental performance of FSCs is strongly related to their supply chain (SC) configuration (i.e. the number, type, and location of facilities and their interconnecting flows, Akkerman et al., 2010a; de Keizer et al., 2017). Hence, reassessing the configuration of FSCs can improve their performance and address inefficiencies in the chain to improve its sustainability (Mota et al., 2018).

However, determining the optimal SC configuration for FSCs is a complex problem, due to the specific characteristics of food products and processes (e.g. de Keizer et al., 2015a; Soto-Silva et al., 2015). Seasonality in production and demand, the perishability of products, and product specific requirements for transportation and storage are a few examples that make the management of FSCs different from other SCs (van der Vorst \& Beulens, 2002; Bourlakis \& Weightman, 2004; Aramyan et al., 2007). Not every characteristic is, however, relevant for each FSC. Perishability and seasonality in production are, for instance, very important in FSCs dealing with fresh fruits, but less important for FSCs in which the products do not spoil that rapidly, as is the case for many pulses. Pulses are generally dried to prevent spoilage, although the weather conditions after harvesting could lead to post-harvest losses for these and other crops. Alternatively, processing plays an important role in, for instance, dairy SCs, but not in SCs for fresh fruit and vegetables, such as cabbages.

Due to the wide variety between FSCs, several sub-types are identified and studied in literature. Often, FSCs are categorised based on differences in shelf life (short and per- 
ishable, long and non-perishable), origin (animal, plant based), processing (fresh without product conversions, processed), or industry (agro-food, food assembly). Each of these sub-groups has a specific set of FSC characteristics.

This chapter investigates decision support modelling for the strategic redesign of SC configurations for agro-food industry, where the main concern of the industry is the conversion of agro-materials into a set of semi-finished and finished products. Recent trends in this industry, such as consolidation, have increased the need for and applicability of models and tools (Ahumada \& Villalobos, 2009; Tsolakis et al., 2014). Due to its dependency on agro-materials, seasonal production, harvesting, and processing are important characteristics of these Agro-Food Supply Chains (AFSCs)(Jonkman et al., 2017). Additionally, agro-materials and their derived products are often perishable, and processing can both positively and negatively influence this perishability. Moreover, the natural variability of agro-materials and weather conditions leads to uncertainties in harvest yields (supply), quality, demand and product prices. Due to these specific characteristics and their influence on the management of SCs, standard SC models have to be adapted to include these characteristics (Ahumada \& Villalobos, 2009; Rajurkar \& Jain, 2011).

These specific characteristics of AFSCs require taking into account harvesting decisions. The seasonal availability of a crop in combination with the perishable harvested agromaterial puts restrictions on processing, and therefore affects the optimal SC configuration. Although the need for integrated support for the design and planning of AFSCs was identified (Ahumada \& Villalobos, 2009; Tsolakis et al., 2014), the recent literature review of Kusumastuti et al. (2016) observes there is little work done in developing and applying a model that integrates harvesting and processing in this context.

This chapter contributes to the literature by presenting a Mixed Integer Linear Programming (MILP) model in which tactical decisions at the harvesting stage (area used for cultivation and time of harvesting) are integrated with strategic decisions on the AFSC design (number, location, and capacity of facilities, and the type of processing pathway to operate). It presents an overview of common characteristics of AFSCs and applies the integrated approach to a case study while accounting for global warming impacts and the presence of uncertainty in harvest yield and demand.

Section 4.2 gives an overview of specific characteristics of AFSCs. Additionally, the related literature on the strategic and tactical design of AFSCs is presented. In Section 4.3, the decision problem is further detailed, and a general description of the model requirements and model formulation is developed. This general approach is applied to a case study building on the work of Kolfschoten et al. (2014) and Jonkman et al. (2017) on sugar beet processing in The Netherlands, as described in Section 4.4. The case study results are presented and discussed in Section 4.5, and conclusions are drawn in Section 4.6. 


\subsection{Literature survey}

There is a growing attention in industry and academia for the management of FSCs (Akkerman et al., 2010a; Tsolakis et al., 2014). In this section, the characteristics relevant for the SC design of an agro-food industrial supply chain are presented, and an overview is given of related literature on the design of AFSCs.

\subsubsection{AFSC characteristics}

AFSCs are FSCs in which agro-materials are converted into a number of semi-finished and finished products. Although agro-materials can be of both plant and animal origin, AFSCs dealing with products from animal origin are excluded from the scope of this chapter due to the differences between animal and crop production, slaughtering and harvesting, and processing of the derived products.

Due to the reliance of AFSCs on agro-materials, seasonality and regional differences play an important role when managing such chains (Lucas \& Chhajed, 2004; Shukla \& Jharkharia, 2013). The crops produced by farmers are only available in a certain region for a limited period of time in which they have to be harvested. The yield and quality of the harvested crop depend on its maturity, weather conditions and the naturally varying crop itself. Hence, the supply in AFSCs is time and region dependent, and uncertain in time, quantity, and quality.

The quality of the harvested agro-materials degrades over time, and logistic operations such as transport, storage, and processing influence the quality as well (van der Vorst et al., 2009; Rong et al., 2011). At various points in the SC, minimum quality levels are required. Hence, quality decay is linked to the configuration of the SC (de Keizer et al., 2017), and perishability has to be considered in AFSC design.

Additionally, the processing of agro-materials leads to a range of products. The processing yield and quality of these products is uncertain due to natural variability, and the possibilities for processing and storage of products depend on the type of process pathway operated (i.e. which combination of technologies is used) for the conversion reaction of agro-materials into products. Process pathways that reduce quality decay could be used close to the supply of agro-materials, to obtain stable products. Pathways that increase quality decay are better located close to the final customers and timed according to demand, in order to avoid unnecessary quality loss (de Keizer et al., 2015a). The interaction with the seasonal, regional, and perishable characteristics therefore makes processing an important feature in the design of AFSCs (Jonkman et al., 2017). 


\subsubsection{Strategic AFSC design}

In the strategic design and redesign of SCs the number, capacity, and location of processing facilities to operate has to be determined; how to allocate supply and demand; and if relevant which process pathway to use (Melo et al., 2009). Although these decisions are of great importance, the number of papers dealing with the configuration of AFSCs is limited (Tsolakis et al., 2014). Decision support models used for the design of AFSCs and other FSCs are discussed in the reviews of Lucas \& Chhajed (2004); Akkerman et al. (2010a) and Soto-Silva et al. (2015), who note that there is a shortage of models that take the specific characteristics of FSCs into account. Additionally, we mention the reviews of De Meyer et al. (2014) and Ba et al. (2016) on methods to optimise biobased SC designs, as these SCs share a number of characteristics with AFSCs due to their dependency on plant-based raw materials. Although harvesting decisions as such received a lot of attention in literature, there is little integration with SC design or decisions in other SC echelons (Tsolakis et al., 2014; Kusumastuti et al., 2016).

Additionally, the seasonality of supply is often left out of scope in AFSC design, and the availability of raw materials in time is generally considered as a given. SC optimisation models taking into account seasonality use multiple time periods related to the seasons to allow for the differences between these periods, although the quantities of raw materials available in these periods are assumed to be given (De Meyer et al., 2014; Ba et al., 2016). The availability of raw materials related to harvesting decisions is mostly investigated within a fixed SC configuration (Ba et al., 2016; Kusumastuti et al., 2016), which decouples these decisions from determining the location and capacity of processing facilities. However, the perishable nature of the harvested agro-materials in AFSCs requires integration between these decisions (Amorim et al., 2013).

Although perishable products received a lot of attention in production planning and inventory management literature (Ahumada \& Villalobos, 2009; Amorim et al., 2013; Pahl \& Voß, 2014), there are only few papers that include perishability into SC design models (Akkerman et al., 2010a; de Keizer et al., 2015b). In the context of network control, perishability is modelled using fixed shelf lifes (i.e. products expire after a given number of time periods) or decay functions (e.g. every time period a certain percentage of products expires, or the quality degrades based upon an underlying distribution and products below a minimal quality level are considered expired). Notable recent contributions are de Keizer et al. (2015a) and de Keizer et al. (2017), who incorporate perishability into a network design model using a quality decay function within a hybrid optimisation-simulation approach and an MILP model, respectively, although seasonality and harvesting are not considered.

In general, the papers that consider processing decisions mainly deal with the selection of 
technologies or process pathways, which is especially prominent in the field of biobased SC design (De Meyer et al., 2014; Ba et al., 2016). However, a certain type of network configuration (i.e. fully centralised or with decentral pre-processing) is assumed, with processing happening in a single stage or echelon of the SC. In the case of AFSCs, multi-stage processing could improve the performance of an AFSC due to the effects of transportation and processing on product quality and perishability (Bruins \& Sanders, 2012). Pre-determining the type of network configuration might therefore be restrictive on the solutions of the design model. As mentioned, there is little integration between harvesting and processing decisions, and often sequential optimisation is implied of first harvesting and subsequently determining the optimal technology selection for processing, the SC configuration, and the allocation of flows within the SC.

Above, we observe a gap in the integration of harvesting decisions with the design of AFSCs while taking into account the identified specific characteristics of AFSCs. Closing this gap could support agro-food industrial companies with the identification of competitive SC configurations.

\subsection{Problem description and model formulation}

In this section we contribute to closing the literature gap by providing a general description of the structure of an AFSC, detailing the design problem, and by presenting a general model formulation.

\subsubsection{Structure of the AFSC}

In general, the AFSC is a multi-product SC ranging from the farmers producing the agro-materials to the customers purchasing the processed products (Figure 4.1). In the production stage, crops (e.g. maize) are grown at farms and yield agro-materials upon harvesting (e.g. maize kernels, corn stover). These agro-materials are processed into semi-finished and finished products in the primary processing stage. The semi-finished products can then be further processed in subsequent processing stages, and all produced products are distributed to the customers in their respective markets in the final stages of the AFSC. The principal flows of goods are therefore between the echelons of production (farmers), processing (agro-food industry), and downstream distribution and consumption (customers).

Although the literature generally assumes a centralised set-up within the processing echelon (Kusumastuti et al., 2016), alternative set-ups with the flow of goods between locations within the processing echelon are possible. Additionally, recent studies have showed the 


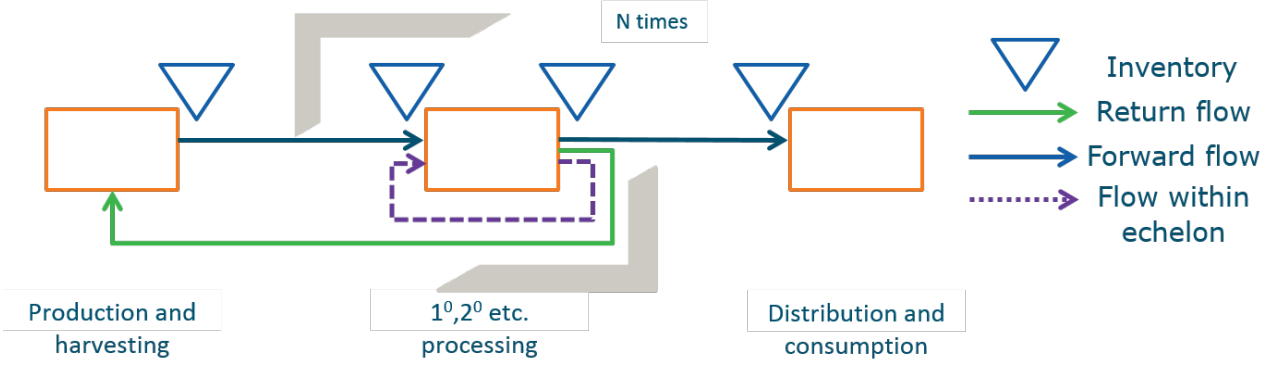

Figure 4.1: Schematic representation of the general Agro-Food industrial Supply Chain

possibility of reverse flows within FSCs, including AFSCs (Banasik et al., 2017; Jonkman et al., 2017; Kang et al., 2017).

Within the AFSC, farmers and processors are mutually dependent, giving rise to SC integration. Organisationally this happens, for instance, through various cooperative structures in which farmers unite to jointly process their harvest, and large scale processors making use of contract farming. This also provides a platform for integrated SC decision making, and the use of related tools and models.

\subsubsection{AFSC design model description}

The integrated AFSC design model has to support selecting the SC configuration that optimises the harvesting and processing of agro-materials, the transportation and storage of raw, semi-finished and finished products, and the reverse flows (Figure 4.1), taking into account the specific characteristics of the AFSC. The decision problem can be described as follows:

Given:

- A set of crops, agro-materials, semi-finished and finished products;

- Maximum age or minimum quality of products;

- A set of processing pathways converting agro-materials into products;

- Possible conversion reactions for a process pathway;

- Required inputs and produced outputs for a process pathway;

- A set of production, processing, and market locations;

- Available land for production; 
- Associated costs to using a location;

- Feasible connections between these locations;

- Expected demand;

- Available capacities;

- Available transport modes;

- Relevant yield, cost and environmental impact parameters;

Select the:

- Area of land to cultivate with a crop;

- Number, size and location of processing facilities;

- Process pathways used;

- Quantities of the crops to harvest in each time period;

- Quantities of the products to produce and the demand to cover in each time period;

- Flow and inventory of agro-materials and products;

Subject to:

- Production and harvest constraints;

- Inventory and transportation constraints;

- Location, allocation and processing constraints;

- Quality and perishability constraints;

- Case specific constraints (e.g. legislative, existing infrastructure);

The design objectives can cover different domains of sustainability (see also Mota et al., 2018), such as the maximisation of the Total Gross Margin (TGM) or the minimisation of Global Warming Potential (GWP) in $\mathrm{CO}_{2}$-equivalents, related to the previously mentioned economic and environmental impact of AFSCs. Additionally, uncertainties related to the AFSC can be incorporated. 
Table 4.1: General categories used for the definitions of subsets

\begin{tabular}{ll}
\hline Set & Subsets \\
\hline $\mathcal{P}$ & crop, agro, in, out \\
$\mathcal{L}$ & farm, processing, market \\
\hline
\end{tabular}

\subsubsection{Model formulation}

The model formulation based on the description from Section 4.3.2 is making use of categories of products and locations, and a general way of modelling perishability, as explained in the following paragraphs.

The structure of the AFSC naturally leads to a number of general subsets or categories of products and locations. These categories can be used in the formulation of the model, as constraints may be relevant to some of these categories, but not to the whole set. For instance, harvesting only occurs at farm locations, which makes production and harvest constraints only relevant to locations in that category. Other categories for locations are processing locations and markets for downstream distribution and consumption. At farm locations the relevant product categories considered are the crops grown, and the obtained agro-materials from these crops after harvesting. Additionally there can be the demand for certain semi-finished or finished products which are outputs of processing. A product is not restricted to one category. Products in the agro-material and outputs categories can, for instance, also be in the processing inputs category. The general category identifiers are shown in Table 4.1.

There are various ways to model perishability (Pahl \& Voß, 2014). In the case that perishability is related to the decline of product quality due to environmental conditions (e.g. temperature, humidity) and time, the perishability of products can be modelled as a number of discrete quality categories, based on a quality decay function (e.g. de Keizer et al., 2017). Alternatively, if the perishability is mainly related to time, it can be incorporated directly or indirectly in the form of shelf life constraints (see also van Elzakker et al., 2014). In the first case, an index is used to represent a discrete quality level, and products will have a lower limit to the quality which is accepted for processing or distribution. In the second case this index can be interpreted as a lifetime counter, and products will have an upper limit to the age at which products are still accepted for processing and distribution. The type of perishability-modelling required is case dependent. 
Based on the description above, an MILP model is formulated. The following indices and sets are used:

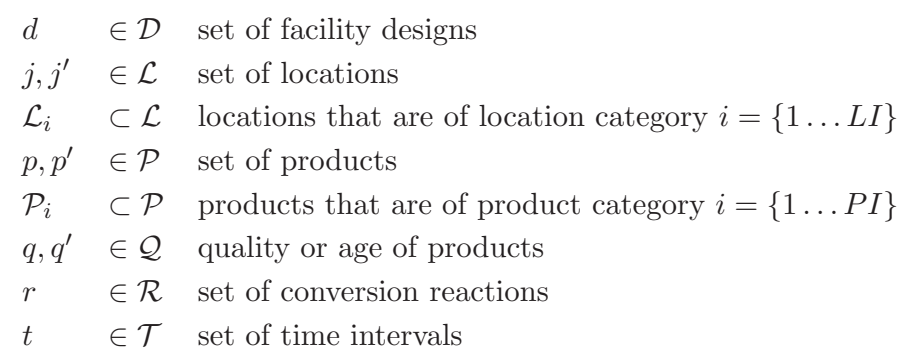

Parameters used in the model are:

\begin{tabular}{|c|c|}
\hline$a l_{j}$ & Arable land available at location $j$ \\
\hline$a q_{p, j}$ & Arable production quota for product $p$ at location $j$ \\
\hline$c d_{p}$ & Disposal cost of product $p$ \\
\hline$c f_{d, j}$ & Fixed cost of opening facility design $d$ at location $j$ \\
\hline$c h_{p}$ & Holding cost of product $p$ \\
\hline$c p_{p, r}$ & Processing cost of $p$ using conversion reaction $r$ \\
\hline$c t_{p, j, j^{\prime}}$ & Transportation cost for transporting product $p$ from location $j$ to $j^{\prime}$ \\
\hline $\operatorname{dem}_{p, j, t}$ & Demand for product $p$ at location $j$ at time $t$ \\
\hline$d f_{p, t, p^{\prime}, j}$ & Demand factor for product $p$ at time $t$ of cultivating crop $p^{\prime}$ at $j$ \\
\hline$e a_{p}$ & Agricultural related $\mathrm{CO}_{2}$-eq emissions of the production of crop $p$ \\
\hline$e d_{p}$ & Disposal related $\mathrm{CO}_{2}$-eq emissions of product $p$ \\
\hline$e p_{p, r}$ & Processing related $\mathrm{CO}_{2}$-eq emissions of $p$ using conversion reaction $r$ \\
\hline$e t_{p, j, j^{\prime}}$ & Transportation related $\mathrm{CO}_{2}$-eq emissions for transporting product $p$ \\
\hline$m b_{p, q, p^{\prime}, q^{\prime}, r}$ & $\begin{array}{l}\text { from location } j \text { to } j^{\prime} \\
\text { Bill of materials of product } p \text { with quality } q \text { from product } p^{\prime} \text { with } \\
\text { quality } q^{\prime} \text { in conversion reaction } r\end{array}$ \\
\hline$p c_{d, r}$ & Processing capacity at facility design $d$ for conversion reaction $r$ \\
\hline$p c l_{p, r}$ & Product capacity load of product $p$ in conversion reaction $r$ \\
\hline$p p_{p}$ & Price of product $p$ \\
\hline$q_{p}^{\lim }$ & Quality limit for product $p$ \\
\hline$q d_{p, q^{\prime}, q}$ & Quality decay factor of product $p$ from $q^{\prime}$ to $q$ per time period \\
\hline$s c_{p, d}$ & Storage capacity for product $p$ at facility design $d$ \\
\hline$y c_{p, q, p^{\prime}, t}$ & Yield of product $p$ with quality $q$ when harvesting crop $p^{\prime}$ at time $t$ \\
\hline
\end{tabular}




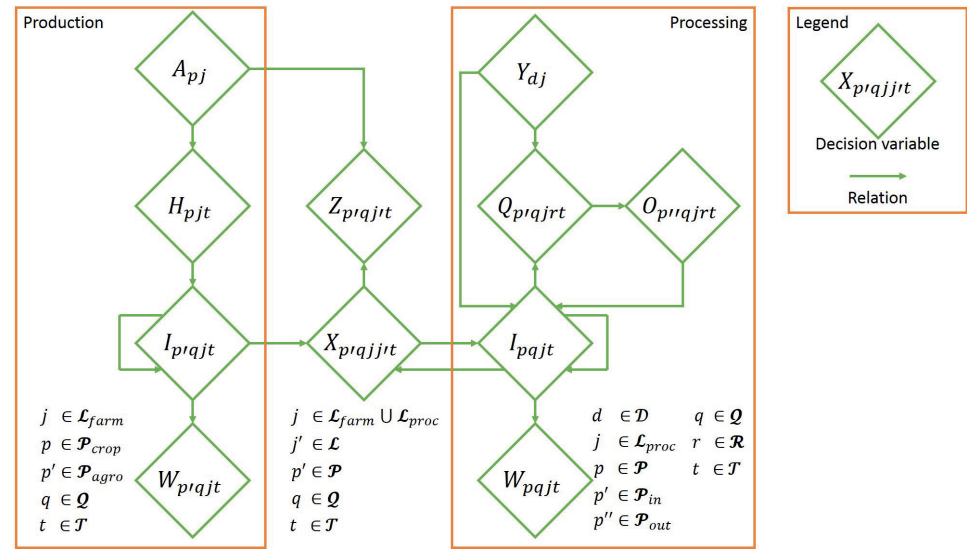

Figure 4.2: The relation between the variables used in the model

Decision variables used in the model are:

$A_{p, j} \quad$ Area of land allocated to growing crop $p$ at location $j$

$H_{p, j, t} \quad$ Harvested area of $p$ at location $j$ at time $t$

$I_{p, q, j, t} \quad$ Inventory of product $p$ with quality $q$ at location $j$ at time $t$

$O_{p, q, j, r, t} \quad$ Output quantity of product $p$ with quality $q$ at location $j$ from reaction $r$ at time $t$

$Q_{p, q, j, r, t} \quad$ Processed quantity of product $p$ with quality $q$ at location $j$ in reaction $r$ at time $t$

$W_{p, q, j, t} \quad$ Wasted product $p$ of quality $q$ at location $j$ at time $t$

$X_{p, q, j, j^{\prime}, t} \quad$ Flow of product $p$ with quality $q$ from $j$ to $j^{\prime}$ at time $t$

$Y_{d, j} \quad$ Facility opened using process design $d$ at location $j$ (binary)

$Z_{p, q, j, t} \quad$ Demand for product $p$ met with quality $q$ at location $j$ at time $t$

The relation between the different variables of the model are represented in Figure 4.2. In the following sections, the constraints specifying these relations are sorted per constraint type as described in section 4.3.2. Constraints are defined using the category identifiers from Table 4.1.

\section{Production and harvest constraints}

The first type of constraints encountered are related to the production of agro-materials in the AFSC. These are formulated as follows: 


$$
\begin{aligned}
\sum_{p \in \mathcal{P}_{\text {crop }}} A_{p, j} & \leq a l_{j} \quad \forall j \in \mathcal{L}_{\text {farm }} \\
\sum_{t \in \mathcal{T}} H_{p, j, t} & =A_{p, j} \quad \forall p \in \mathcal{P}_{\text {crop }}, j \in \mathcal{L}_{\text {farm }}
\end{aligned}
$$

Equation (4.1) limits the total land allocated to crops to the total arable available land at a location. Complete harvest over time of the allocated land is ensured by Equation (4.2). In some cases, specific constraints to limit the maximum area of certain crops may be required, for instance, to prevent mono-cropping or allow for crop rotation (see also Mandryk et al., 2014). In this work, only a single year is taken into account. If more than a single year or harvest season is considered, an additional time dimension can be added to these constraints representing the year or season.

The harvested crops remove nutrients and soil from the production location, which can be partially replenished by returning by-products and waste streams from the processing facilities to the farms. For example, tare soil and lime fertiliser are produced within the sugar beet processing chain, which can be returned to the farms for fertilisation. The demand for these return flows therefore depends on the area under cultivation. Hence, a demand constraint for these return products can be added, as described by Equation (4.3). In the case there are legislative or practical restrictions for the production of a harvested crop, such as was the case under the European sugar beet quota system, a constraint is applicable to restrict the quantity of a crop produced at a farm, as described by Equation (4.4).

$$
\begin{gathered}
\sum_{q \in \mathcal{Q}} Z_{p, q, j, t} \leq \sum_{p^{\prime} \in \mathcal{P}_{\text {crop }}} d f_{p, t, p^{\prime}, j} \times A_{p^{\prime}, j} \quad \forall p \in \mathcal{P}_{\text {return }}, j \in \mathcal{L}_{\text {farm }}, t \in \mathcal{T} \\
\sum_{q \in \mathcal{Q}} \sum_{p^{\prime} \in \mathcal{P}_{\text {crop }}} \sum_{t \in \mathcal{T}} y c_{p, q, p^{\prime}, t} \times H_{p^{\prime}, j, t} \leq a q_{p, j} \quad \forall p \in \mathcal{P}, j \in \mathcal{L}_{\text {farm }}
\end{gathered}
$$

\section{Inventory and transportation constraints}

Harvested crops are added to the inventory at farm locations. Since harvesting is not relevant to other locations, the inventory balance equation is split into two parts. The inventory balance at farm locations is described by Equation (4.5a). For every agromaterial, the quantity in stock at the start of a period is determined by the harvest yield 
of that product at that quality, and the stock that is carried over from the previous period. This is defined as the difference between the inventory of the previous period, the amount of product removed through transportation, waste and demand coverage, multiplied with a decay factor to determine the quality in the next time period.

$$
\begin{aligned}
I_{p, q, j, t}= & \sum_{p^{\prime} \in \mathcal{P}_{\text {crop }}} y c_{p, q, p^{\prime}, t} \times H_{p^{\prime}, j, t}+\sum_{q^{\prime} \in \mathcal{Q}} q d_{p, q^{\prime}, q} \times\left(I_{p, q^{\prime}, j, t-1}-\sum_{j^{\prime} \in \mathcal{L}_{p r o c}} X_{p, q^{\prime}, j, j^{\prime}, t-1}\right. \\
& \left.-W_{p, q^{\prime}, j, t-1}-Z_{p, q^{\prime}, j, t-1}\right) \quad \forall p \in \mathcal{P}_{\text {agro }}, q \in \mathcal{Q}, j \in \mathcal{L}_{\text {farm }}, t \in \mathcal{T}
\end{aligned}
$$

Similarly, Equation (4.5b) describes the available quantity of a product with a certain quality at a processing location in time. The inventory at the start of a period again is dependent on the stock carried over from the previous period, subject to a decay factor to determine the quality in the current period. The first two terms refer to the inventory of the previous period and the incoming quantity of products. The third and fourth term represent the quantity of products being consumed and produced through processing while the last three terms refer to the quantity of products being removed through transportation, waste and demand coverage.

$$
\begin{gathered}
I_{p, q, j, t}=\sum_{q^{\prime} \in \mathcal{Q}} q d_{p, q^{\prime}, q} \times\left(I_{p, q^{\prime}, j, t-1}+\sum_{j^{\prime} \in \mathcal{L}} X_{p, q^{\prime}, j^{\prime}, j, t-1}-\sum_{r \in \mathcal{R}} Q_{p, q^{\prime}, j, r, t-1}\right. \\
\left.+\sum_{r \in \mathcal{R}} O_{p, q^{\prime}, j, r, t-1}-\sum_{j^{\prime} \in \mathcal{L}} X_{p, q^{\prime}, j, j^{\prime}, t-1}-W_{p, q^{\prime}, j, t-1}-Z_{p, q^{\prime}, j, t-1}\right) \\
\forall p \in \mathcal{P}, j \in \mathcal{L}_{p r o c}, t \in \mathcal{T}, q \in \mathcal{Q}
\end{gathered}
$$

In both equations, a parameter $i_{p, q, j}^{0}$ can be added for $t=1$ to represent any starting inventory of product $p$ with quality $q$ at location $j$. In the case that perishability is modelled using the index $q$ as an age-counter, the decay parameter will take the value 1 if $q^{\prime}=q-1$ and 0 otherwise, which means the constraints of Equation (4.5a) and Equation (4.5b) can be reduced to direct shelf life constraints Equation (4.5c) and Equation (4.5b), respectively. For a more detailed description of direct shelf life constraints we refer to van Elzakker et al. (2014). 


$$
\begin{aligned}
& I_{p, q, j, t}= \sum_{p^{\prime} \in \mathcal{P}_{\text {crop }}} y c_{p, q, p^{\prime}, t} \times H_{p^{\prime}, j, t}+I_{p, q-1, j, t-1}-\sum_{j^{\prime} \in \mathcal{L}_{p r o c}} X_{p, q-1, j, j^{\prime}, t-1} \\
&-W_{p, q-1, j, t-1}-Z_{p, q-1, j, t-1} \quad \forall p \in \mathcal{P}_{\text {agro }}, q \in \mathcal{Q}, j \in \mathcal{L}_{f a r m}, t \in \mathcal{T} \\
& I_{p, q, j, t}= I_{p, q-1, j, t-1}+\sum_{j^{\prime} \in \mathcal{L}} X_{p, q-1, j^{\prime}, j, t-1}-\sum_{r \in \mathcal{R}} Q_{p, q-1, j, r, t-1} \\
&+\sum_{r \in \mathcal{R}} O_{p, q-1, j, r, t-1}-\sum_{j^{\prime} \in \mathcal{L}} X_{p, q-1, j, j^{\prime}, t-1}-W_{p, q-1, j, t-1}-Z_{p, q-1, j, t-1} \\
& \forall p \in \mathcal{P}, j \in \mathcal{L}_{\text {proc }}, t \in \mathcal{T}, q \in \mathcal{Q}
\end{aligned}
$$

The flow of products is limited to the available quantity in a time period by Equation (4.6). This formulation allows a flow of products between locations in the same echelon and locations in different echelons. The return flow of products in the model is therefore enabled in combination with the demand for these products as described by Equation (4.3).

$$
\sum_{j^{\prime} \in \mathcal{L}} X_{p, q, j, j^{\prime}, t} \leq I_{p, q, j, t}+\sum_{r \in \mathcal{R}} O_{p, q, j, r, t}-\sum_{r \in \mathcal{R}} Q_{p, q, j, r, t} \quad \forall p \in \mathcal{P}, j \in \mathcal{L}, t \in \mathcal{T}, q \in \mathcal{Q}
$$

Location, allocation and processing constraints

The location, allocation and processing constraints ensure that allocation of supply and demand and processing can only occur at active locations. Inventory is limited to the available inventory capacity by Equation (4.7). Similarly, the weighted sum of processed products is limited to the available processing capacity by Equation (4.8), and the opening of facilities at a single location is restricted by Equation (4.9). The quantity of processed products is limited by the available quantity of products from the inventory and transportation through Equation (4.10).

$$
\begin{array}{rlrl}
\sum_{q \in \mathcal{Q}} I_{p, q, j, t} & \leq \sum_{d \in \mathcal{D}} s c_{p, d} \times Y_{d, j} & & \forall p \in \mathcal{P}, j \in \mathcal{L}_{\text {proc }}, t \in \mathcal{T} \\
\sum_{p \in \mathcal{P}} \sum_{q \in \mathcal{Q}} p c l_{p, r} \times Q_{p, q, j, r, t} & \leq \sum_{d \in \mathcal{D}} p c_{d, r} \times Y_{d, j} & & \forall r \in \mathcal{R}, j \in \mathcal{L}_{\text {proc }}, t \in \mathcal{T} \\
\sum_{d \in \mathcal{D}} Y_{d, j} & \leq 1 & \forall j \in \mathcal{L}_{\text {proc }} \\
\sum_{r \in \mathcal{R}} Q_{p, q, j, r, t} & \leq I_{p, q, j, t}+\sum_{j^{\prime} \in \mathcal{L}} X_{p, q, j^{\prime}, j, t} & \forall p \in \mathcal{P}, q \in \mathcal{Q}, j \in \mathcal{L}_{\text {proc }}, t \in \mathcal{T}
\end{array}
$$


In addition, Equation (4.11) relates the required amount of process inputs to the produced outputs according to the bill of materials of the conversion reaction:

$$
O_{p^{\prime}, q^{\prime}, j, r, t}=\sum_{p \in \mathcal{P}} \sum_{q \in \mathcal{Q}} m b_{p, q, p^{\prime}, q^{\prime}, r} \times Q_{p, q, j, r, t} \quad \forall p^{\prime} \in \mathcal{P}, q^{\prime} \in \mathcal{Q}, j \in \mathcal{L}_{\text {proc }}, r \in \mathcal{R}, t \in \mathcal{T}
$$

Allocation of supply to the processing capacity is controlled by the combination of Equation (4.5b), Equation (4.6), Equation (4.8), and Equation (4.10). Allocation of the demand is accounted for by Equation (4.12).

$$
\sum_{q \in \mathcal{Q}} Z_{p, q, j, t} \leq \operatorname{dem}_{p, j, t} \quad \forall p \in \mathcal{P}, j \in \mathcal{L}, t \in \mathcal{T}
$$

This constraint works in conjunction with the inventory balance constraints Equation (4.5a) and Equation (4.5b). These ensure that demand can only be covered from inventory with acceptable quality levels, as products are counted as waste when the quality level becomes unacceptable. Note that the demand constraint can be substituted with, or extended by, similar formulations indicating a lower bound to demand coverage. Additional case specific constraints for processing can be added, for instance, to limit the number of facilities to be opened, or to represent any existing infrastructure.

\section{Quality and perishability constraints}

Quality decay of inventories and through processing is accounted for by Equation (4.5a), Equation (4.5b), and Equation (4.11), respectively. When products reach a quality level below their quality limit, or are not used before their maximum age is reached, the products are considered as waste. This is described by Equation (4.13) for a lower quality limit. If quality is modelled as age, the quality limit turns into an upper bound instead.

$$
\begin{aligned}
W_{p, q, j, t}= & I_{p, q, j, t}+\sum_{j^{\prime} \in \mathcal{L}} X_{p, q, j^{\prime}, j, t}-\sum_{j^{\prime} \in \mathcal{L}} X_{p, q, j, j^{\prime}, t}+\sum_{r \in \mathcal{R}} O_{p, q, j, r, t}-\sum_{r \in R} Q_{p, q, j, r, t} \\
& \forall p \in \mathcal{P}, j \in \mathcal{L}, t \in \mathcal{T}, q \in \mathcal{Q} \mid q \leq q_{p}^{l i m}
\end{aligned}
$$


Alternatively, an implicit description of waste is obtained from the inventory balance Equations (4.5a) and (4.5b) and the restriction that the inventory equals zero for all products $p \in \mathcal{P}$ for values of $q \in \mathcal{Q}$ below the cutoff value $q_{p}^{l i m}$.

\section{Objective functions}

Two objective functions are considered. The TGM represents the economic objective to be maximised and the GWP as environmental objective to be minimised.

$$
\begin{aligned}
T G M= & \sum_{p \in \mathcal{P}} \sum_{q \in \mathcal{Q}} \sum_{j \in \mathcal{L}} \sum_{t \in \mathcal{T}} p p_{p} \times Z_{p, q, j, t}-\sum_{p \in \mathcal{P}} \sum_{q \in \mathcal{Q}} \sum_{j \in \mathcal{L}} \sum_{j^{\prime} \in \mathcal{L}} \sum_{t \in \mathcal{T}} c t_{p, j, j^{\prime}} \times X_{p, q, j, j^{\prime}, t} \\
& -\sum_{p \in \mathcal{P}} \sum_{q \in \mathcal{Q}} \sum_{j \in \mathcal{L}} \sum_{t \in \mathcal{T}} c h_{p} \times I_{p, q, j, t}-\sum_{p \in \mathcal{P}} \sum_{q \in \mathcal{Q}} \sum_{j \in \mathcal{L}} \sum_{t \in \mathcal{T}} c d_{p} \times W_{p, q, j, t} \\
& -\sum_{p \in \mathcal{P}} \sum_{q \in \mathcal{Q}} \sum_{j \in \mathcal{L}} \sum_{r \in \mathcal{R}} \sum_{t \in \mathcal{T}} c p_{p, r} \times Q_{p, q, j, r, t}-\sum_{d \in \mathcal{D}} \sum_{j \in \mathcal{L}} c f_{d, j} \times Y_{d, j} \\
G W P= & \sum_{p \in \mathcal{P}} \sum_{j \in \mathcal{L}} e a_{p} \times A_{p, j}+\sum_{p \in \mathcal{P}} \sum_{q \in \mathcal{Q}} \sum_{j \in \mathcal{L}} \sum_{j^{\prime} \in \mathcal{L}} \sum_{t \in \mathcal{T}} e t_{p, j, j^{\prime}} \times X_{p, q, j, j^{\prime}, t} \\
& +\sum_{p \in \mathcal{P}} \sum_{q \in \mathcal{Q}} \sum_{j \in \mathcal{L}} \sum_{t \in \mathcal{T}} e d_{p} \times W_{p, q, j, t}+\sum_{p \in \mathcal{P}} \sum_{q \in \mathcal{Q}} \sum_{j \in \mathcal{L}} \sum_{r \in \mathcal{R}} \sum_{t \in \mathcal{T}} e p_{p, r} \times Q_{p, q, j, r, t}
\end{aligned}
$$

Equation (4.14) describes the TGM, and consists of the difference between the value of all products sold and the costs for transportation, inventory holding, waste disposal, processing, and facility depreciation costs. In this formulation, the transportation mode for a product between two locations is considered as a given, hence the transportation cost is dependent on the product, and not explicitly on the transportation mode. The cost parameter for processing includes the cost of sourcing all process inputs and operational costs from energy and labour.

Similarly, Equation (4.15) describes the GWP of the modelled system and includes the $\mathrm{CO}_{2}$-eq related to agricultural production, transportation, waste disposal and processing, respectively. Because the transportation mode for a product between two locations is fixed in this formulation, the emissions related to transportation are dependent on the product and not explicitly on the transportation mode. To include modality into the decision variables, an extra index can be added to the flow of goods, and the parameters for transportation cost and transportation emissions should be defined related to this index instead of the product index. 


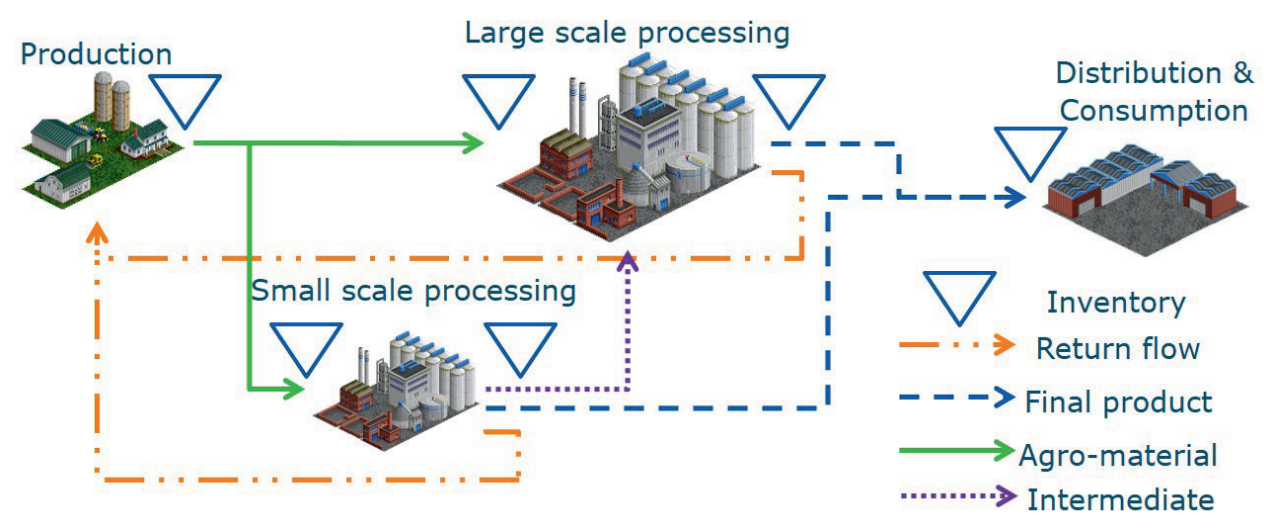

Figure 4.3: Stages and types of flows of goods considered in the case implementation

\subsection{Case study description}

The general model as presented in Section 4.3.3 is applied to the sugar beet processing chain in The Netherlands, building on the work of Kolfschoten et al. (2014) and Jonkman et al. (2017). This processing chain is experiencing major changes in the supply of sugar beet and the markets for their final products due to changing legislation of the European Union (Suiker Unie, 2011; EU, 2013). Similar changes in the dairy sector led to substantial changes in that sector, hence there is an urgency to evaluate the current SC configuration in the sugar beet sector, and investigate re-design options. An increase of sugar beet supply of $20 \%$ is foreseen, due to growing markets and new uses for sugar beet derived products.

This case study can show the applicability of the model for real life applications, as it integrates harvest and processing decisions in an AFSC design problem with seasonable and perishable products, forward and return flows, capacity limitations, and allows for product flows within the processing echelon (Figure 4.3).

Every production location has the following decisions:

i How much land to allocate to produce a crop, given the available land;

ii In which period to harvest the crop, given the maturation of the crop;

The sugar beet campaign typically lasts for about three to four months, and campaign duration and harvest yield depend on uncertain weather conditions. Decision (i) affects the demand of a farm for the return flows of tare soil and lime fertiliser from the processing echelon. Additionally, decision (ii) determines the quantity of crops that is available for 
transport at a certain time.

Processing locations can receive agro-materials from production locations, and intermediate products from other processing locations. These inputs can be converted into outputs such as intermediate products, return products, and final products. Decisions modelled are:

iii The facility design type opened and process pathway operated at the location;

iv The amount of inputs and outputs to receive and dispatch every period.

The quantity of inputs that can be processed into outputs depends on decision (iii), and in turn affects the quantity of products that can be dispatched (iv). The flow of products to downstream distribution and consumption, and the flow of return products back to production locations is limited by the respective demand for these products.

The product and location categories shown in Table 4.1 are used in the model, with an additional category for products that have a backward flow in the SC as they are returned from the processing echelon to the farms, according to the description provided above. Values for the location related parameters are presented in Table 4.2.

The products considered in the case, and their membership of different subsets are presented in Table 4.3 for clarification. Additionally, values of product related parameters are presented in Table 4.4. The process designs considered in (iii) are the conventional design used in the existing facilities, and a smaller scale biorefinery design as proposed by Kolfschoten et al. (2014). The conventional design is focused on processing sugar beet into white sugar, with lime fertiliser, beet pulp, molasses and tare soil as additional products. The small scale design is processing sugar beet and beet leaves into raw sugar, ethanol, biogas and tare. The raw sugar can be sold on the market as a final product, but can also be refined by conventional facilities into white sugar.

Parameter values related to the processing are presented in Table 4.5. The required procurement and shipping of other processing inputs is indirectly accounted for in the processing cost, as is the cost of purchasing the sugar beet from the farmers. Emissions related to the processing are calculated based upon the energy consumption of a conversion. The biogas produced by the biorefinery prevents emissions from other energy sources by the customers. These prevented emissions are subtracted from the emissions related to the conversion reaction in the biorefinery, leading to a negative emission value. 
Table 4.2: Location related parameter values

\begin{tabular}{lcl}
\hline Description & Value & Based on \\
\hline $\begin{array}{c}\text { Transport } \\
c t\end{array}$ & $*$ & \\
$e t$ & $82.5 \mathrm{~g} \mathrm{CO}_{2}$-eq $/$ ton $/ \mathrm{km}$ & Konkman et al. (2017) \\
Supply and demand & & \\
al and $b q$ & $*$ & CBS (2016) \\
$y c$ for sugar beet & 80 ton $/$ ha & Kolfschoten et al. (2014) \\
ea for sugar beet & 2.69 ton $\mathrm{CO}_{2}$-eq/ha & Klenk et al. (2012a) \\
dem & $*$ & Jonkman et al. (2017) \\
\hline
\end{tabular}

* Not included for brevity, available upon request.

Table 4.3: Products and membership of subsets

\begin{tabular}{ll}
\hline $\mathcal{P}_{i}$ & Members \\
\hline crop & beetroot \\
agro & sugar beet, beet leaves \\
in & sugar beet, beet leaves, raw sugar \\
out & sugar, raw sugar, ethanol, biogas, lime fertiliser, molasses, beet pulp, tare soil \\
return & molasses, beet pulp, lime fertiliser, tare soil \\
final & sugar, raw sugar, ethanol, biogas \\
\hline
\end{tabular}

Table 4.4: Product related parameter values, based on a) Jonkman et al. (2017); b) Kolfschoten et al. (2014); c) assumption

\begin{tabular}{|c|c|c|c|c|}
\hline Product & $\begin{array}{c}p p^{a} \\
(€ / \text { ton })\end{array}$ & $\begin{array}{c}m b \\
\text { Traditional }^{b}\end{array}$ & $\begin{array}{c}m b \\
\text { Biorefinery }^{b}\end{array}$ & $\begin{array}{c}m b \\
\text { Raw sugar } \\
\text { refining }\end{array}$ \\
\hline sugar beet & . & 1 & 1 & . \\
\hline beet leaves & . & . & 0.5 & . \\
\hline white sugar & 500 & 0.14625 & . & 0.9 \\
\hline raw sugar & 450 & . & 0.125 & 1 \\
\hline ethanol & 400 & . & 0.01875 & . \\
\hline biogas & 90 & . & 0.1575 & . \\
\hline molasses & 150 & 0.03375 & . & 0.1 \\
\hline beet pulp & 45 & 0.1 & . & . \\
\hline lime & 6 & 0.0275 & . & . \\
\hline tare & 10 & 0.125 & 0.125 & . \\
\hline
\end{tabular}


Table 4.5: Process related parameter values, based on a) Kolfschoten et al. (2014); b) Jonkman et al. (2017); c) assumption; d) calculated based on Asadi (2006); Klenk et al. (2012a)

\begin{tabular}{|c|c|c|c|c|c|c|c|c|}
\hline \multirow[t]{2}{*}{ Facility design ${ }^{a}$} & \multirow{2}{*}{$\begin{array}{c}\text { Daily } \\
\text { capacity } \\
\text { (kton) }\end{array}$} & \multirow{2}{*}{$\begin{array}{l}\begin{array}{c}\text { Annual } \\
\text { fixed cost } \\
(\mathrm{M} €)\end{array} \\
8.33\end{array}$} & \multicolumn{3}{|c|}{$\begin{array}{c}c p \\
\text { Trad. }^{b} \text { Bioref. }{ }^{b} \text { Refin. } .^{c} \\
(€ / \text { ton })\end{array}$} & \multicolumn{3}{|c|}{$\begin{array}{c}\text { ep } \\
\text { Trad. }{ }^{d} \text { Bioref. }{ }^{d} \text { Refin. }{ }^{d}{ }^{d} \\
\left(\mathrm{~kg} \mathrm{CO}_{2} \text {-eq/ton }\right)\end{array}$} \\
\hline & & & 62.3 & . & 12.9 & & & \\
\hline \multirow[t]{3}{*}{ Conventional } & 15 & 5 & 63.36 & . & . & 60.27 & . & 29 \\
\hline & 10 & 3.67 & 65.49 & . & . & & & \\
\hline & 15 & 5 & & 63.36 & . & & & \\
\hline \multirow[t]{2}{*}{ Biorefinery } & 10 & 3.67 & & 65.49 & . & . & -92.4 & \\
\hline & 6 & 2.67 & & 69.53 & . & & & \\
\hline
\end{tabular}

\subsection{Case results and discussion}

To validate the model, the base result of Jonkman et al. (2017) was reproduced. The cost and revenue metrics calculated based on the results were validated using Rosenboom et al. (2013). The calculated carbon footprint of $731 \mathrm{~kg} \mathrm{CO}_{2}$-eq per ton sugar was within the range of $242-748 \mathrm{~kg} \mathrm{CO}$-eq reported as average for the EU by Klenk et al. (2012a).

After validation of the model, constraint Equation (4.4) was relaxed to represent the disappearing legislative restriction on beet production (EU, 2013), allowing for an increase in beet cultivation to accommodate for the expected growth of $20 \%$. The optimal supply chain configuration was determined without taking the seasonal supply and perishability of the sugar beet into account. Subsequently the presented model was used to determine the optimal supply chain configuration while including harvesting decisions, seasonal supply and the perishability of sugar beet. Twelve time intervals were taken for a year, while harvesting is possible in three of these intervals, each with its expected harvest yield. Sugar beet leaves are only available during the time interval of harvesting due to their perishability, while the age limit of sugar beet was put at the time interval after harvesting.

The sensitivity of the model result was investigated for demand, harvest yield, transport cost, and data aggregation of supply and demand at municipality level or at regional level. The model was solved using different instances of these parameters, and using the two objectives. The optimal configuration did not change upon changes in transportation cost in the tested range of $\pm 10 \%$. Similarly, aggregating the supply and demand related parameters at regional level $\left(\mathcal{L}_{\text {farm }}, \mathcal{L}_{\text {market }}=\{1, \ldots, 66\}\right)$ did not lead to a different 
optimal SC configuration compared to the initial aggregation scale at the municipality level $\left(\mathcal{L}_{\text {farm }}, \mathcal{L}_{\text {market }}=\{1, \ldots, 403\}\right)$. Changes of the demand parameter in the interval $-10 \%$ to $+20 \%$ did affect the optimal combination of facility designs, their capacities, the location, and the allocation of supply. The obtained optimal SC configurations are discussed in more detail in the following sections.

The optimal SC configuration determined without taking seasonality into account and the configuration determined with the proposed model are the same in those cases in which the TGM is optimised and the harvest yield does not vary much during the harvesting season. Similarly, once perishability is less restrictive the two approaches yield the same result. SC configurations with additional processing capacity are obtained with the proposed model in those cases where crops have a clear peak in the harvest yield, and in those cases where availability of crops is more restricted than assumed in the case where harvesting decisions were not explicitly taken into account.

\subsubsection{Trade-off between objectives}

The trade-off between the economic and environmental objective was investigated using the $\epsilon$-constraint method (see for instance Mavrotas, 2009). The TGM was optimised while using $\epsilon$-constraints on the environmental objective represented by the GWP. The obtained trade-off curve is shown in Figure 4.4, relative to the performance of the currently existing SC configuration. Figure 4.4 shows that under the new legislative paradigm, opportunities exist to improve on both objectives. Each segment of the Pareto-efficient frontier corresponds to a SC configuration. The facilities opened in these configurations in addition to the existing facilities are described by indicating their location number (1-14); a design type identifier for conventional (C) or biorefinery (B); and the daily processing capacity in kton. The performance metrics of these configurations at the transition points on the frontier are presented in Table 4.6. Each optimal SC configuration corresponds to a specific integer solution of the model. The transitions from one configuration to another therefore lead to a non-convex trade-off curve.

Although the locations selected to open new facilities are similar throughout these configurations, there are differences between the type of facilities selected, and in some cases between the capacities. All solutions reduce the GWP by reducing average transportation distances. Additionally, using facilities with the biorefinery design improves on the environmental objective due to its negative contribution through the production of biogas. Part of the raw sugar produced by the biorefineries is refined into white sugar in those cases where the additional transportation and processing cost is offset by the benefit from the added economic value of refining the raw sugar. 


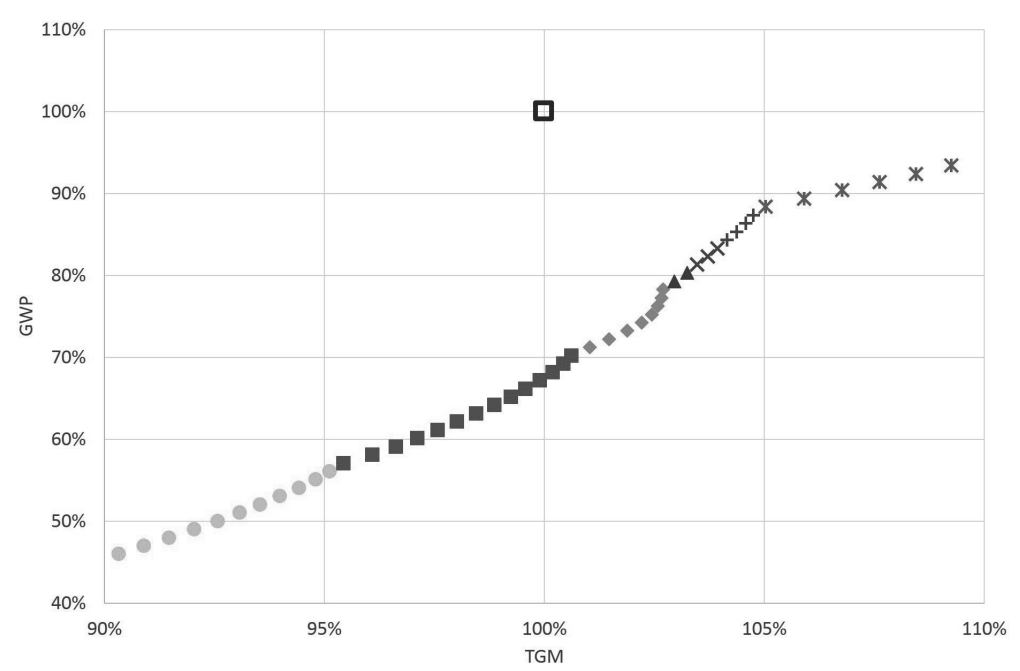

Figure 4.4: Trade-off curve between the economic and environmental objective. Segments of the frontier correspond to different supply chain configurations. Additional facilities per segment are detailed using their location number, a design type identifier for conventional (C) or biorefinery (B), and the daily processing capacity in kton. $\square$ existing infrastructure;

1B15,8B15; 8B15; $1 \mathrm{C} 15,8 \mathrm{~B} 15 ; \boldsymbol{\Delta} 3 \mathrm{~B} 15,8 \mathrm{C} 15 ; \times 1 \mathrm{~B} 15,8 \mathrm{C} 15 ;+1 \mathrm{~B} 10,8 \mathrm{C} 15 ;$ 米 $8 \mathrm{C} 15$

The reduction of the GWP by using a biorefinery design is most clearly seen when comparing the configurations in which only a single additional facility is opened, either of the biorefinery design (8B15) or of the conventional design (8C15). The total GWP calculated for these $\mathrm{SC}$ configurations is respectively $494 \mathrm{~kg} \mathrm{CO}_{2}$-eq and $686 \mathrm{~kg} \mathrm{CO}_{2}$-eq per ton sugar, even though the average transportation distances for the configuration with the biorefinery design are longer $(35.8 \mathrm{~km}$ for agro-materials and $48.3 \mathrm{~km}$ for products versus $34.5 \mathrm{~km}$ and $48.2 \mathrm{~km}$ ). This indicates that producing by-products with a negative associated footprint has a bigger impact on the GWP of the case study than reducing the average distances. The total product portfolio of the biorefinery design has a lower value, however, leading to the trade-off between the GWP and the TGM.

The trade-off curve shows that only a limited number of facility locations are part of the optimal SC configurations. The sensitivity analysis showed, however, that the optimal $\mathrm{SC}$ configuration was affected by the values of the uncertain parameters for demand and harvest yield. Hence, a solution has to be found that performs well given the uncertain parameter values affecting the optimal SC configuration. 
Table 4.6: Deterministic performance metrics of the SC configurations at the transition points on the Pareto-efficient frontier, additional facilities are presented using their location number, design type conventional (C) or biorefinery (B), and the daily processing capacity in kton

\begin{tabular}{|c|c|c|c|c|c|c|}
\hline Configuration & $\begin{array}{l}\text { TGM } \\
(\mathrm{M} €)\end{array}$ & $\begin{array}{c}\text { GWP (kg } \\
\mathrm{CO}_{2} \text {-eq } \\
\text { per ton } \\
\text { sugar) }\end{array}$ & $\begin{array}{c}\text { Average } \\
\text { trans- } \\
\text { portation } \\
\text { distance } \\
\text { agro- } \\
\text { materials } \\
(\mathrm{km})\end{array}$ & $\begin{array}{l}\text { Average } \\
\text { trans- } \\
\text { portation } \\
\text { distance } \\
\text { products } \\
\quad(\mathrm{km})\end{array}$ & $\begin{array}{c}\text { Sugar } \\
\text { beet } \\
\text { processed } \\
\text { (Mton) }\end{array}$ & $\begin{array}{c}\text { Demand } \\
\text { for sugar } \\
\text { covered } \\
(\%)\end{array}$ \\
\hline 1B15,8B15 & 54.7 & 394 & 31.0 & 42.0 & 6.27 & 100 \\
\hline $8 \mathrm{~B} 15$ & 57.9 & 494 & 35.8 & 48.3 & 6.18 & 100 \\
\hline 1C15,8B15 & 59.1 & 551 & 31.0 & 43.2 & 6.13 & 100 \\
\hline $3 \mathrm{~B} 15,8 \mathrm{C} 15$ & 59.4 & 565 & 30.3 & 44.9 & 6.19 & 100 \\
\hline 1B15,8C15 & 59.8 & 586 & 31.8 & 42.5 & 6.10 & 100 \\
\hline 1B10,8C15 & 60.3 & 615 & 32.0 & 44.1 & 6.08 & 100 \\
\hline $8 \mathrm{C} 15$ & 64.3 & 686 & 34.5 & 48.2 & 6.01 & 100 \\
\hline
\end{tabular}

\subsubsection{Demand and harvest yield uncertainty}

Given the uncertainties related to harvest yield (due to e.g. uncertain weather conditions) and uncertainties in the expected growth of the demand for products, a stochastic version of the model was used to include these uncertainties in the determination of the optimal SC configuration. Scenarios were developed relating to a demand according to the currently expected growth $(+20 \%)$, no growth in demand, and a small reduction in demand for the products produced $(-10 \%)$, with expected probabilities of $0.4,0.45$, and 0.15 , respectively. Similarly, scenarios were developed representing harvest yields above expectations, according to current expectations, and below expectation, with probabilities of $0.15,0.60$, and 0.25 , respectively. In total, this led to 9 scenarios tested with the stochastic version of the model. An index $s$ was defined to represent the different scenarios, and was added to the variables $H, I, O, Q, W, X, Z$, and parameters dem, and $y c$. An additional parameter $p r_{s}$ was defined to represent the probability of each scenario, and used to formulate the objective function maximising the expected TGM over all scenarios according to :

$$
\max \sum_{s \in \mathcal{S}} p r_{s} \times T G M_{s}
$$


Table 4.7: Weighted sum over all scenarios of the performance metrics of the optimal SC configuration obtained with the deterministic and the stochastic version of the model. Additional facilities are presented using their location number, design type conventional (C) or biorefinery (B), and the daily processing capacity in kton

\begin{tabular}{|c|c|c|}
\hline & Deterministic & Stochastic \\
\hline Additional facilities & $8 \mathrm{C} 15$ & $1 \mathrm{C} 15,8 \mathrm{C} 15$ \\
\hline Expected TGM (M€) & 65.7 & 66.5 \\
\hline Expected GWP (kg CO $2^{-}$eq/ton sugar) & 712 & 704 \\
\hline Average transp. distance agro-materials (km) & 37.3 & 32.6 \\
\hline Average transp. distance products $(\mathrm{km})$ & 49.2 & 43.0 \\
\hline Transp. cost agro-materials ( $€ /$ ton agro-material) & 3.73 & 3.26 \\
\hline Transp. cost products (€/ton agro-material) & 2.13 & 1.86 \\
\hline Acreage of beetroot (kha) & 90 & 90 \\
\hline Sugar beet processed (Mton) & 6.26 & 6.37 \\
\hline Expected demand for sugar covered (\%) & 98.0 & 99.5 \\
\hline
\end{tabular}

In which the probability of a scenario is used as a weight to the performance of that scenario. The weighted performance over all scenarios of this configuration is presented in Table 4.7. For comparison, the performance of the SC configuration obtained with the deterministic approach was calculated for all scenarios used in the stochastic model, and the weighted performance is presented alongside the stochastic results.

Taking into account the uncertainties related to demand and harvest yield leads to an optimal SC configuration with more additional processing capacity than was the case for the deterministic version. The expected performance on both objectives of this configuration for the tested scenarios is better than the performance of the deterministic configuration. Additional capacity gives flexibility to deal with increased product demand, with high harvest yields, and with peaks in harvest yields. However, the stochastic configuration leads to lower performance in scenarios where the demand is lower than currently the case, due to the depreciation on facilities regardless of whether the capacity is used. Since the economic objective was maximised, no facilities with the biorefinery design were selected, although these are expected to appear in cases where a balance is sought between the economic and the environmental objective. 


\subsection{General discussion and conclusions}

Not much work exists which presents SC design models tailored to applications in the context of AFSCs. There is a gap integrating harvesting decisions with SC design, taking into account the specific characteristics and uncertainties of the AFSC. Integrating these decisions into strategic AFSC design leads to the identification of SC configuration that are more tailored to the seasonal characteristics of the AFSC. The general problem description and model formulation presented in this work can support decision makers in agro-food industry to identify interesting opportunities for AFSC design and re-design while the stochastic version supports finding solutions that are capable to perform well given the uncertainties related to the AFSC.

Applicability of the model formulation was shown using the case study of the sugar beet processing chain in The Netherlands. The case study results show that opportunities exist for SC improvement using more decentralised processing, indicating that decentralised processing or decentral pre-processing are potentially interesting SC configurations in the context of agro-food industry. Additionally, the limited sensitivity of the optimal SC configuration to spatial data aggregation at municipality level or regional level is interesting for further analysis. Although less aggregation leads to more detailed results, the positive effect of aggregation on model run-time and the effort of dealing with the detailed data can justify using aggregated data for strategic SC design studies in agro-food industry.

Explicitly including harvesting decisions into the SC design is mainly important for those AFSCs in which the expected harvest yield shows large differences between time intervals. The importance increases further when these yields are subject to uncertainties due to, for instance, weather conditions. In AFSCs in which the expected harvest yield is certain and does not vary much between time intervals, a more indirect approach suffices by indirectly taking seasonality into account in parameter values, rather than explicitly modelling harvesting decisions.

The presented model, with its stochastic alternative, allows for SC optimisation of a variety of AFSCs. It accommodates for forward and reverse flows of seasonal and perishable goods between and within SC echelons. Perishability can be incorporated in the form of discrete quality categories or in the form of shelf life limitations. In the case of AFSCs dealing with highly perishable goods, more detailed time intervals may be necessary than were used in the current case. Alternatively, different uncertainties can play a role, increasing the importance of the stochastic version of the presented model. This could lead to issues regarding model size and run-time. Hence, the monolithic approach used in this work could be extended using other modelling and solution techniques to deal with case 
studies of larger sizes. Additionally, methods to facilitate the implementation and use of these techniques within agro-food industry deserve attention. 



\section{Chapter 5}

\section{Network level}

\section{Designing a biobased supply chain using a multi-actor optimisation model}

- We design eco-efficient biomass supply chains using multi-actor optimisation models

- Competing crops, production dependent prices, and regional features are considered

- We use the sugar beet processing chain in The Netherlands as an example

- Fair distribution of benefits is needed to make optimal designs attractive

- Locating bio-refineries in regions with the most productive soils results in ecoefficient chain designs

This chapter is based on:

Jonkman, J., Kanellopoulos, A., Bloemhof, J. M. (submitted). Designing an ecoefficient biomass-based supply chain using a multi-actor optimisation model. 


\section{Abstract}

Sustainability concerns emphasise the importance of identifying eco-efficient supply chain configurations which balance economic and environmental chain objectives. The applied modelling approaches for this purpose often assume the availability of raw materials and full coordination within the supply chain studied. Some or all actors in the chain can, however, pursue individual objectives, making the obtained solutions unfeasible in practice. Economic incentives support aligning the objectives of the different supply chain actors. This chapter explores the design of eco-efficient biomass supply chains and economic gain allocation between the supply chain partners. A case study is developed for the sugar beet processing chain in The Netherlands, in which farmers can also choose to produce other competing crops. We observe that higher yields often lead to lower carbon emissions per ton of produce. Hence, eco-efficient solutions are found to have production and processing locations in the most productive regions. Additionally, margin sharing above the minimum sugar beet price is necessary to ensure the production of the desired quantity of sugar beet. Realistic sugar beet prices are determined using a Shapley-value approach, leading to a fair distribution of margin among the farmers and processor in the supply chain. 


\subsection{Introduction}

Over the past two decades, societal concerns and technological innovations triggered research into the topic of biobased supply chains and biorefining (Lynd et al., 1999; Langeveld, 2010). In a biobased Supply Chain (SC), biomass is converted through biorefining into a range of valuable products, such as fuels, functional components and platform chemicals (Langeveld, 2010). Biobased chemical products are positioned as a more sustainable alternative to oil-derived products. Additionally, biomass is seen as a renewable energy source to replace fossil fuels (Andiappan et al., 2015; Kokossis et al., 2015). To promote the use of biomass for the production of such products, both the economic and environmental benefits of alternative logistic structures of the biobased SC must be evaluated. This supports identifying eco-efficient solutions which balance the economic and environmental performance.

To evaluate such alternative biorefining technologies quantitatively, decision support tools have been developed in the body of literature discussing strategic biobased SC design, covering decisions such as facility location, technology selection and sourcing (Sharma et al., 2013). Methods applied for the network design problem include multicriteria decision analysis, heuristics and mathematical programming. The vast majority of literature in this field uses mathematical programming, and more specifically Mixed Integer Linear Programming (MILP) models with a single objective function (De Meyer et al., 2014; Ba et al., 2016). This is similar to the literature in the related field of agricultural and food SC design (Lucas \& Chhajed, 2004; Soysal et al., 2012).

The main objective of current decision support tools is to optimise the total economic benefits of the whole chain (Yue et al., 2014; Sahay \& Ierapetritou, 2016). The objectives of individual chain actors (e.g. suppliers, processor) are generally not taken into account (Yue \& You, 2014a). This implies that there is full coordination in the chain (Kusumastuti et al., 2016), and the solutions of such decision support tools might conflict with the objectives of individual actors in the chain. As a consequence, these solutions can be difficult to implement.

Moreover, decision support tools for biobased SCs assume implicitly that the availability of biomass is exogenous and they do not account for competition between different types of biomass for the same agricultural land. Mostly, authors deal with the competition over the same biomass for different applications (e.g. food or non-food purposes, Bai et al., 2012; Giarola et al., 2011), or consider land-use activities which all produce biomass that can be processed by the processor (e.g. Correll et al., 2014). However, in practice the biomass suppliers (such as farmers) can decide to switch to other production activities. The optimal allocation of land to crops according to a farmer can therefore compete 
with the optimal allocation of land according to the biorefinery processor. Moreover, the farmers are often small scale suppliers which can switch between different production activities. Therefore, the benefits of a biobased SC have to be distributed fairly among the SC actors, providing (in most cases economic) incentives for suppliers of biomass to execute the desired production practices.

An approach commonly used to fairly allocate benefits to different SC actors is the Shapley-value approach, rooting from collaborative GT (Naber et al., 2015). This approach allocates to each SC actor the average of the actor's marginal contribution to the SC for the different combinations of collaborating SC actors. The approach has been used for cost allocation in biomass transportation (Frisk et al., 2010), and has several attractive properties relevant for a biobased SC design problem: All benefits are distributed (efficiency) in such a way that actors with equal marginal contributions are allocated an equal amount (symmetry), and actors with zero marginal contribution are allocated nothing (zero player) (Shapley, 1953). The approach can be used in combination with a biobased SC design model to determine the distribution of costs and benefits in a SC configuration between the participating actors (i.e. the farmers and processor).

This chapter therefore proposes to use a Shapley-value approach for the design of ecoefficient biomass SCs, taking into account the individual goals and strategic decision making of the different actors involved. An MILP model is developed for a representative biomass SC, involving suppliers with alternative production activities, multiple processing technologies, and multiple final products. The case study and the formulation of the model are described in Section 5.2 and Section 5.3. The model is used to explore the trade-off between the economic and environmental objective within the SC. The Shapleyvalue approach from collaborative GT is applied to allocate the generated benefits among the chain actors. The obtained results are provided and discussed in Section 5.4, and conclusions are drawn in Section 5.5.

\subsection{Case description}

Sugar beet is one of the major arable crops grown in The Netherlands in terms of production area and quantity. European legislation previously ensured farmers a minimum price per ton of beet delivered, but regulated sugar production through a quota system, limiting the production of sugar and beets. Changing legislation in the European Union (EU), however, removed the quota system and will affect the sugar beet processing industry (EU, 2013; Suiker Unie, 2011). An increase in the production of sugar beets and beet derived products of $20 \%$ is expected due to growing markets and new uses for these products. Additionally, new technologies are developed which enable alternative SC con- 
figurations, and the production of a different product portfolio (Kolfschoten et al., 2014). The case study investigates the re-design of the Dutch sugar beet processing chain, to identify eco-efficient SC configurations taking into account the expected growth and the individual actors within the chain. Farmers and processor are separate actors in the chain and their decisions making is described in the following sections.

\subsubsection{Farmers}

Farmers choose how to allocate their land to a number of available crops. We assume their objective is to maximise the total economic margin of the farm. Each farm has access to a set of land-use activities for the production and management of different crops, and the margin generated equals the revenue gained from selling the harvest minus the production costs. The yields of crops and costs of production depend on regional characteristics such as soil type (see Figure 5.1). Additionally, the market price of a crop depends on the supply, and farmers cannot freely choose how to allocate their land. Legal and practical restrictions apply for the production of crops, limiting, for instance, the number of consecutive years a crop can be grown at the same location and enforcing crop rotation Mandryk et al. (2014). Additionally, governmental subsidies can exist to promote specific land-use activities or the production of crops. These aspects have to be taken into account.

\subsubsection{Processor}

We assume the processor tries to maximise its generated margin by optimising the SC configuration through locating facilities, selecting the technologies to use for processing, and allocating available supply to these facilities to cover demand. The processor has two existing sugar beet processing facilities (Figure 5.2). The sugar beet processing chain in the Netherlands has focused on utilising economies of scale, leading to a SC configuration centred around processing efficiency. Conventionally the main product produced was white sugar, although a diversification has happened by valorising by-product streams. Recently, small scale biorefining technologies have been developed (Kolfschoten et al., 2014). This technology offers possibilities to open smaller facilities and reduce the total transportation (and consequently $\mathrm{CO}_{2}$ emissions). Additionally, it has a flexible product portfolio in which the production of raw sugar or ethanol can be adjusted according to the need. Because farming extracts nutrients from the soil, by-products from processing sugar beet are returned from the processor to the beet farms (see Kolfschoten et al., 2014). The processor has to determine a base price per ton of beet which provides enough incentive for farmers to participate in the SC and produce the desired quantity of sugar beet. 


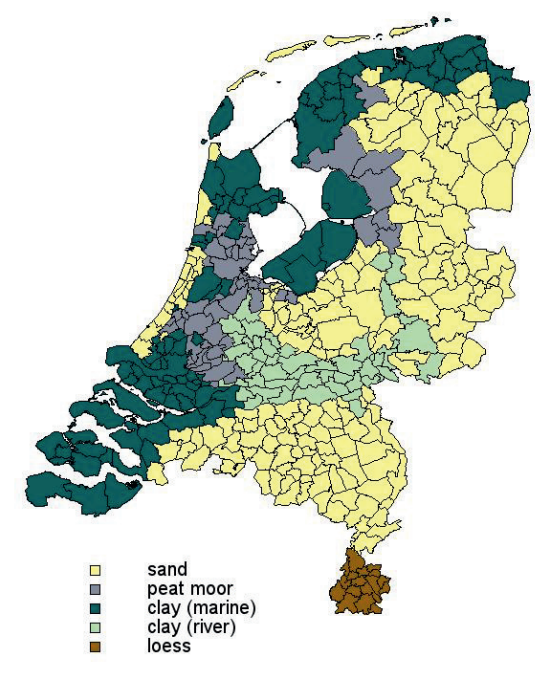

Figure 5.1: Generalised dominant soil types in The Netherlands, based on Wageningen Environmental Research (2006) and Rijksinstituut voor Volksgezondheid en Milieu (2017)

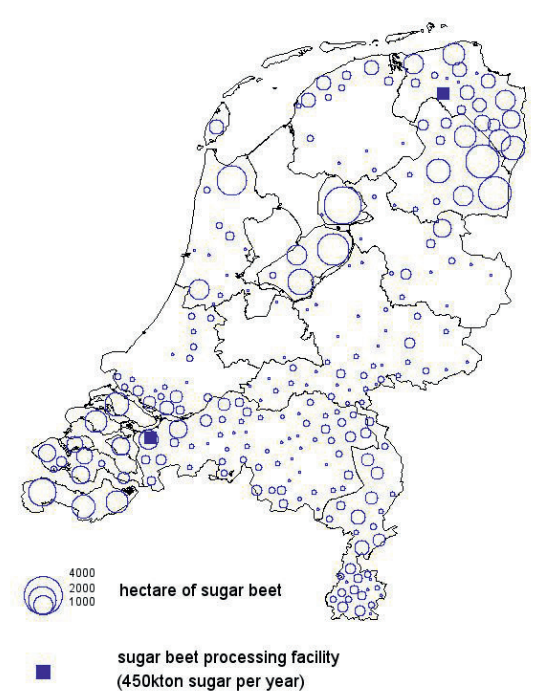

Figure 5.2: Sugar beet supply and existing processing facilities in The Netherlands, based on CBS (2016) and Suiker Unie (2010)

\subsubsection{Supply chain coordination}

The sugar beet processing chain mainly operates business-to-business, and besides economic objectives, the actors have a shared objective to minimise the carbon footprint of the sugar beet processing chain. The carbon footprint is affected by sourcing decisions, facility location and transportation decisions, and technology selection. The new biorefinery process produces biogas, which can replace the use of fossil fuels and leads to a negative carbon emission for the biorefinery process. Hence, we explore the trade-off resulting from these decisions on the economic objectives of the SC actors and the shared environmental objective. Alternative to the base beet price, a fair price is determined to allocate the total margin generated in the chain according to each actor's contribution.

An SC optimisation model is formulated in Section 5.3, and the data used for the case study is presented. The different model components and their interaction are represented in Figure 5.3. It is assumed that decisions in the chain are optimised with complete information availability to all actors. 


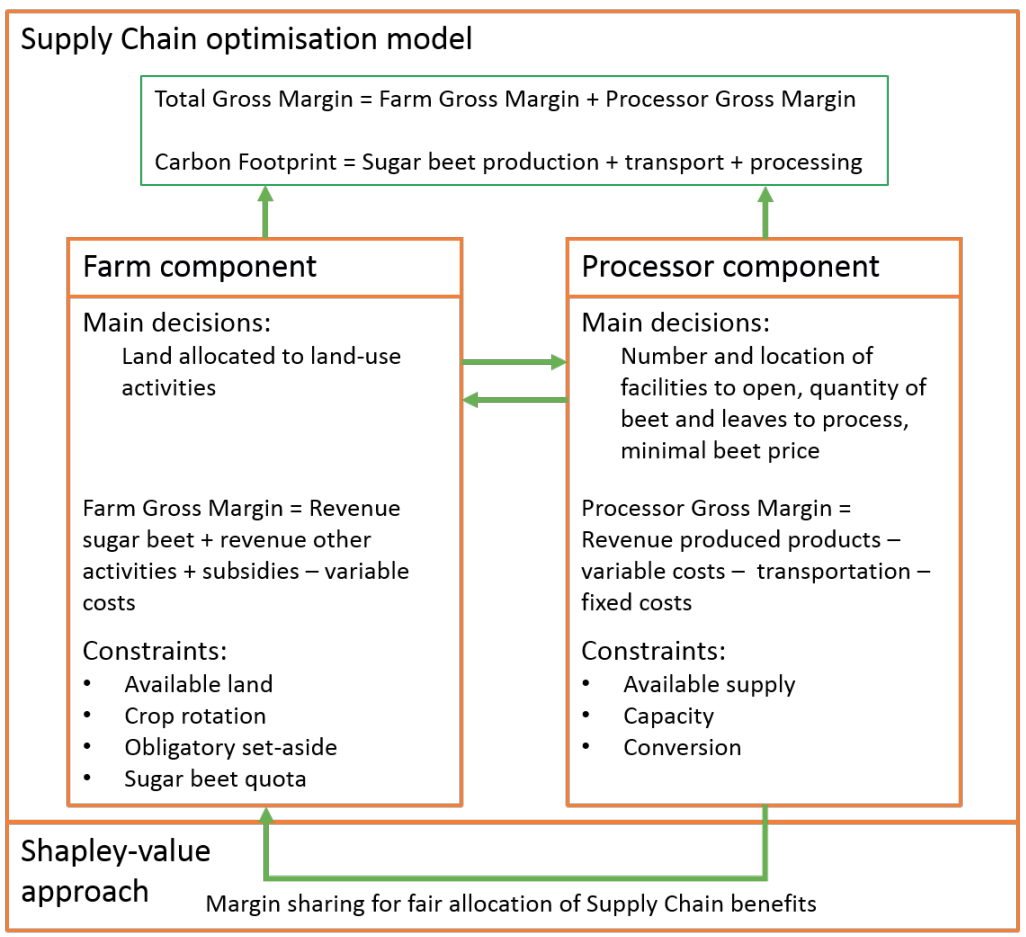

Figure 5.3: Representation of main model components and their interactions

\subsection{Model formulation}

The objective of the farmers is to maximise their gross margin subject to constraints on the available land, crop rotation, and legislative constraints on the obligatory set-aside of land and the production quota of sugar beet. We assume an inverse linear relation between crop prices and production quantities. Hence, the harvest revenue of a crop is described with a quadratic function.

The objective of the processor is to maximise its gross margin subject to constraints on the available supply, processing capacity, and processing conversion. Payments between processor and farms of a base price for sugar beet are included in the SC optimisation model. The determination of a fair allocation of the total gross margin in the SC is done using a Shapley-value approach in addition to the SC optimisation. 


\subsubsection{Optimisation model}

In the optimisation model, the following indices and sets are used:

$b \in B \quad$ set of possible biorefinery locations

$c \in C \quad$ set of land-use activities

$C_{i} \subset C \quad$ land-use activities member of category $i$

$f \in F \quad$ set of farm regions

$i \quad \in I \quad$ set of land-use activity categories

$j \in J \quad$ set of material categories

$k \in K \quad$ set for the discrete additional payments per ton beet

$m \in M \quad$ set of materials

$M_{j} \subset M$ materials member of category $j$

$p \quad \in P \quad$ set of processes

The decision variables used in the model are:

$A_{c f} \quad$ area of land allocated to land-use activity $c$ at location $f$

$H_{c f} \quad$ harvested quantity of $c$ at location $f$

$L_{f b p} \quad$ quantity of sugar beet leaves transported from farm region $f$ to a biorefinery at location $b$ which uses process $p$

$R_{m f b} \quad$ quantity of material $m$ returned to farm region $f$ from biorefinery location $b$

$S_{f b p} \quad$ quantity of sugar beet transported from farm region $f$ to a biorefinery at location $b$ which uses process $p$

$V_{k} \quad$ selected value $k$ of additional margin shared per ton beet (binary)

$W_{f k} \quad$ total amount of margin shared with farm $f$ for the additional payment $k$

$Y_{b p} \quad$ biorefinery at location $b$ using process $p$ open or not (binary)

Parameters used in the model are:

$b c_{b} \quad$ Processing capacity at biorefinery location $b$

$b i_{m p} \quad$ Quantity of input $m$ required per ton beet for process $p$

$b o_{m p} \quad$ Quantity of output $m$ produced per ton beet for process $p$

$c f_{b p} \quad$ Fixed annual cost of opening biorefinery location $b$ with process $p$

$c l_{f c} \quad$ Cultivation cost of land-use activity $c$ at farm region $f$

$c p_{p b} \quad$ Processing cost per ton beet for process $p$ at biorefinery location $b$

$c t_{m} \quad$ Transportation cost of material $m$ per ton per $\mathrm{km}$

$c c_{f b p}$ Cumulative transportation cost of processing inputs per ton beet from farm $f$ to biorefinery $b$ for process $p$

$d t_{f b} \quad$ Transportation distance between farm region $f$ and biorefinery location $b$

$e l_{f} \quad$ Sugar beet cultivation related emissions at farm region $f$

$e p_{p} \quad$ Sugar beet processing related emissions using process $p$

$e t_{f b p}$ Transportation related emissions per ton beet from farm region $f$ to biorefinery $b$ using process $p$

$f a_{f} \quad$ Available arable land at farm region $f$ 
$f l \quad$ Sugar beet leaves produced per ton sugar beet

$f m_{f} \quad$ Maximum harvest quantity of sugar beet from farm $f$

fo Obligatory set-aside fraction

$f q_{f} \quad$ Sugar beet quota at farm region $f$

$f r_{c} \quad$ Rotational constraint fraction for land-use activity $c$

$f p \quad$ Additional rotational constraint fraction for potato crops

ft Additional rotational constraint fraction for root and tuber crops

$f s_{c} \quad$ Government subsidy for producing crop $c$ per ha

$f y_{f c} \quad$ Yield of land-use activity $c$ at farm region $f$

$l a_{c} \quad$ Linear coefficient used in describing the relation between price per ton and quantity of a crop from land-use activity $c$

$l b_{c} \quad$ Constant used in describing the relation between price per ton and quantity of a crop from land-use activity $c$

$p b_{f} \quad$ Price paid per ton beet sourced from farm region $f$

$p m_{c} \quad$ Maximum price per ton of a crop from land-use activity $c$

$p o_{m} \quad$ Price per ton of output material $m$

$s m_{k} \quad$ Additional shared margin $k$ per ton beet

The Total Gross Margin (TGM) is used as economic objective function for the coordinated SC. It is defined as the of sum farmers' gross margin (FGM) and the processor's gross margin (PGM):

$$
\max \quad T G M=F G M+P G M
$$

The FGM is formulated as:

$$
\begin{aligned}
F G M= & \sum_{f \in F} \sum_{c \in C_{Q \text { Quad }}}\left(l a_{c} \times H_{c f}{ }^{2}+l b_{c} \times H_{c f}\right)+\sum_{f \in F} \sum_{c \in C} f s_{c} \times A_{c f} \\
& +\sum_{f \in F} \sum_{b \in B} \sum_{p \in P} p b_{f} \times S_{f b p}-\sum_{f \in F} \sum_{c \in C} c l_{f c} \times A_{c f}
\end{aligned}
$$

The total costs of producing crop $c$ at farm $f$ are subtracted from the sum of the total harvest revenue of all crops and the government subsidies paid per hectare of crop $c \in$ C. 
The PGM is formulated as:

$$
\begin{aligned}
P G M= & \sum_{f \in F} \sum_{b \in B} \sum_{p \in P} \sum_{m \in M_{\text {Out }}} p o_{m} \times b o_{m p} \times S_{f b p}-\sum_{f \in F} \sum_{b \in B} \sum_{p \in P} c p_{p b} \times S_{f b p} \\
& -\sum_{b \in B} \sum_{p \in P} c f_{b p} \times Y_{b p}-\sum_{f \in F} \sum_{b \in B} \sum_{p \in P} c c_{f b p} \times S_{f b p}-\sum_{m \in M_{R e t}} \sum_{f \in F} \sum_{b \in B} d t_{f b} \times c t_{m} \times R_{m f b}
\end{aligned}
$$

The first term describes the total revenue from the produced products. The other terms represent the total processing cost (including the base sugar beet price and sourcing of other raw materials), the investment cost for the facilities, and the transportation cost of the required raw materials and return flows.

Additionally, the shared environmental objective of the chain actors is to minimise the total carbon footprint of the sugar beet chain:

$$
\min \sum_{f \in F} e l_{f} \times A_{c f}+\sum_{f \in F} \sum_{b \in B} \sum_{p \in P} e p_{p} \times S_{f b p}+\sum_{f \in F} \sum_{b \in B} \sum_{p \in P} e t_{f b p} \times S_{f b p} \quad c=\text { Sugar beet }
$$

In Equation (5.4), the first term describes the total footprint related to the production of sugar beet. The footprint related to processing and transportation of raw materials is described by the second and third term, respectively. Constraints used in the model are discussed per actor in the following sub-sections.

\section{Farm level}

The following constraints hold for the farmers, related to the production of crops:

$$
\begin{aligned}
& \sum_{c \in C} A_{c f} \quad=f a_{f} \quad \forall f \in F \\
& A_{c f} \quad \geq f o \times f a_{f} \quad \forall f \in F, c=\text { Set-aside } \\
& A_{c f} \quad \leq f r_{c} \times f a_{f} \quad \forall c \in C, f \in F \\
& \sum_{c \in C_{\text {Pota }}} A_{c f} \quad \leq f p \times f a_{f} \quad \forall f \in F \\
& \sum_{c \in C_{R o o t}} A_{c f} \quad \leq f t \times f a_{f} \quad \forall f \in F \\
& H_{c f} \quad=f y_{f c} \times A_{c f} \quad \forall c \in C, f \in F \\
& H_{c f} \quad \leq f q_{f} \quad \forall f \in F, c=\text { Sugar beet }
\end{aligned}
$$


Equation (5.5) limits the total land use per farming region $f$ to the available arable land in that region. Equation (5.6) ensures the legally required minimum amount of land is set aside. Crop rotation is accounted for by Equation (5.7), with the additional constraints on the sum of potato crops given in Equation (5.8) and on the sum of all root and tuber crops in Equation (5.9). Equation (5.10) links the produced quantity of crop $c$ at farm region $f$ to the allocated hectares and regional crop yield of that region. The sugar beet quota system previously in place is described by Equation (5.11).

\section{Processor level}

The following constraints hold for the processor, related to the processing and transportation of the sugar beet:

$$
\begin{array}{lll}
\sum_{b \in B} \sum_{p \in P} S_{f b p} \leq H_{f c} & \forall f \in F, c=\text { Sugar beet } \\
\sum_{f \in F} S_{f b p} & \leq b c_{b} \times Y_{b p} & \forall b \in B, p \in P \\
\sum_{b \in B} \sum_{p \in P} L_{f b p} \leq f l \times H_{f c} & \forall f \in F, c=\text { Sugar beet } \\
\sum_{f \in F} L_{f b p} & =\sum_{f \in F} b i_{m p} \times S_{f b p} & \forall b \in B, p \in P, m=\text { Beet leaves } \\
\sum_{b \in B} R_{b f m} & =\sum_{b \in B} \sum_{p \in P} b o_{m p} \times S_{f b p} & \forall f \in F, m \in M_{\text {Ret }} \\
\sum_{f \in F} R_{b f m} & =\sum_{f \in F} \sum_{p \in P} b o_{m p} \times S_{f b p} & \forall b \in B, m \in M_{\text {Ret }}
\end{array}
$$

The supply of sugar beet per farming region $f$ is limited to the amount produced by Equation (5.12). Equation (5.13) allows the flow of sugar beet to a biorefinery at location $b$ up to its capacity, only when a facility is opened. Equations (5.14) and (5.15) limit the supply of sugar beet leaves per farming region $f$ and ensure that the required amount of sugar beet leaves is transported to a biorefinery at location $b$ using process $p$. Equations (5.16) and (5.17) restrict the return flows of lime fertiliser and tare soil to farming region $f$ and ensure the total amount of these outputs is returned to the farming regions. 
Additionally, constraints were added to limit the opening of facilities:

$$
\begin{array}{lll}
\sum_{p \in P} Y_{b p} & \leq 1 & \\
\sum_{b \in B} \sum_{p \in P} Y_{b p} & \leq X &
\end{array}
$$

Equation (5.18) ensures only a single facility is opened at a location $b$, while the total number of facilities is restricted to the number of $X$ by Equation (5.19), which depends on the total budget available to invest in facilities.

\section{Base beet price determination}

In the case of competition for agricultural land, it is important that the total margin a farmer can expect per hectare of cultivated land is at least equal to the margin that could be obtained when cultivating one of the competitive crops. If a processor fails to offer enough compensation, the required supply of agro-materials is jeopardised, as farmers may switch to more lucrative crops.

The processor pays a minimum price per ton beet, which is exogenous to the optimisation model (see Table 5.5). However, a higher price may be required as an incentive to farmers to produce the quantity of sugar beet required by the processor. This is especially relevant when taking the expected growth of the market into account. Additional payments per ton beet are added to the model as a decision variable. However, to avoid non-linearities in the model, $k=\{1, \ldots, K\}$ discrete payments were defined, using steps of $€ 0.01$ per ton beet. The following constraints are added:

$$
\begin{array}{rlrl}
\sum_{k \in K} V_{k} & =1 & \\
W_{f k} & \leq f m_{f} \times s m_{k} \times V_{k} & & \forall f \in F, k \in K \\
W_{f k} & \leq \sum_{b \in B} \sum_{p \in P} s m_{k} \times S_{f b p} & & \forall f \in F, k \in K \\
W_{f k} & \geq \sum_{b \in B} \sum_{p \in P} s m_{k} \times S_{f b p}-f m_{f} \times s m_{k} \times\left(1-V_{k}\right) & & \forall f \in F, k \in K
\end{array}
$$

Equation (5.20) ensures a selection is made for additional payments per ton beet while the combination of Equations (5.21) to (5.23) is a linear formulation linking the selected additional payment per ton beet with the sourced quantity of beet from a farm. This 
combination of constraints therefore describes the total additional payments on top of the base beet price made by the processor to the farms. The additional payments are included into the individual objective functions of the farmers (Equation (5.2)) and processor (Equation (5.3)) as follows:

$$
\begin{gathered}
F G M=\sum_{f \in F} \sum_{c \in C_{\text {Quad }}}\left(l a_{c} \times H_{c f}{ }^{2}+l b_{c} \times H_{c f}\right)+\sum_{f \in F} \sum_{c \in C} f s_{c} \times A_{c f} \\
+\sum_{f \in F} \sum_{b \in B} \sum_{p \in P} p b_{f} \times S_{f b p}-\sum_{f \in F} \sum_{c \in C} c l_{f c} \times A_{c f}+\sum_{f \in F} \sum_{k \in K} W_{f k} \\
P G M=\sum_{f \in F} \sum_{b \in B} \sum_{p \in P} \sum_{m \in M_{\text {Out }}} p o_{m} \times b o_{m p} \times S_{f b p}-\sum_{f \in F} \sum_{b \in B} \sum_{p \in P} c p_{p} \times S_{f b p}-\sum_{b \in B} \sum_{p \in P} c f_{b p} \times Y_{b p} \\
-\sum_{f \in F} \sum_{b \in B} \sum_{p \in P} c c_{f b p} \times S_{f b p}-\sum_{m \in M_{R e t}} \sum_{f \in F} \sum_{b \in B} d t_{f b} \times c t_{m} \times R_{m f b}-\sum_{f \in F} \sum_{k \in K} W_{f k}
\end{gathered}
$$

The minimal additional payment per ton beet is determined by optimising the PGM according to Equation (5.25) while enforcing that the FGM according to Equation (5.24) is equal to or greater than the FGM obtainable using Equation (5.2).

The quadratic part of the optimisation model was converted into MILP-form using a piecewise-linear $\lambda$-reformulation. The MILP model was programmed and solved to optimality using Xpress-IVE (Version 1.24.12) and the Xpress Optimiser (Version 29.01.10) on a $3.6 \mathrm{GHz}$ Intel core i7 computer with $8 \mathrm{~GB}$ RAM.

\subsubsection{Allocation of Supply Chain benefits}

In a collaborative context, especially when farmers and processors are part of a cooperation, additional margin sharing can be used to distribute the generated economic margin among the different actors in a fair way. Such systems of income sharing are used in practice by processors to ensure a steady supply of agro-materials throughout the years. Additionally, long term relations between suppliers and processors improve overall yield and quality in the SC.

A fair price per ton beet is calculated following a Shapley-value approach (Shapley, 1953). This approach is used in practice to allocate costs and benefits to the actors participating in a coalition. When the SC is considered as a coalition, the Shapley-value approach can be used to determine a price per ton beet that fairly allocates the gross margin generated 
in the sugar beet processing chain to the farmers and processor collaborating in the SC. The Beet chain Gross Margin (BGM) is the sum of the PGM and the margin farmers have on the cultivation of beet (Equation (5.26)).

$$
B G M=P G M+\sum_{f \in F} \sum_{b \in B} \sum_{p \in P} p b_{f} \times S_{f b p}-\sum_{f \in F} c l_{f c} \times A_{c f} \quad c=\text { Sugar beet }
$$

The part of the BGM allocated to every actor is calculated using Equation (5.27):

$$
E_{i}(v)=(1 / N !) \times \sum_{R}\left[v\left(P_{i}^{R} \cup\{i\}\right)-v\left(P_{i}^{R}\right)\right]
$$

where $E_{i}(v)$ is the amount an $\mathrm{SC}$ actor $i$ is given in an SC with $N$ actors in total. For every order $R$ of the SC actors in $N$, the set $P_{i}^{R}$ is the set of actors that precede $i$ in the order $R$. For each order in $R$, the first element in the summation represents the margin generated in the SC if actor $i$ participates $\left(v\left(P_{i}^{R} \cup\{i\}\right)\right)$ while the second element represents the margin generated in the $\mathrm{SC}$ if actor $i$ does not participate $\left(v\left(P_{i}^{R}\right)\right)$. An illustrative example for the Shapley-value approach is presented in Section 5.A.

\subsubsection{Case data}

The data required for the optimisation model was obtained from publicly available sources. The elements of the sets and subsets used in the optimisation model are shown in Table 5.2 .

\section{Farm and processor}

The available farm resources were aggregated at municipality level as a set of farm regions $F(\mathrm{n}=403)$, according to the Dutch Central Bureau of Statistics (CBS) municipality list of 2014. Available arable land per farm region was determined based on the average sum of land-used to cultivate crops $c \in C$ in the years 2011-2015 (CBS, 2016). The differences between municipalities in the cultivation characteristics of a soil type lead to the identification of several soil type-specific regions (see Table 5.3). Crop yields and production costs per hectare were obtained from KWIN-AGV (2009) for the different regions and soil types in The Netherlands (see Figure 5.1). Data for the crop rotation constraints was obtained from Mandryk et al. (2014). The sugar beet quota system was 


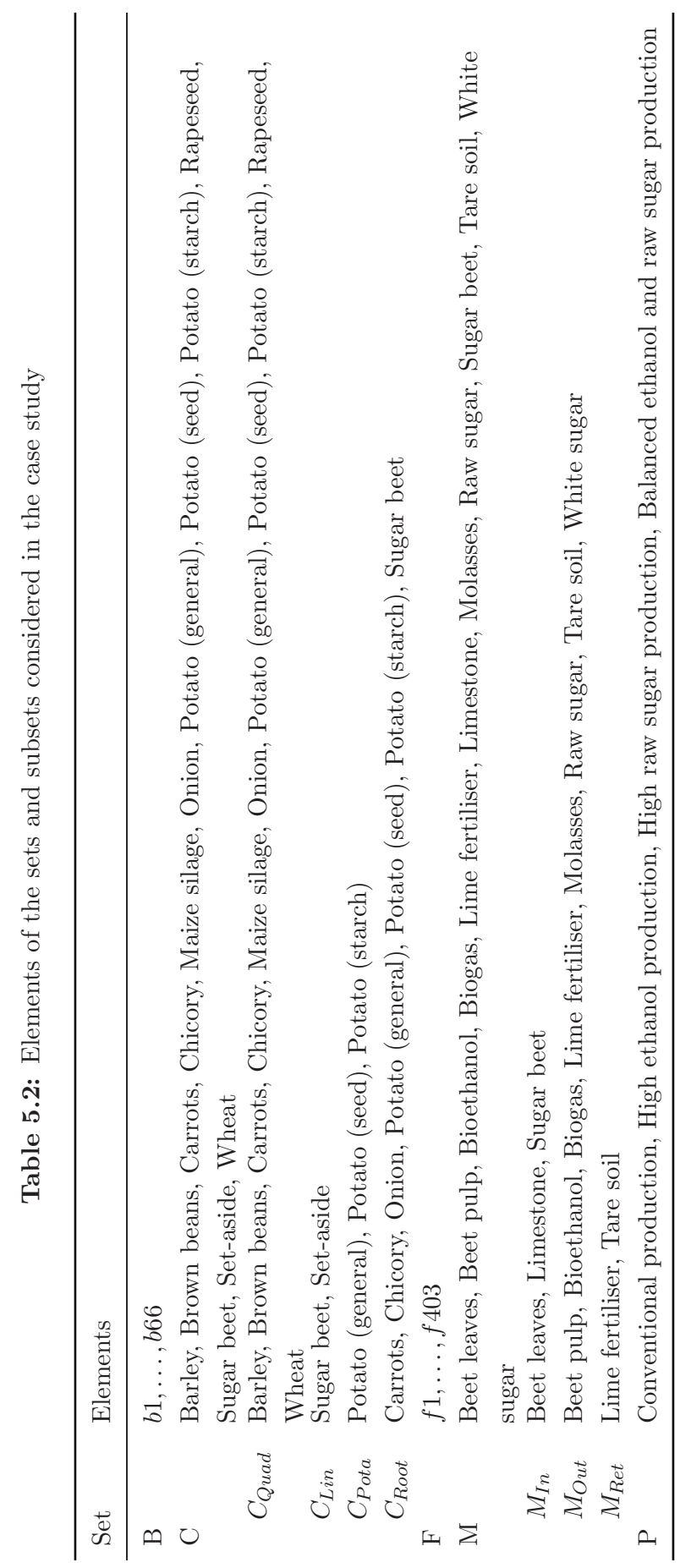


Table 5.3: Inputs and outputs per hectare of sugar beet based on soil type and region and calculated $\mathrm{CO}_{2}$-eq per ton sugar beet, data adapted from a) KWIN-AGV (2009); b) Klenk et al. $(2012 \mathrm{a}, \mathrm{b})$

\begin{tabular}{|c|c|c|c|c|c|c|c|}
\hline & $\begin{array}{l}\text { Clay } \\
\text { Central } \\
\text { polders }^{a}\end{array}$ & $\begin{array}{l}\text { South- } \\
\text { West }^{a}\end{array}$ & River $^{a}$ & $\operatorname{North}^{a}$ & $\begin{array}{l}\text { Sand } \\
\text { South- } \\
\text { East }^{a}\end{array}$ & $\operatorname{North}^{a}$ & $\begin{array}{c}\mathrm{CO}_{2} \text {-eq } \\
(\mathrm{kg} / \mathrm{kg})^{b}\end{array}$ \\
\hline Yield (ton) & 74 & 68 & 66 & 65 & 63 & 63 & \\
\hline Seed requirement $(\mathrm{kg})$ & 6 & 6 & 6 & 6 & 6 & 6 & 3.54 \\
\hline N-fertiliser (kg) & 150 & 150 & 150 & 150 & 150 & 150 & 5.88 \\
\hline P-fertiliser (kg) & 79 & 79 & 79 & 79 & 0 & 90 & 1.01 \\
\hline K-fertiliser (kg) & 60 & 54 & 60 & 60 & 240 & 171 & 0.58 \\
\hline Chemicals (solid, kg) & 1.5 & 3.5 & 1.5 & 1.5 & 0 & 0 & 10.97 \\
\hline Chemicals (liquid, l) & 3.9 & 3.68 & 4.15 & 4 & 5.33 & 3.94 & 10.97 \\
\hline Fuel consumption (l) & 103 & 107 & 107 & 107 & 80 & 100 & 3.14 \\
\hline $\mathrm{CO}_{2}$-eq $(\mathrm{kg} /$ ton $)$ & 18.93 & 21.02 & 21.45 & 21.76 & 21.46 & 23.02 & \\
\hline
\end{tabular}

approximated using the sugar beet production per farm region for the year 2014 (see Figure 5.2).

Besides the existing traditional facilities, the processor can open new facilities operating a novel biorefinery process, modelled after the description of Kolfschoten et al. (2014). A set $B$ of possible locations is considered $(n=66)$, which are central locations in the agricultural regions defined by the CBS. A set $M$ of material inputs and outputs was defined for the processes in $P$, of which the lime fertiliser and the tare soil are returned to the beet farms. The set of processes contains the conventional process and three proxies for the new biorefinery process. Of these, one is focusesd on producing the maximum amount of sugar, one is focusesd on producing the maximum amount of bioethanol, and one is producing a balanced amount of these main products. Processing and product related data are shown in Table 5.4 and Table 5.5, respectively.

Data on the carbon footprint of sugar beet production, transportation and processing was obtained from Klenk et al. (2012a,b) and KWIN-AGV (2009). The calculated footprint of sugar beet production for different regions in The Netherlands is shown in Table 5.3. The footprint related to the sugar beet processing was calculated based on Asadi (2006); Klenk et al. (2012a) and Kolfschoten et al. (2014) (see table 5.4). 
Table 5.4: Process related parameter values, based on a) Jonkman et al. (2017); b) Asadi (2006); Klenk et al. (2012a) and Kolfschoten et al. (2014)

\begin{tabular}{|c|c|c|}
\hline & Conventional & Small scale biorefinery \\
\hline Seasonal capacity ${ }^{a}$ (kton beet) & 2900 & 696 \\
\hline Annual investment $\operatorname{cost}^{a}(\mathrm{M} €)$ & 8.33 & 5 \\
\hline Processing $\operatorname{cost}^{a}(€ /$ ton beet $)$ & 32.3 & 39.53 \\
\hline Emissions $^{b}\left(\mathrm{~kg} \mathrm{CO} 2^{-}\right.$eq/ton beet) & 60.27 & -92.4 \\
\hline
\end{tabular}

Table 5.5: Product related parameter values, based on a) Jonkman et al. (2017); b) Kolfschoten et al. (2014)

\begin{tabular}{|c|c|c|c|c|c|}
\hline \multirow{2}{*}{ Product } & \multirow{2}{*}{$\begin{array}{l}\text { Price }^{a} \\
(€ / \text { ton })\end{array}$} & \multicolumn{4}{|c|}{ Material balance } \\
\hline & & Conventional $^{b}$ & & Biorefinery $^{b}$ & \\
\hline Sugar beet & 26.25 & 1 & 1 & 1 & 1 \\
\hline Beet leaves & $\cdot$ & . & 0.57 & 0.57 & 0.57 \\
\hline Limestone & 22 & 0.1 & $\cdot$ & $\cdot$ & $\cdot$ \\
\hline White sugar & 500 & 0.14625 & . & . & . \\
\hline Raw sugar & 500 & $\cdot$ & 0.125 & 0.06875 & 0.0125 \\
\hline Ethanol & 400 & . & 0.01875 & 0.040625 & 0.0625 \\
\hline Biogas & 90 & . & 0.1575 & 0.1575 & 0.1575 \\
\hline Molasses & 150 & 0.03375 & $\cdot$ & $\cdot$ & $\cdot$ \\
\hline Beet pulp & 45 & 0.1 & . & . & . \\
\hline Lime fertiliser & 3.7 & 0.0275 & . & . & . \\
\hline Tare soil & 2 & 0.125 & 0.125 & 0.125 & 0.125 \\
\hline
\end{tabular}


Table 5.6: Coefficients of the linear relation between crop production and market price, and the maximum market price per ton of product, determined based on CBS (2016) and Wageningen Economic Research (2016)

\begin{tabular}{|c|c|c|c|}
\hline & \multicolumn{2}{|c|}{ Linear coefficients } & \multirow{2}{*}{$\begin{array}{l}\text { Maximum price } \\
\qquad(€ / \text { ton })\end{array}$} \\
\hline & $l a_{c}:$ slope & $l b_{c}:$ intercept & \\
\hline Barley & $-0.47 \cdot 10^{-3}$ & 297.16 & 234 \\
\hline Brown beans & $-22.15 \cdot 10^{-3}$ & 854.42 & 940 \\
\hline Carrots & $-0.29 \cdot 10^{-3}$ & 260.65 & 189 \\
\hline Chicory & $-0.23 \cdot 10^{-3}$ & 104.65 & 74 \\
\hline Maize silage & $-1.49 \cdot 10^{-6}$ & 58.57 & 53 \\
\hline Onion & $-0.15 \cdot 10^{-3}$ & 299.46 & 182 \\
\hline \multicolumn{4}{|l|}{ Potato } \\
\hline general & $-0.14 \cdot 10^{-3}$ & 619.24 & 189 \\
\hline seed & $-0.04 \cdot 10^{-3}$ & 327.94 & 292 \\
\hline starch & $-0.04 \cdot 10^{-3}$ & 142.50 & 72 \\
\hline Rapeseed & $-24.73 \cdot 10^{-3}$ & 567.72 & 435 \\
\hline Wheat & $-0.11 \cdot 10^{-3}$ & 318.17 & 238 \\
\hline
\end{tabular}

Crop price determination

The base price of sugar beet is determined in the SC optimisation model. However, a farmer can also allocate land to the production of crops which are not of interest to the processor, but which do generate margin for the farmer. The price for these crops is related to the total produced quantity of that crop in a year, and subject to international market prices. To capture this relation between crop production and crop price, historic data on crop production and crop market price per ton was used to derive the relation between total production and the price per ton of product. A linear relation between crop price per ton and crop production was assumed, which is illustrated in Figure 5.4. The determined linear coefficients for the different crops are presented in Table 5.6. A more detailed investigation of the price elasticity of supply is considered beyond the scope of this chapter. The international market was taken into account by using the maximum price observed in the historic data as an upper limit to the crop price, assuming that crops are sourced internationally once the price within the Netherlands goes above this maximum limit (see Figure 5.4). This approach takes into account the interaction between farmers' decisions and prevents the model to suggest an allocation of all available land to the most profitable land-use activity. 


\subsubsection{Model runs}

The average percentage of land allocated to a land-use activity during the years 2011-2015 was determined using data from CBS (2016). This average of the actual land allocation was used as a benchmark for the land-use allocation resulting from the optimisation model runs.

The existing SC configuration was used as a base case for the optimisation model. The locations of the existing traditional processing facilities were fixed $(X=2)$, and the optimisation model was used to examine the effect of coordination in the sugar beet supply chain on land allocation. Two model runs were executed to compare the modelled current situation without SC coordination between the farmers and processor with the modelled current situation with SC coordination. In the base case, the sugar beet production is assumed to be limited through the quota system which was previously in place. In the non-coordinated model run of the base case, the optimal land allocation was determined by maximising the FGM according to Equation (5.2), subject to Equations (5.5) to (5.19). Alternatively, the optimal land allocation for the coordinated version of the base case was determined by maximising the TGM according to Equation (5.1), subject to Equations (5.2) to (5.19).

Subsequently, a future case model run was executed to determine the optimal land allocation taking into account the expected increase in sugar beet supply and product demand and showing the consequence of the changing legislation. Equation (5.11) was relaxed, and the opening of a maximum of two additional facilities was allowed $(X=4)$. The minimum beet price for the coordinated version of the future case was determined by optimising the TGM according to Equation (5.1), subject to Equations (5.5) to (5.25), while forcing the FGM according to Equation (5.24) to be equal to or greater than the FGM obtainable by maximising Equation (5.2). The trade-off between the SC economic and environmental objective (Equation (5.1) and Equation (5.4), respectively) was explored using the $\epsilon$-constraint method to identify eco-efficient SC configurations.

In the future case, the contribution of farmers and processor to the generated margin has changed from the current situation modelled in the base case. Hence, we determine how the generated margin in the coordinated version of the future case can be allocated to the $\mathrm{SC}$ actors in a fair way according to the Shapley-value approach (Equation (5.27)). The contribution of a farmer to the BGM is dependent on the distance between the farm and the biorefinery. Longer distances come with higher transportation costs related to the sourcing of agro-materials. This leads to a lower BGM generated per ton beet compared to beets sourced from shorter distances. Therefore, the Shapley-value approach was used to calculate fair prices per ton beet, dependent on the distance of a farm to a biorefinery. A price was determined for beet sourced from within $50 \mathrm{~km}$ from a processing location 
while a different price was determined for beet sourced from distances longer than 50 $\mathrm{km}$.

\subsection{Results and discussion}

The optimised land allocation for the base case and the future case model runs are shown in Table 5.7. It can be seen that for the base case, which represents the modelled current situation, the distribution of land to the different land-use activities is similar to that of the benchmark. The total calculated economic margin created by arable farms in the non-coordinated version of the base case was $\mathrm{M} € 1,197$, and the total carbon footprint per ton sugar was calculated at $536 \mathrm{~kg} \mathrm{CO}$-eq, using economic allocation. In reality, the CBS reports a generated economic margin of farmers of $\mathrm{M} € 1,462$ (CBS, 2016). A range of 242-771 kg CO Ceq -er ton sugar is reported by Klenk et al. (2012a) for sugar production in the EU, with the Dutch sugar industry reporting a value of $480 \mathrm{~kg} \mathrm{CO}_{2}$-eq per ton sugar. Table 5.7 shows a larger percentage of land is allocated to the production of sugar beet in the coordinated version of the base case, compared to the non-coordinated base case. This indicates a conflict between the individual objective of the farmers and the objective of the processor. This conflict is further discussed in Section 5.4.1. Additionally, the results show that an increase in the allocation of land to sugar beet production mainly lead to a reduction of the land allocated to the production of barley. The conflict between the economic and environmental objective of the coordinated SC is discussed in section 5.4.2.

\subsubsection{Conflicting objectives actor level}

Coordination between farmers and the processor leads to a higher BGM. In the future case, coordination increases the modelled BGM to M€112, an increase of $21 \%$ compared to the non-coordinated future case $(\mathrm{M} € 92)$. However, a larger share of land needs to be allocated to sugar beet production for the coordinated run of both the base case and the future case (Table 5.7). The allocation of this land deviates from the optimal land allocation that maximises the FGM of the farmer, as is seen in the non-coordinated base case. Therefore, additional payments are required on top of the minimum price per ton beet as an incentive to farmers to produce the desired quantity of sugar beet. A minimum amount of $€ 0.15$ per ton beet on top of the minimum price is required to compensate farmers for their lost margin when they produce the desired quantity of beet (Table 5.8). Such a minimal compensation leaves most of the margin generated within the sugar beet $\mathrm{SC}$ at the processor. The fair distribution of the economic margin according to the Shapley-value approach is presented in Table 5.8. The Shapley-value approach allocates 


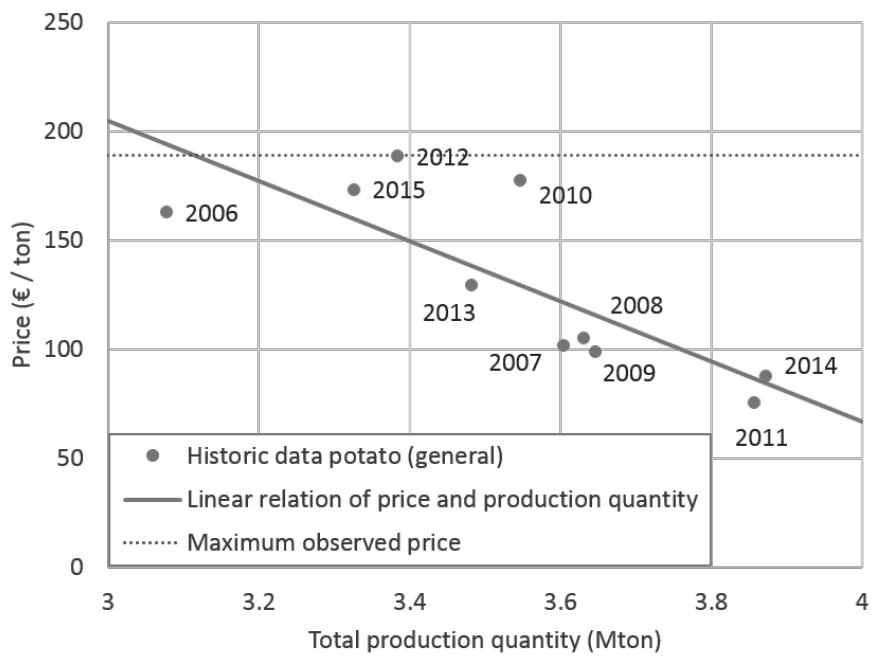

Figure 5.4: Estimated linear relationship between price and production of potatoes, and the maximum price, based on CBS (2016) and Wageningen Economic Research (2016)

Table 5.7: Actual and optimised percentage of land allocated to each crop. a: Calculated based on CBS (2016)

\begin{tabular}{lcccc}
\hline Crop & Benchmark $^{a}$ & \multicolumn{2}{c}{ Base case } & Future \\
& & non-coordinated & coordinated & coordinated \\
\hline Barley & 4.5 & 4.7 & 4.0 & 3.9 \\
Brown beans & 0.2 & 0.4 & 0.4 & 0.4 \\
Carrots & 0.9 & 0.6 & 0.6 & 0.6 \\
Chicory & 0.5 & 0.4 & 0.4 & 0.4 \\
Maize silage & 33.7 & 35.6 & 35.8 & 34.0 \\
Onion & 3.3 & 2.0 & 2.0 & 2.0 \\
Potato (total) & 23.0 & 23.9 & 23.5 & 23.5 \\
\multicolumn{1}{c}{ general } & 10.6 & 9.1 & 9.1 & 9.1 \\
$\quad$ seed & 5.9 & 9.5 & 9.1 & 9.2 \\
Rtarch & 6.5 & 5.3 & 5.3 & 5.3 \\
Rapeseed & 0.4 & 0.2 & 0.2 & 0.2 \\
Sugar beet & 10.4 & 11.4 & 12.3 & 14.2 \\
Set aside & 1.1 & 1.0 & 1.0 & 1.0 \\
Wheat & 21.9 & 19.9 & 19.9 & 19.9 \\
\hline
\end{tabular}


Table 5.8: Margin from the beet processing chain per chain actors without additional income sharing, with minimal compensation, and according to the Shapley-value approach

\begin{tabular}{llrrr}
\hline & & \multicolumn{3}{c}{ Future case, coordinated } \\
& & 111.93 & 111.93 & 111.93 \\
& $(\mathrm{M} €)$ & 29.88 & 31.15 & 81.73 \\
BGM & $(\mathrm{M} €)$ & 17.93 & 18.66 & 51.32 \\
Farmers & & 11.95 & 12.49 & 30.42 \\
$\quad<50 \mathrm{~km}$ & & 82.05 & 80.78 & 30.19 \\
$\quad>50 \mathrm{~km}$ & $(\mathrm{M} €)$ & 4.70 & 4.90 & 12.85 \\
PGM & $(€ /$ ton beet $)$ & 12.90 & 12.70 & 4.75 \\
Farmers margin & 89.61 & 88.22 & 32.97 \\
Processor margin & $(€ /$ ton beet $)$ & 26.25 & 26.40 & 35.42 \\
Processor margin & $(€ /$ ton sugar $)$ & 26.25 & 26.40 & 33.04 \\
Beet price $<50 \mathrm{~km}$ & $(€ /$ ton beet $)$ & &
\end{tabular}

most margin generated in the sugar beet processing chain to the farmers. In practice, the Dutch sugar production chain operates as a cooperative, and margin sharing is applied. Rosenboom et al. (2013) report a margin of the processor of $€ 37$.- per ton of sugar after payments were made to the cooperative's member farmers, which is in the same order as the $€ 32.97$ determined with the Shapley-value approach in this study. The Shapley-value approach hence resulted in a realistic distribution of the economic gains between farmers and processor.

\subsubsection{Conflicting objectives chain level}

In the coordinated model run of the future case, a conflict is observed between the economic and environmental objective of the sugar beet processing chain. Figure 5.5 shows that using additional biorefinery facilities supports reducing the carbon footprint while still being able to achieve similar economic margin as in the base case situation. In general, Table 5.3 shows that sourcing beet from productive soil types is beneficial from the perspective of carbon footprint. This is also seen in Figure 5.5, in which all eco-efficient configurations contain an additional biorefinery in the central polders, the most productive region within the Netherlands. Opening two additional biorefineries reduces the average transportation distance from farms to a biorefinery, and improves the environmental performance of the chain. However, a single additional facility has enough processing capacity to cover the expected increase in demand. The effective use of processing capacity therefore leads to a higher TGM for the SC configuration with only a single additional biorefinery. The SC configurations on the eco-efficient frontier do not only contain opened 


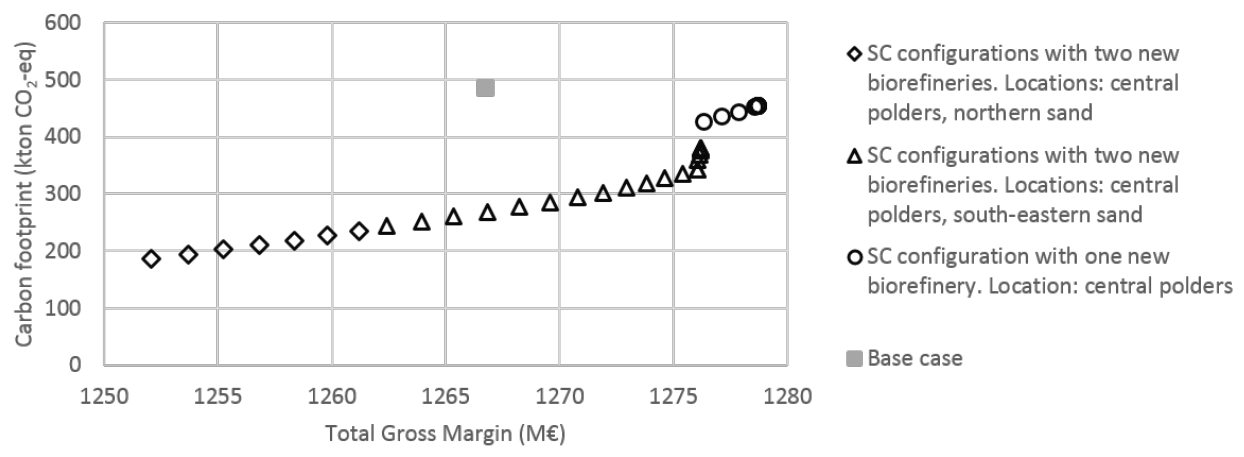

Figure 5.5: Pareto-efficient solutions calculated using the $\epsilon$-constraint method with carbon footprint and total gross margin as objectives

facilities in the agricultural regions with the highest sugar beet yield per hectare, but also in regions where there is an overall good performance on the economic and environmental objective. For instance, the northern sand region itself is less productive than other regions and has a higher footprint per ton beet produced (Table 5.3), but the available land and other soil types in the region lead to relatively short transportation distances if a facility is opened there. The reduced emissions related to transportation in that case compensate for the higher emissions related to cultivation.

\subsection{Conclusions}

This chapter investigated the design of biobased SCs, taking into account competitive land use and the multi-actor properties of the biomass SC. Economic and environmental objectives were included at chain level while conflicting economic objectives of the SC actors were considered through gain sharing using the Shapley-value approach. The case study shows that the individual objectives of farmers can jeopardise the supply of raw materials required for the optimal SC configuration. The farmers may deviate from the desired optimal production of crops to satisfy their own objectives. Optimising the SC assuming full coordination can therefore lead to design solutions unattractive to one or more of the chain actors. Gain sharing is required as an incentive for all actors to participate. The Shapley-value approach showed that a fair distribution of the generated margin to the SC actors allocates most of the margin to the farmers.

Other game-theoretic approaches have been used in the analysis of biobased SCs, but their inclusion into biobased SC design is limited and leads to non-linearities in biobased SC design models. For instance, Sun et al. (2013) analysed a competitive biobased SC with 
one supplier and two competing buyers. They determined the crop price of the supplier and the possibility for the buyers to co-exist if supply did not cover their demand, but did not optimise the SC design. Yue \& You (2014a) investigated fair economic profit allocation between actors in biobased SC using a Nash-bargaining solution approach. With this approach, the determination of the allocated profit is treated as a non-cooperative game in which the SC actors try to demand the maximum possible without jointly demanding more than is available. Because this approach leads to non-linearities in the SC design model, the authors propose a bi-level modelling framework and solution algorithm to obtain globally optimal solutions (Yue \& You, 2014b, 2017). Similarly, Ortiz-Gutiérrez et al. (2015) optimised a linearised form of the Nash-objective function to find the optimal chain configuration and transfer price for a bioethanol SC with a dedicated supplier and a processor. Because the Shapley-value approach was used external to the SC design model itself it does not affect the complexity of the SC design model, giving it an advantage over these other game-theoretic approaches.

In the case study, high crop yields were observed to often be related to lower carbon footprints per ton of product. Hence, opening processing facilities in productive regions reduces both the carbon footprint of agro-material production, and the transportation distances between supply and the processing facility with their related transportation costs and emissions. Site specific information (e.g. soil type, climate) related to the productivity of biomass should therefore be taken into account explicitly to benefit the most from strategic biobased SC design. Additionally, results indicate that the current $\mathrm{SC}$ configurations can improve on both the economic and environmental objectives using the new biorefinery process.

In this study, we extended the biobased SC design problem by accounting for competitive land use and price-supply relationships explicitly. These extensions supported identifying eco-efficient SC configurations and identifying conflicts between the individual goals of the SC actors. These actors participate in multiple chains in a SC network, and the implementation of the optimisation of one of these chains will only be successful if the network level is taken into account. The Shapley-value approach adopted to allocate gain sharing among the actors in the SC supported finding SC configurations in which all actors are likely to participate. Additionally, agreements developed based on gain sharing will support long term relationships between suppliers and processors. This allows farmers to build expertise in the production of a specific crop, and can improve the overall yield and quality of the agro-materials in the SC. This is specifically important in biobased SCs dealing with food products, where quality control is an ever-pressing issue.

An actors' relative contribution to the economic and environmental objectives may differ. Extensions of gain sharing to take into account multiple objectives could be used to encourage improvements in the environmental performance of the chain. 


\section{A Shapley-value with an illustrative example}

We illustrate the Shapley-value approach with an example. Imagine a SC where a processor, $P 1$ and two farmers $F 1$ and $F 2$ collaborate. The minimum market price is fixed at $€ 26.25$ per ton of agro-material supplied by the farmers. Cultivation costs per ton of agro-material are $€ 20$ and $€ 22.25$ for F1 and F2, respectively. Transporting and processing a ton of agro-material from $\mathrm{F} 1$ to $\mathrm{P} 1$ costs $€ 40$, and transporting and processing a ton of agro-material from F2 to P1 costs $€ 38$. The processor has a fixed cost for opening a facility of $€ 5$ per ton of processing capacity. The value of the produced products is $€ 83$ per ton agro-material processed.

For this example, we assume each farmer supplies 1 ton of agro-material, and the processor opens a facility with a capacity of exactly 2 tons. Following Equation (5.26), the generated margin equals $€ 37.75$. Following a straightforward fractional allocation, F1 is allocated $€ 26.25-€ 20=€ 6.25$, F2 is allocated $€ 26.25-€ 22.25=€ 4$, and P1 is allocated the remaining $€ 25.5$. To calculate a more fair allocation of the generated margin, Equation (5.27) is applied. Without the farmers, the processor incurs costs for opening a facility, but does not generate revenue as there is nothing to process. Without the processor, farmers can still sell the agro-material at the market price. All possible orders and the contribution of each actor to the gross margin in each order are shown in Figure 5.6.

Following Equation (5.27), the margin allocated to F1, F2, and P1 are as follows:

$$
\begin{aligned}
& F 1: \frac{23+23+6.25+6.25+23+6.25}{6}=€ 14.63 \\
& F 2: \frac{22.75+22.75+22.75+4+4+4}{6}=€ 13.38 \\
& P 1: \frac{-10-10+6.75+25.5+8.75+25.5}{6}=€ 3.88
\end{aligned}
$$




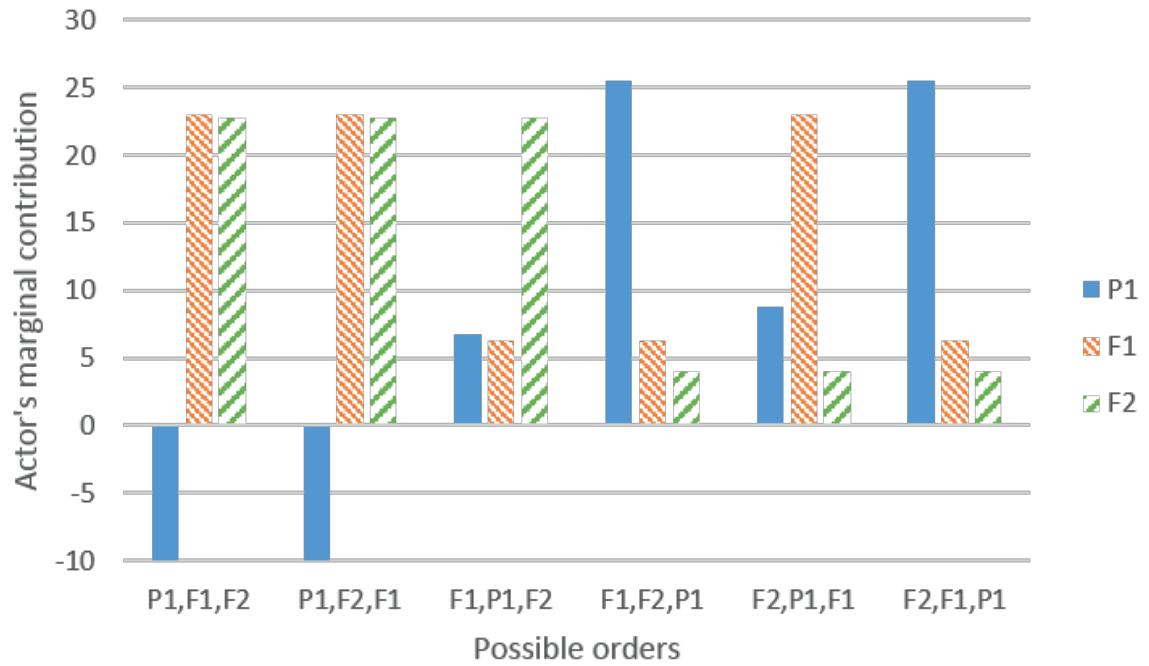

Figure 5.6: Possible orders, and each actors' marginal contribution in each order 
Chapter 6

\section{Multi-level synthesis}


The previous chapters show that re-considering the current set-up of Food Supply Chains (FSCs) can lead to a more efficient production of food, with an improved economic and environmental performance of the FSC. Each chapter shows how methods from the field of Process Systems Engineering (PSE) and Supply Chain Management (SCM) can be used to support answering strategic questions relevant for agro-food industry at the product level, process and enterprise level, Supply Chain (SC) level, and SC network level. At these levels, the approach supported finding answers to the following questions:

- Which intermediates to make from the available agro-materials in order to produce the desired consumer products?

- Which production processes to produce the desired intermediates?

- Where to execute production processes in the FSC, and at what time?

- How to ensure the participation of all the required actors in the desired FSC network?

This chapter connects the work presented in Chapters 2 to 5 , and discusses the necessity of taking an integrated approach combining process engineering and SC design. Additionally, the general applicability of the proposed approach to other FSCs is discussed, and future research opportunities are identified.

\subsection{Multi-level interdependency}

From the conclusions of the previous chapter a clear interdependency is observed between decisions made at the different levels (Figure 6.1). Selecting an intermediate-product portfolio inherently leads to the selection of processing pathways (Chapter 2) while the choice for a process pathway implies a certain set-up of the FSC (Chapter 3). The specific characteristics of the FSC in turn affect how operable a process pathway is (Chapter 4), and a $\mathrm{SC}$ configuration is prescriptive towards the role of each actor participating in the FSC. This role can be jeopardised by the role the same actor plays in other SCs in the network, hence SC collaboration is required to align the objectives of different SC actors (Chapter 5).

Optimising the strategic decisions at a single level therefore affects the freedom to make decisions at the other levels. Optimising the set-up of agro-food SCs at each level independently therefore leads to a lock-in effect. It is unlikely to achieve a substantial change from the status quo over the whole FSC in this way. However, such a change is necessary to reduce inefficiencies in the production of food (van der Goot et al., 2016). Therefore, an integrated multi-scale approach towards the design of an agro-food SC is needed. In 


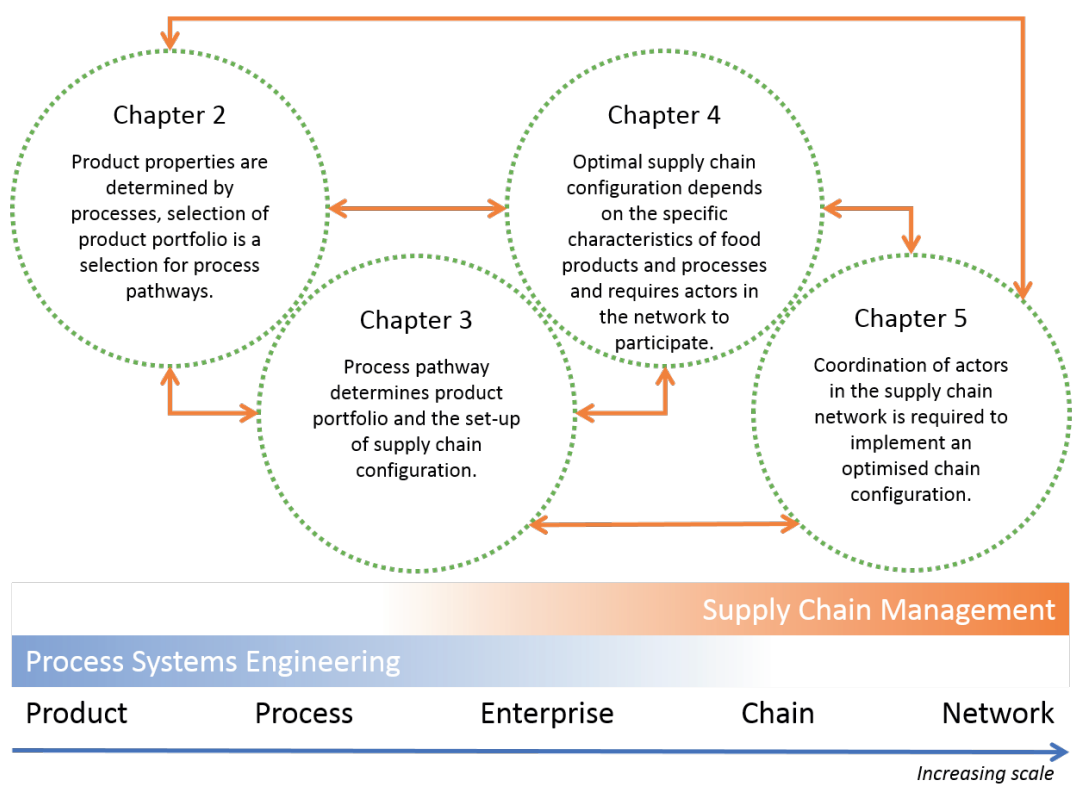

Figure 6.1: Interdependency of decision making at the different levels

the next paragraphs the implications are discussed within the traditional scope of PSE and then within the traditional scope of SCM.

\subsubsection{Implications within the traditional scope of PSE}

At the interaction between the product level and the process and enterprise level, a better understanding of the effect of processing on the composition of intermediates helps to identify better fractionation pathways. For example, in the case study of Chapter 2, the representation with ternary diagrams shows that a small shift is required in the composition of one intermediate to overlap with the specification of a final application (illustrated in Figure 6.2). Additionally, the diagram shows which two processing steps could be altered to achieve the desired target (i.e. air classification and fibre separation). Pelgrom et al. (2014a) shows how changing the process settings during air classification of lupin alters the obtained fractions, which is indicated in Figure 6.2. Such a change in process settings would alter the starting material for the fibre separation step and in turn shift the obtained fractions from the fibre separation step.

The consequence on the resulting intermediates and on the final combination of process steps in the fractionation pathway is unfortunately hard to predict. The product properties are not only determined by chemical composition, but also by the distribution of 


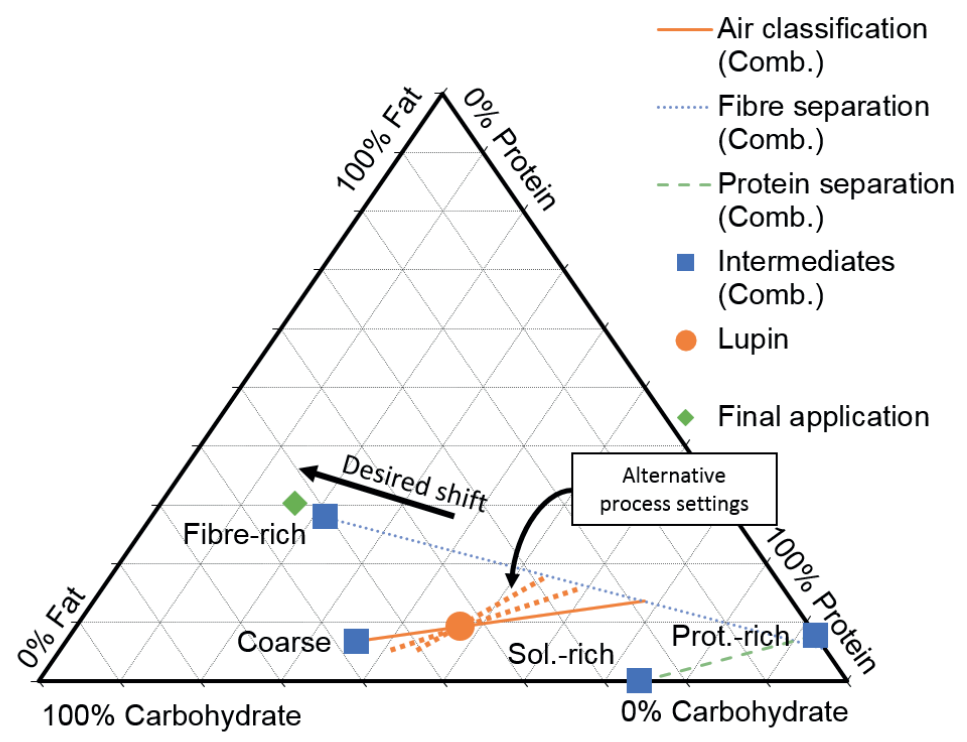

Figure 6.2: Identification of opportunities for process improvement using the ternary diagrams introduced in Chapter 2

components through the product and product-process interactions (Meeuse, 2007). The understanding of these interactions at the product and process level is still limited (Datta, 2016), and accounting for the relevant interactions can require detailed non-linear models (Ho et al., 2013). Geerts et al. (2017b) and Geerts et al. (2017a) take first steps linking product composition and product processing to the obtained functional properties.

\subsubsection{Implications within the traditional scope of SCM}

To prevent sub-optimisation of a FSC, a whole-chain SC design approach is required, ranging from the processing level up to the network level. In the field of SCM, SC design methods often do not consider the processing level, or only consider linearised black-box approximations (Melo et al., 2009). However, the type of production processes an enterprise operates determines the set-up of its SC, and product and process characteristics affect the optimal SC configuration (Chapter 3, Chapter 4). Furthermore, this optimal SC configuration cannot be implemented without the consideration of all the SC actors and their role in the SC network (Chapter 5).

Integrating the process and enterprise level with the SC level could lead to the introduction of non-linearities into SC design models (e.g. You \& Grossmann, 2008), and very quickly 
leads to optimisation problems which are non-tractable (Yue et al., 2014). Several authors therefore propose to reduce the amount of detail included whenever possible (Ho et al., 2013; Yue et al., 2014). Additionally, decomposition approaches and hierarchical decision support frameworks are proposed to deal with the resulting mathematical problems (e.g. Amorim et al., 2016; Tsolakis et al., 2014, respecitvely).

Alternative to the approach taken in Chapter 5, the use of complex-adaptive systems modelling and agent-based modelling is proposed as a method to study the interactions of the SC actors at the network level (Perrot et al., 2016). These approaches are especially useful to investigate the consequences of the behaviour of individual SC actors at the network level, and complement the optimisation approach currently used.

Today, the direct integration of all the levels into a single model is unfeasible. The details to include at each level lead to very large models, which would be impossible to solve. Moreover, the approach required at the different levels can be of a very different nature because they deal with different space and time scales, and it is not obvious how these should be integrated (Grossmann, 2014). Hence, an integrated approach requires the iteration between the sub-parts for decision making support at the different levels (Perrot et al., 2016). The methods presented in the different chapters of this study should therefore be used in an iterative manner, and the consequences should be investigated of optimising the decisions at one level on the optimal decisions at the other levels. This integrated multi-level approach is needed in order to prevent sub-optimisation of the FSC resulting from optimising a single sub-part at one of the individual levels.

\subsection{Applicability in agro-food supply chains}

The strategic questions of agro-food industry covered in this study were answered for specific case studies of legume processing (Chapter 2), and the sugar beet processing chain in The Netherlands (Chapters 3 to 5). The previously discussed interdependencies between the different levels cause concrete answers to these strategic questions to be very case specific. The proposed approach can, however, be applied to other agro-food industrial chains without difficulty.

For each case, the relevant characteristics of FSCs that influence decision making have to be determined. In general terms, agro-food industry can be categorised based on, for example, the raw materials (animal/plant based), the perishability of raw materials and products (long/short), the type of processing (fresh/processed) and products (specialised/commodity), and the length of the FSC (local/global). For example, a grain processor does not have to deal with the same type of perishability and seasonal supply as a sugar beet processor (Chapters 3 and 4), and often globally sources the raw ma- 
terials, thus reducing the necessity of taking local production by farmers into account (Chapter 5). Similarly, the dimensions used to represent the intermediate selection problem in a ternary diagram could be adapted to more relevant examples, such as fibre, starch, and protein (Chapter 2). For instance, a dairy processor has to deal with even stricter perishability constraints than the sugar beet processor, and the time needed to rear animals for the production of milk adds to the importance of SC coordination.

There is, however, no comprehensive classification system that links the differentiating categories to relevant specific characteristics of FSCs. In practice companies can be involved in several SCs. They can function in both the agro-food industry and the food assembly industry, making classification difficult. Still, a research opportunity exists to identify different archetypes of FSCs which will support the categorisation of FSCs and help to quickly identify their relevant characteristics.

\subsection{Directions for future research}

This thesis shows that bridging process engineering and SC design for agro-food processing chains leads to an increased economic and environmental performance of the FSC. The combination of the fields of PSE and SCM from the process level up to the SC network level leads to new optimisation opportunities which would not easily have been identified otherwise.

Detailed understanding of products and production processes typically found in the field of PSE is, for instance, required in SCM to identify opportunities for Close-Loop Supply Chain (CLSC) design. Krikke et al. (2003) explore this concept for the concurrent design of a refrigerator and the required forward and reverse SCs. CLSC design in the context of FSCs was only recently studied by Banasik et al. (2017), who observed the possibility of economic and environmental improvements in a mushroom processing chain. This train of research is comparatively underdeveloped, and deserves more attention.

The interdependency of the processing level and the SC level explored in Chapter 3 also leads to symbiosis between the fields. Understanding which product functionalities are required by customers, and knowing how the specific characteristics of products affect the logistics in the SC, supports identifying better intermediates and processing pathways in food industry. For instance, Depping et al. (2017) recently showed that producing milk concentrates rather than the conventional dried skim milk powder has a lower environmental impact, even up to truck shipping distances of $1000 \mathrm{~km}$. The optimisation of products in the context of SCs should be addressed in future studies.

In the literature on FSC design, the set-up of chains is often prescribed to be centralised 
in nature (Kusumastuti et al., 2016). Introducing the process level into SC design enables the optimised SC configurations to also have a non-centralised set-up. Future work is needed to explore this further. Chapters 3 and 4 show that this extension of SC design with more detailed processing insights leads to the identification of partially decentralised FSC configurations with superior economic and environmental performance compared to the current centralised SC.

The seasonality of the supply of agro-materials in many FSCs can justify research towards small-scale mobile or semi-mobile processing. Such processing units could be re-located depending on the changing seasonal demand and supply (Zimmer et al., 2018). Although mobile processing of, for instance, fruit juice exists in practice, there is yet little research to the extent at which such processing and SC concepts could improve the performance of FSCs. Additionally, such novel processing concepts bring processing closer to the producers of agro-materials. This would change the role of many actors participating in the SC, leading to completely different SC networks.

An integrated approach to the optimisation of agro-food SCs, and FSCs in general, enables us to re-consider the current set-up of food processing and reduce inefficiencies in the production of food. Iteration is required between the product level, the process and enterprise level, the SC level, and the network level to optimise decisions at these levels without risking a sub-optimisation of the entire FSC. Hence, combining methods and expertise from the fields of PSE and SCM is essential for the development of more efficient FSC networks. 



\section{References}

Ahumada, O., \& Villalobos, J. R. (2009). Application of planning models in the agri-food supply chain: A review. European Journal of Operational Research, 196, 1-20.

Akkerman, R., Farahani, P., \& Grunow, M. (2010a). Quality, safety and sustainability in food distribution: a review of quantitative operations management approaches and challenges. OR Spectrum, 32, 863-904.

Akkerman, R., van der Meer, D., \& van Donk, D. P. (2010b). Make to stock and mix to order: choosing intermediate products in the food-processing industry. International Journal of Production Research, 48, 3475-3492.

Amorim, P., Curcio, E., Almada-Lobo, B., Barbosa-Póvoa, A. P., \& Grossmann, I. E. (2016). Supplier selection in the processed food industry under uncertainty. European Journal of Operational Research, 252, 801-814.

Amorim, P., Meyr, H., Almeder, C., \& Almada-Lobo, B. (2013). Managing perishability in production-distribution planning: A discussion and review. Flexible Services and Manufacturing Journal, 25, 389-413.

Andiappan, V., Ko, A. S. Y., Lau, V. W. S., Ng, L. Y., Ng, R. T. L., Chemmangattuvalappil, N. G., \& Ng, D. K. S. (2015). Synthesis of sustainable integrated biorefinery via reaction pathway synthesis: Economic, incremental enviromental burden and energy assessment with multiobjective optimization. AIChE Journal, 61, 132-146.

Apaiah, R. K., \& Hendrix, E. M. T. (2005). Design of a supply chain network for pea-based novel protein foods. Journal of Food Engineering, 70, 383-391.

Aramyan, L. H., Oude Lansink, A. G. J. M., van der Vorst, J. G. A. J., \& van Kooten, O. (2007). Performance measurement in agri-food supply chains: a case study. Supply Chain Management-an International Journal, 12, 304-315.

Asadi, M. (2006). Beet-Sugar Handbook. John Wiley \& Sons.

Augustin, M. A., Riley, M., Stockmann, R., Bennett, L., Kahl, A., Lockett, T., Osmond, M., Sanguansri, P., Stonehouse, W., Zajac, I., \& Cobiac, L. (2016). Role of food processing in food and nutrition security. Trends in Food Science and Technology, 56, 
$115-125$.

Ba, B. H., Prins, C., \& Prodhon, C. (2016). Models for optimization and performance evaluation of biomass supply chains: An Operations Research perspective. Renewable Energy, 87, 977-989.

Bai, Y., Ouyang, Y., \& Pang, J.-S. (2012). Biofuel supply chain design under competitive agricultural land use and feedstock market equilibrium. Energy Economics, 34, 16231633.

Banasik, A., Kanellopoulos, A., Claassen, G. D. H., Bloemhof, J. M., \& van der Vorst, J. G. A. J. (2017). Closing loops in agricultural supply chains using multi-objective optimization: A case study of an industrial mushroom supply chain. International Journal of Production Economics, 183, 409-420.

Barbosa-Póvoa, A. P. (2014). Process Supply Chains Management-Where are We? Where to Go Next? Frontiers in Energy Research, 2, 23.

Berghout, J. A. M., Boom, R. M., \& Van der Goot, A. J. (2014). The potential of aqueous fractionation of lupin seeds for high-protein foods. Food chemistry, 159, 64-70.

Berghout, J. A. M., Pelgrom, P. J. M., Schutyser, M. A. I., Boom, R. M., \& van der Goot, A. J. (2015). Sustainability assessment of oilseed fractionation processes: A case study on lupin seeds. Journal of Food Engineering, 150, 117-124.

Berk, Z. (1992). Technology of Production of Edible Flours and Protein Products from Soybeans. Number 97 in FAO agricultural bulletin. Food and Agriculture Organization of the United Nations.

Bongers, P. M. M. (2009). Process and Equipment Design Optimising Product properties and attributes. Computer Aided Chemical Engineering, 26, 225-230.

Bourlakis, M., \& Weightman, P. (2004). Food Supply Chain Management. Blackwell Publishing, Oxford, UK.

Bruins, M. E., \& Sanders, J. P. M. (2012). Small-scale processing of biomass for biorefinery. Biofuels, Bioproducts and Biorefining, 6, 135-145.

Castiglioni, A., Jonkman, J., Akkerman, R., \& van der Padt, A. (2018). Selection of fractionation pathways and intermediates for mixed consumer products. Computer Aided Chemical Engineering, 43, 651-656.

CBS (2016). Centraal Bureau voor de Statistiek; Landbouw; gewassen, dieren en grondgebruik naar gemeente. Last accessed November 2016.

Charpentier, J.-C. (2009). Perspective on multiscale methodology for product design and engineering. Computers 83 Chemical Engineering, 33, 936-946.

Chopra, S., \& Meindl, P. (2015). Supply Chain Management: Strategy, Planning, and 
Operation, Global Edition. Pearson Education Limited.

Correll, D., Suzuki, Y., \& Martens, B. (2014). Biorenewable fuels at the intersection of product and process flexibility: A novel modeling approach and application. International Journal of Production Economics, 150, 1-8.

Datta, A. (2016). Toward computer-aided food engineering: Mechanistic frameworks for evolution of product, quality and safety during processing. Journal of Food Engineering, $176,9-27$.

De Meyer, A., Cattrysse, D., Rasinmäki, J., \& Van Orshoven, J. (2014). Methods to optimise the design and management of biomass-for-bioenergy supply chains: A review. Renewable and Sustainable Energy Reviews, 31, 657-670.

De Meyer, A., Cattrysse, D., \& Van Orshoven, J. (2015). A generic mathematical model to optimise strategic and tactical decisions in biomass-based supply chains (OPTIMASS). European Journal of Operational Research, 245, 247-264.

Depping, V., Grunow, M., van Middelaar, C., \& Dumpler, J. (2017). Integrating environmental impact assessment into new product development and processing-technology selection: Milk concentrates as substitutes for milk powders. Journal of Cleaner Production, 149, 1-10.

Dubbelboer, A., Janssen, J., Krijgsman, A., Zondervan, E., \& Meuldijk, J. (2015). Integrated Product and Process Design for the Optimization of Mayonnaise Creaminess. Computer Aided Chemical Engineering, 37, 1133-1138.

Duranti, M. (2000). Pasta enriched with vegetable proteins. EP 0997078 A2.

Dusselier, M., Mascal, M., \& Sels, B. F. (2014). Top Chemical Opportunities from Carbohydrate Biomass: A Chemist's View of the Biorefinery. In M. K. Nicholas (Ed.), Selective Catalysis for Renewable Feedstocks and Chemicals. Topics in Current Chemistry (pp. 1-40). Cham: Springer International Publishing.

ECSIP Consortium (2016). The Competitive Position of the European Food and Drink Industry: Final Report. European Competitiveness and Sustainable Industrial Policy Consortium, European Commission.

van Elzakker, M. A. H., Zondervan, E., Raikar, N. B., Hoogland, H., \& Grossmann, I. E. (2014). Optimizing the tactical planning in the Fast Moving Consumer Goods industry considering shelf-life restrictions. Computers \&6 Chemical Engineering, 66, 98-109.

EU (2013). Regulation No 1308 of the European Parliament and of the Council of 17 Dec 2013 establishing a common organisation of the markets in agricultural products. Last accessed August 2016.

Frisk, M., Göthe-Lundgren, M., Jörnsten, K., \& Rönnqvist, M. (2010). Cost allocation 
in collaborative forest transportation. European Journal of Operational Research, 205, 448-458.

Geerts, M. E. J. (2018). Functionality-driven fractionation. Wageningen University. PhDthesis.

Geerts, M. E. J., Mienis, E., Nikiforidis, C. V., van der Padt, A., \& van der Goot, A. J. (2017a). Mildly refined fractions of yellow peas show rich behaviour in thickened oilin-water emulsions. Innovative Food Science and Emerging Technologies, 41, 251-258.

Geerts, M. E. J., Strijbos, M., van der Padt, A., \& van der Goot, A. J. (2017b). Understanding functional properties of mildly refined starch fractions of yellow pea. Journal of Cereal Science, 75, 116-123.

Giarola, S., Zamboni, A., \& Bezzo, F. (2011). Spatially explicit multi-objective optimisation for design and planning of hybrid first and second generation biorefineries. Computers \& Chemical Engineering, 35, 1782-1797.

van der Goot, A. J., Pelgrom, P. J. M., Berghout, J. A. M., Geerts, M. E. J., Jankowiak, L., Hardt, N. A., Keijer, J., Schutyser, M. A. I., Nikiforidis, C. V., \& Boom, R. M. (2016). Concepts for further sustainable production of foods. Journal of Food Engineering, $168,42-51$.

Govindan, K. (2018). Sustainable consumption and production in the food supply chain: A conceptual framework. International Journal of Production Economics, 195, 419431.

Grossmann, I. E. (2005). Enterprise-wide optimization: A new frontier in process systems engineering. AIChE Journal, 51, 1846-1857.

Grossmann, I. E. (2014). Challenges in the application of mathematical programming in the enterprise-wide optimization of process industries. Theoretical Foundations of Chemical Engineering, 48, 555-573.

Grossmann, I. E., \& Guillen-Gosalbez, G. (2010). Scope for the application of mathematical programming techniques in the synthesis and planning of sustainable processes. Computers \& Chemical Engineering, 34, 1365-1376.

Grossmann, I. E., \& Westerberg, A. W. (2000). Research challenges in process systems engineering. AIChE Journal, 46, 1700-1703.

Gustavsson, J., Cederberg, C., Sonesson, U., van Otterdijk, R., \& Meybeck, A. (2011). Global food losses and food waste: extent, causes and prevention. Rome: FAO.

Hadiyanto, H., van Straten, G., Boom, R. M., van Boxtel, A. J. B., \& Esveld, D. C. (2008). Potential of Conceptual Design Methodology for Food Process Innovation. Food Science and Technology International, 14, 139-149. 
Halasz, L., Povoden, G., \& Narodoslawsky, M. (2005). Sustainable processes synthesis for renewable resources. Resources, Conservation and Recycling, 44, 293-307.

Hart, W. E., Laird, C., Watson, J.-P., \& Woodruff, D. L. (2012). Pyomo-Optimization Modeling in Python volume 67. Springer Science \& Business Media.

Hart, W. E., Watson, J.-P., \& Woodruff, D. L. (2011). Pyomo: modeling and solving mathematical programs in python. Mathematical Programming Computation, 3, 219260.

Henke, S., Bubník, Z., Hinková, A., \& Pour, V. (2006). Model of a sugar factory with bioethanol production in program sugars ${ }^{\mathrm{TM}}$. Journal of Food Engineering, 77, 416 420 .

Higgins, A., Thorburn, P., Archer, A., \& Jakku, E. (2007). Opportunities for value chain research in sugar industries. Agricultural Systems, 94, 611-621.

Ho, Q. T. et al. (2013). Multiscale modeling in food engineering. Journal of Food Engineering, 114, 279-291.

Hosseini, S. A., \& Shah, N. (2011). Multi-scale process and supply chain modelling: from lignocellulosic feedstock to process and products. Interface focus, 1, 255-262.

Ioannou, G. (2005). Streamlining the supply chain of the hellenic sugar industry. Journal of Food Engineering, 70, 323-332.

Jonkman, J., Bloemhof, J. M., van der Vorst, J. G. A. J., \& van der Padt, A. (2015). A sustainability driven methodology for process synthesis in agro-food industry. Computer Aided Chemical Engineering, 37, 1289-1294.

Jonkman, J., Bloemhof, J. M., van der Vorst, J. G. A. J., \& van der Padt, A. (2017). Selecting food process designs from a supply chain perspective. Journal of Food Engineering, 195, 52-60.

Kang, K., Wang, X., \& Ma, Y. (2017). A collection-distribution center location and allocation optimization model in closed-loop supply chain for chinese beer industry. Mathematical Problems in Engineering, 2017, 15.

de Keizer, M., Akkerman, R., Grunow, M., Bloemhof, J. M., Haijema, R., \& van der Vorst, J. G. A. J. (2017). Logistics network design for perishable products with heterogeneous quality decay. European Journal of Operational Research, 262, 535-549.

de Keizer, M., Haijema, R., Bloemhof, J. M., \& van der Vorst, J. G. A. J. (2015a). Hybrid optimization and simulation to design a logistics network for distributing perishable products. Computers $\&$ Industrial Engineering, 88, 26-38.

de Keizer, M., van der Vorst, J. G. A. J., Bloemhof, J. M., \& Haijema, R. (2015b). Floricultural supply chain network design and control: industry needs and modelling 
challenges. Journal on Chain and Network Science, 15, 61-81.

Klenk, I., Landquist, B., \& de Imana, O. R. (2012a). The Product Carbon Footprint of EU beet sugar (Part I). Sugar Industry-Zuckerindustrie, 137, 169-177.

Klenk, I., Landquist, B., \& de Imana, O. R. (2012b). The Product Carbon Footprint of EU beet sugar (Part II). Sugar Industry-Zuckerindustrie, 137, 213.

Kokossis, A. C., Tsakalova, M., \& Pyrgakis, K. (2015). Design of integrated biorefineries. Computers \& Chemical Engineering, 81, 40-56.

Kolfschoten, R. C., Bruins, M. E., \& Sanders, J. P. M. (2014). Opportunities for smallscale biorefinery for production of sugar and ethanol in the Netherlands. Biofuels, Bioproducts and Biorefining, 8, 475-486.

Kostin, A. M., Guillén-Gosálbez, G., Mele, F. D., Bagajewicz, M. J., \& Jiménez, L. (2012). Design and planning of infrastructures for bioethanol and sugar production under demand uncertainty. Chemical Engineering Research and Design, 90, 359-376.

Krikke, H., Bloemhof, J. M., \& Van Wassenhove, L. N. (2003). Concurrent product and closed-loop supply chain design with an application to refrigerators. International Journal of Production Research, 41, 3689-3719.

Kristianto, Y., Gunasekaran, A., Helo, P., \& Sandhu, M. (2012). A decision support system for integrating manufacturing and product design into the reconfiguration of the supply chain networks. Decision Support Systems, 52, 790-801.

Kusumastuti, R. D., van Donk, D. P., \& Teunter, R. (2016). Crop-related harvesting and processing planning: a review. International Journal of Production Economics, 174, 76-92.

KWIN-AGV (2009). Kwantitatieve informatie akkerbouw en vollegrondsgroenteteelt. IKC-Landbouw and Praktijkonderzoek voor de Akkerbouw en de Vollegrondsgroenteteelt and De Landbouwvoorlichting, DLV, Proefstation voor de Akkerbouw en de Groenteteelt in de Vollegrond, Lelystad.

Langeveld, J. W. A. (2010). The Biobased Economy. Routledge.

Leone, A., Tamborrino, A., Zagaria, R., Sabella, E., \& Romaniello, R. (2015). Plant innovation in the olive oil extraction process: A comparison of efficiency and energy consumption between microwave treatment and traditional malaxation of olive pastes. Journal of Food Engineering, 146, 44-52.

Li, X., \& Kraslawski, A. (2004). Conceptual process synthesis: past and current trends. Chemical Engineering and Processing: Process Intensification, 43, 583-594.

Lucas, M. T., \& Chhajed, D. (2004). Applications of location analysis in agriculture: a survey. Journal of the Operational Research Society, 55, 561-578. 
Lynd, L. R., Wyman, C. E., \& Gerngross, T. U. (1999). Biocommodity Engineering. Biotechnology Progress, 15, 777-793.

Maia, L. O. A., Lago, R. A., \& Qassim, R. Y. (1997). Selection of postharvest technology routes by mixed-integer linear programming. International Journal of Production Economics, 49, 85-90.

Mandryk, M., Reidsma, P., Kanellopoulos, A., Groot, J. C. J., \& van Ittersum, M. K. (2014). The role of farmers' objectives in current farm practices and adaptation preferences: a case study in Flevoland, the Netherlands. Regional Environmental Change, $14,1463-1478$.

Manfredi, M., \& Vignali, G. (2015). Comparative Life Cycle Assessment of hot filling and aseptic packaging systems used for beverages. Journal of Food Engineering, 147, 39-48.

Mavrotas, G. (2009). Effective implementation of the $\epsilon$-constraint method in multiobjective mathematical programming problems. Applied Mathematics and Computation, 213, 455-465.

Meeuse, F. M. (2007). Process synthesis for structured food products. Computer Aided Chemical Engineering, 23, 167-179.

Melo, M. T., Nickel, S., \& Saldanha-da Gama, F. (2009). Facility location and supply chain management - A review. European Journal of Operational Research, 196, 401412.

Moncada, J. B., Aristizábal, V. M., Cardona, A., \& Carlos, A. (2016). Design strategies for sustainable biorefineries. Biochemical Engineering Journal, 116, 122-134.

Mota, B., Gomes, M. I., Carvalho, A., \& Barbosa-Póvoa, A. P. (2018). Sustainable supply chains: An integrated modeling approach under uncertainty. Omega, 77, 32-57.

Naber, S. K., de Ree, D. A., Spliet, R., \& van den Heuvel, W. (2015). Allocating $\mathrm{CO}_{2}$ emission to customers on a distribution route. Omega, 54, 191-199.

Ortiz-Gutiérrez, R. A., Giarola, S., Shah, N., \& Bezzo, F. (2015). An approach to optimize multi-enterprise biofuel supply chains including Nash equilibrium models. Computer Aided Chemical Engineering, 37, 2255-2260.

van der Padt, A. (2014). Sustainable Production of Food. Wageningen, The Netherlands: Wageningen University.

Pahl, J., \& Voß, S. (2014). Integrating deterioration and lifetime constraints in production and supply chain planning: A survey. European Journal of Operational Research, 238, 654-674.

Pelgrom, P. J. M., Berghout, J. A. M., van der Goot, A. J., Boom, R. M., \& Schutyser, 
M. A. I. (2014a). Preparation of functional lupine protein fractions by dry separation. LWT - Food Science and Technology, 59, 680-688.

Pelgrom, P. J. M., Boom, R. M., \& Schutyser, M. A. I. (2014b). Functional analysis of mildly refined fractions from yellow pea. Food Hydrocolloids, 44, 12-22.

Pelgrom, P. J. M., Vissers, A. M., Boom, R. M., \& Schutyser, M. A. I. (2013). Dry fractionation for production of functional pea protein concentrates. Food research international, 53, 232-239.

Perrot, N., De Vries, H., Lutton, E., van Mil, H. G., Donner, M., Tonda, A., Martin, S., Alvarez, I., Bourgine, P., van der Linden, E., \& Axelos, M. A. (2016). Some remarks on computational approaches towards sustainable complex agri-food systems. Trends in Food Science 83 Technology, 48, 88-101.

Quaglia, A., Sarup, B., Sin, G., \& Gani, R. (2012). Integrated business and engineering framework for synthesis and design of enterprise-wide processing networks. Computers Es Chemical Engineering, 38, 213-223.

Raak, N., Symmank, C., Zahn, S., Aschemann-Witzel, J., \& Rohm, H. (2017). Processingand product-related causes for food waste and implications for the food supply chain. Waste Management, 61, 461-472.

Rajurkar, S. W., \& Jain, R. (2011). Food supply chain management: review, classification and analysis of literature. International Journal of Integrated Supply Management, 6, 33-72.

Render, H. (1989). Ein Strukturkonzept zur Verbesserung der Wettbewerbsstellung der norddeutschen Zuckerwirtschaft. Ph.D. thesis University of Bonn, Germany. European University Studies Series V, Economics and Management, Vol. 1013. Peter Lang.

Rijksinstituut voor Volksgezondheid en Milieu (2017). Regio's Landelijk Meetnet effecten Mestbeleid, lmm14. Last accessed March 2017.

Rong, A., Akkerman, R., \& Grunow, M. (2011). An optimization approach for managing fresh food quality throughout the supply chain. International Journal of Production Economics, 131, 421-429.

Rosenboom, N., Boschloo, M., van der Noll, R., \& Tieben, B. (2013). Prijzige suiker, De prijsopbouw en prijsontwikkeling van suiker. SEO-report nr 2013-28, SEO Economisch Onderzoek.

van Rossum, C. T. M., Buurma-Rethans, E. J. M., Vennemann, F. B. C., Beukers, M., Brants, H. A. M., De Boer, E. J., \& Ocké, M. C. (2016). The diet of the Dutch: Results of the first two years of the Dutch National Food Consumption Survey 2012-2016. Technical Report, Rijksinstituut voor Volksgezondheid en Milieu RIVM. 
Sahay, N., \& Ierapetritou, M. (2016). Multienterprise supply chain: Simulation and optimization. AIChE Journal, 62, 3392-3403.

Santibañez-Aguilar, J. E., González-Campos, J. B., Ponce-Ortega, J. M., Serna-González, M., \& El-Halwagi, M. M. (2014). Optimal planning and site selection for distributed multiproduct biorefineries involving economic, environmental and social objectives. Journal of Cleaner Production, 65, 270-294.

Schutyser, M. A. I., Pelgrom, P. J. M., van der Goot, A. J., \& Boom, R. M. (2015). Dry fractionation for sustainable production of functional legume protein concentrates. Trends in Food Science and Technology, 45, 327-335.

Searchinger, T., Hanson, C., Ranganathan, J., Lipinski, B., Waite, R., Winterbottom, R., Dinshaw, A., \& Heimlich, R. (2013). Creating a Sustainable Food Future: A menu of solutions to sustainably feed more than 9 billion people by 2050. World Resources Report 2013-14, World Resources Institute. Interim Findings.

Shapley, L. S. (1953). A Value for n-person Games. Annals of Mathematics Studies, 28, 307-317.

Sharma, B., Ingalls, R. G., Jones, C. L., \& Khanchi, A. (2013). Biomass supply chain design and analysis: Basis, overview, modeling, challenges, and future. Renewable and Sustainable Energy Reviews, 24, 608-627.

Shukla, M., \& Jharkharia, S. (2013). Agri-fresh produce supply chain management: a state of the art literature review. International Journal of Operations 8 Production Management, 33, 114-158.

Solana, M., Mirofci, S., \& Bertucco, A. (2016). Production of phenolic and glucosinolate extracts from rocket salad by supercritical fluid extraction: Process design and cost benefits analysis. Journal of Food Engineering, 168, 35-41.

Soto-Silva, W. E., Nadal-Roig, E., González-Araya, M. C., \& Pla-Aragones, L. M. (2015). Operational research models applied to the fresh fruit supply chain. European Journal of Operational Research, 251, 345-355.

Soysal, M., Bloemhof, J. M., Meuwissen, M. P. M., \& van der Vorst, J. G. A. J. (2012). A review on quantitative models for sustainable food logistics management. International Journal on Food System Dynamics, 3, 136-155.

Suiker Unie (2010). Corporate video. http://www.suikerunie.nl/Home.aspx?lang=en-GB, last accessed July 2016.

Suiker Unie (2011). Long-term stability of the european sugar sector, also after 2015; position paper dutch sugar sector.

Sukumara, S., Faulkner, W., Amundson, J., Badurdeen, F., \& Seay, J. (2014). A mul- 
tidisciplinary decision support tool for evaluating multiple biorefinery conversion technologies and supply chain performance. Clean Technologies and Environmental Policy, 16, 1027-1044.

Sun, J., Lin, J., \& Qian, Y. (2013). Game-theoretic analysis of competitive agri-biomass supply chain. Journal of Cleaner Production, 43, 174-181.

Tamayo Tenorio, A., Kyriakopoulou, K. E., Suarez-Garcia, E., van den Berg, C., \& van der Goot, A. J. (2018). Understanding differences in protein fractionation from conventional crops, and herbaceous and aquatic biomass - Consequences for industrial use. Trends in Food Science and Technology, 71, 235-245.

Timmermans, A. J. M., Ambuko, J., Belik, W., \& Huang, J. (2014). Food losses and waste in the context of sustainable food systems. Technical Report, CFS Committee on World Food Security HLPE.

Tsolakis, N. K., Keramydas, C. A., Toka, A. K., Aidonis, D. A., \& Iakovou, E. T. (2014). Agrifood supply chain management: A comprehensive hierarchical decisionmaking framework and a critical taxonomy. Biosystems Engineering, 120, 47-64.

UN General Assembly (2015). Transforming our world: The 2030 agenda for sustainable development. Technical Report, A/RES/70/1, 21 October.

Vila, D., Martel, A., \& Beauregard, R. (2006). Designing logistics networks in divergent process industries: A methodology and its application to the lumber industry. International Journal of Production Economics, 102, 358-378.

van der Vorst, J. G. A. J., \& Beulens, A. J. M. (2002). Identifying sources of uncertainty to generate supply chain redesign strategies. International Journal of Physical Distribution E5 Logistics Management, 32, 409-430.

van der Vorst, J. G. A. J., Tromp, S.-O., \& van der Zee, D.-J. (2009). Simulation modelling for food supply chain redesign; integrated decision making on product quality, sustainability and logistics. International Journal of Production Research, 47, 66116631.

Wageningen Economic Research (2016). Agrimatie - informatie over de agrosector, sector akkerbouw. Last accessed December 2016.

Wageningen Environmental Research (2006). Grondsoortenkaart. Last accessed March 2017.

Westerberg, A. W. (2004). A retrospective on design and process synthesis. Computers 85 Chemical Engineering, 28, 447-458.

Wouda, F. H. E., van Beek, P., van der Vorst, J. G. A. J., \& Tacke, H. (2002). An application of mixed-integer linear programming models on the redesign of the supply 
network of Nutricia Dairy \& Drinks Group in Hungary. OR Spectrum, 24, 449-465.

You, F., \& Grossmann, I. E. (2008). Design of responsive supply chains under demand uncertainty. Computers 8 Chemical Engineering, 32, 3090-3111.

Yue, D., \& You, F. (2014a). Fair profit allocation in supply chain optimization with transfer price and revenue sharing: MINLP model and algorithm for cellulosic biofuel supply chains. AIChE Journal, 60, 3211-3229.

Yue, D., \& You, F. (2014b). Game-theoretic modeling and optimization of multi-echelon supply chain design and operation under Stackelberg game and market equilibrium. Computers \& Chemical Engineering, 71, 347-361.

Yue, D., \& You, F. (2017). Stackelberg-game-based modeling and optimization for supply chain design and operations: A mixed integer bilevel programming framework. Computers 8 Chemical Engineering, 102, 81-95.

Yue, D., You, F., \& Snyder, S. W. (2014). Biomass-to-bioenergy and biofuel supply chain optimization: Overview, key issues and challenges. Computers $\mathscr{G}$ Chemical Engineering, $66,36-56$.

Zimmer, T., Breun, P., \& Schultmann, F. (2018). Deployment and relocation of semimobile facilities in a thermal power plant supply chain. In Operations Research Proceedings 2016 (pp. 185-190). Springer.

Zondervan, E., Nawaz, M., de Haan, A. B., Woodley, J. M., \& Gani, R. (2011). Optimal design of a multi-product biorefinery system. Computers \& Chemical Engineering, 35, 1752-1766. 



\section{Summary}

This thesis focuses on the current set-up of food processes and the related Supply Chains (SCs), a main cause for inefficiencies in the production of food. In Europe, these Food Supply Chains (FSCs) have developed over time with a strong focus on economies of scale. Food processing split into the production of well-defined and purified intermediates (e.g. starch, protein isolates, sugar) produced by the agro-food industry, and the production of consumer products from these intermediates by the food assembly industry (e.g. bakeries, beverage manufacturing, confectionery producers). The production of such intermediates consumes large quantities of energy and water, and leads to losses in the conversion of agro-materials into final consumer products. To reconsider this set-up of FSCs, decision makers in the food industry are confronted with strategic questions at the level of products, processes and enterprise, the FSC, and the FSC network. In specific, decision makers in the agro-food industry have to find answers to the following questions:

- Which intermediates to make from the available agro-materials in order to produce the desired consumer products?

- Which production processes to produce the desired intermediates?

- Where to execute production processes in the FSC, and at what time?

- How to ensure the participation of all the required actors in the desired FSC network?

This study shows how methods from the fields of Process Systems Engineering (PSE) and Supply Chain Management (SCM) can be used to provide the decision support needed for answering the above questions.

In Chapter 2 the product level is considered. By determining the needs of the customer in terms of product specification and functionality, a shift can be made towards intermediates with lower chemical purity. An optimal portfolio of intermediates is determined using Mixed-Integer Linear Programming. The approach considers aspects of joint product and process optimisation and SC integration, and shows how the agro-food industry benefits from this novel combination. Results show an increased resource efficiency, reducing 
energy use and water consumption by $22 \%$ and $37 \%$, respectively, while reducing costs by $13 \%$.

Chapter 3 focuses on the process level and enterprise level. A multi-product locationallocation model is adapted to select production processes while taking into account the specific characteristics of FSCs. Results indicate that the choice for a production process implies a certain set-up of the FSC. This affects the overall FSC performance. Indeed, the illustrative case shows that optimising the process selection with an SC perspective increased the modelled profit by more than $4 \%$.

Chapter 4 presents a general description of the agro-food SC design problem at the FSC level. For the design of these chains, a multi-objective optimisation model is presented which takes the specific characteristics of the FSC and the related uncertainties (e.g. seasonal harvest yield) into account. Application of the model to a case study shows that changing the SC configuration to a less centralised set-up allows for an improvement of the environmental performance $\left(\mathrm{CO}_{2}\right.$-eq) of over $30 \%$ without impairing the economic performance. Additionally, uncertainty in timing and quantity of sugar beet supply and product demand affects the optimal type and capacity of production processes, but not the location of facilities. The chapter calls for the investigation of decentralised SC configurations in FSCs, requiring matching production processes.

Chapter 5 considers the different actors collaborating at the SC network level. Using a whole-chain optimisation model, a conflict is observed between the individual objectives of FSC actors (farmers) and the objective of the FSC. Gain sharing between actors is used to align the individual objectives with the FSC objective, allowing an increase in the total gross margin of the SC of more than 20\%. Subsequently, a Shapley-value approach is used to allocate the gross margin of the FSC to the different actors. The combination of multi-actor SC design and gain sharing shows how the availability of supply in these FSCs is not self-evident.

Chapter 6 discusses the applicability to different agro-food SCs. Optimising the decisions at a single level inherently restricts or even specifies the decisions at the other levels, leading to a possible lock-in. Hence, the specific characteristics of food products, food processing, and the FSC require a multi-scale approach towards the design of an agro-food SC.

The thesis shows that bridging process engineering and SC design for agro-food processing chains leads to new optimisation opportunities. These opportunities are not strictly in the domain of PSE or SCM alone. An integrated approach towards them leads to a more efficient production of food, increasing the economic and environmental performance of FSCs. 


\section{Publications}

\section{In this dissertation}

Jonkman, J., Bloemhof, J. M., van der Vorst, J. G. A. J., van der Padt, A. (2015). A Sustainability Driven Methodology for Process Synthesis in Agro-Food Industry. Computer Aided Chemical Engineering, 37, 1289-1294

Jonkman, J., Bloemhof, J. M., van der Vorst, J. G. A. J., van der Padt, A. (2017). Selecting food process designs from a supply chain perspective. Journal of Food Engineering, $195,52-60$

Castiglioni, A., Jonkman, J., Akkerman, R., van der Padt, A. (2018). Selection of fractionation pathways and intermediates for mixed consumer products. Computer Aided Chemical Engineering, 43, 651-656

Jonkman, J., Barbosa-Póvoa, A.P., Bloemhof, J. M. (submitted). Integrating harvesting decisions in supply chain design in agro-food industry.

Jonkman, J., Kanellopoulos, A., Bloemhof, J. M. (submitted). Designing an eco-efficient biomass-based supply chain using a multi-actor optimisation model.

Jonkman, J., Castiglioni, A., Akkerman, R., van der Padt, A. (in preparation). Nonconventional intermediate products improve the resource use in agro-food industry.

\section{Other scientific publications}

Chadare, F. J., Jonkman, J., Wolkers-Rooijackers, J., Nout, M. J. R., Hounhouigan, J. D., Zwietering, M. H. (2011). Microbiota of Tayohounta, a fermented baobab flavour food of Benin. African Journal of Biotechnology, 10, 15607-15615 
Jankowiak, L., Jonkman, J., Rossier-Miranda, F. J., van der Goot, A. J., Boom, R. M. (2014). Exergy driven process synthesis for isoflavone recovery from okara. Energy, 74, 471-483

Buisman, M.E., Jonkman, J. (submitted) How healthy can we eat: Dietary trends in traditional Dutch recipes from 1950-2010

\section{Publications in a professional journal}

Jonkman, J. (2017). Niet blindstaren op procesefficiëntie - Logistieke verschuiving biedt kansen voor agrofood. Voedingsmiddelentechnologie, 7, 32-33

Geerts, M., Jonkman, J. (2017). 'Clean label' door milde raffinage - Mild fractioneren verduurzaamt bestanddelen. Voedingsmiddelentechnologie, 12, 32-33 


\section{Acknowledgements}

-Deus est fortitudo spesque nostramotto of the city of Wageningen

You have reached what arguably will be one of the most-read sections in the dissertation. Here I would like to express my gratitude to all who contributed to bringing my $\mathrm{PhD}$ project to a successful end. Your contributions to the content of this dissertation, to my mental well-being, and to my physical health have been indispensable. I feel blessed with so many wonderful people surrounding me, and I hope to be able to thank you all in person for your support. Nevertheless, I will mention a few names below, yet refrain from making this a full-length chapter.

Jacqueline and Albert, it has been a pleasure having the two of you as my promotors. Jack, that also counts for you, even though you left as a supervisor when you changed jobs. To the three of you, and to all the colleagues from the Operations Research and Logistics group, the Information Technology group, and the Food Process Engineering group, I would like to say thank you very much. All the meetings, discussions, coffee breaks, sports activities, and the social and cultural events provided me with the constructive and enjoyable work environment necessary for me to flourish. I would like to thank Anne, Claudia, Ilona (FPE), Ilona (ORL), Jeannette, Marjan, and Natasja from the secretariats for enabling the work at our groups to go as smoothly as possible.

Additionally, thanks to my co-authors for their input in the project, and to the students whose hard work contributed to the chapters present in this dissertation: Alexandra, Anne, Christa, Dana, Floor, Marijn, Alberto, Drystan, Oberon, Remco, and Sirapak. I would also like to acknowledge the members of the ISPT cluster 'Mild Fractionation for Food'. Thanks for the open discussions during the project meetings. Special thanks to Edwin Poiesz from Royal Cosun. Your involvement was very supportive and your questions and feedback helped me a lot to improve my drafts.

Finally, thanks to my family and friends. All of you helped shape me to become the person that I am, and will continue to shape me in the future. I am lucky to have met such great people in courses, at my student association, in church, at work, at dinner club, in Portugal, with Science Café, at the BigBand Sound of Science etc. It is a privilege knowing all of you, thanks a thousand times.

Jochem

Wageningen, September 2018 

Jochem Jonkman

Wageningen School of Social Sciences (WASS)

Completed Training and Supervision Plan

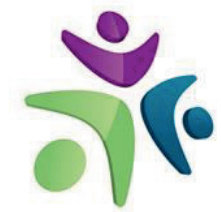

Wageningen School

of Social Sciences

\begin{tabular}{llll}
\hline Name of the learning activity $\quad$ Department/Institute & Year & ECTS*
\end{tabular}

A) Project related competences

Operations Research and Logistics, WUR

2014

6

ORL 30806

Programming in Python, INF 22306

WUR

$2014 \quad 6$

Quantitative Modelling and Analysis

GP-OML

2014

1

of Supply Chains

Data Analysis and Statistics

GP-OML

20143

Chemical Product Centric Process

OSPT

2015

0.6

Design

Process Economics and Cost

OSPT

2015

Engineering

Robust Optimization

LNMB

20164

EURO PhD School Sustainable Supply

EURO working group

2016

5

Chains

Sustainable Supply Chains

\section{B) General research related competences}

Introduction course

WASS

Proposal writing

Scientific writing

Communication with the Media and

the General Public

Reviewing a scientific paper

Philosophy and Ethics of Food Science VLAG

and Technology

'Niet blindstaren op procesefficiëntie VMT

- Logistieke verschuiving biedt kansen

voor agrofood'

' 'Clean label' door milde raffinage VMT

- Mild fractioneren verduurzaamt

bestanddelen'
Elsevier

WUR

WGS

WGS

$2016 \quad 1$

$2017 \quad 1.5$

$2017 \quad 0.5$

$2017 \quad 0.5$ 
'A Sustainability Driven

Methodology for Process Synthesis in Agro-Food Industry' $12^{\text {th }}$ International Symposium 2015

1

on Process Systems

Engineering and $25^{\text {th }}$

European Symposium on

Computer Aided Process

Engineering, Copenhagen

Integrated Process and Network

Optimisation for Sustainable Food

Supply Chains'

'Multi-actor logistic network design for sustainable agro-food processing chains'

'Selection of fractionation pathways and intermediates for mixed consumer products' $27^{\text {th }}$ European Conference on

2015

1

Operational Research, Glasgow

$1^{\text {st }}$ Conference of the EURO

2016

1

Working Group on Sustainable

Supply Chains, Aachen

$28^{\text {th }}$ European Symposium on 2018

Computer Aided Process

Engineering, Graz

\section{C) Career related competences/personal development}

Symposium session convener, participant

Supervision of thesis and internship students with projects on linear and non-linear modelling of food production processes and food supply chains

Research and Logistics courses 2018

Total

*One credit according to ECTS is on average equivalent to 28 hours of study load 

The work presented in this dissertation was supported by the Institute for Sustainable Process Technology (The Netherlands) within the Mild Fractionation for Food cluster, project CM-20-01: Process Synthesis.

Cover design by Dennis Hendriks | ProefschriftMaken.nl 



\section{Propositions}

1. A symbiosis between Process Systems Engineering and Supply Chain Management is not a bridge too far.

(this thesis)

2. The current lock-in of agro-food supply chains is caused by a disjointed optimisation of products, production processes, and supply chains.

(this thesis)

3. Contrary to the meaning of the word "objective", the maximisation of profit is not an objective function.

4. Descriptive insight far too often results in prescriptive statements.

(Bear, A., Knobe, J., 2017. Normality: Part descriptive, part prescriptive.

Cognition, 167, 25-37)

5. The culture of bonuses reduces managers' abilities to make rational decisions. (Cools, R., 2016. The costs and benefits of brain dopamine for cognitive control. WIREs Cognitive Science, 7, 317-329)

6. A Dutch PhD graduation ceremony is like a single person wedding.

Propositions belonging to the thesis, entitled

'Bridging process engineering and supply chain design for agro-food processing chains'.

Jochem Jonkman

Wageningen, 5 October 2018. 